\title{
Energy for rural development
}

Cecile Thom 


\section{Executive summary}

\section{The rural areas and rural people}

The rural areas of Scuth Africa are characterised by a division between the former homelands and 'coloured reserves' on the one hand, and commercial farmland and state-owned land on the other. Poverty in these areas is both widespread and extreme. In the homeland areas agricultural activity is very limited and people are mainly dependent on urban cash transfers for income. Households employ a variety of poverty coping options to supplement their low and often unreliable incomes from urban sources. The population in these areas is skewed, with significantly higher numbers of women and children. Most incidences of extreme poverty are found in the homeland areas.

In the 'white' commercial farming areas, on the other hand, farmworkers generally earn low but regular wage incomes, but their opportunities for off-farm income are severely restricted. Their situation of poverty is characterised by dependency on the farmers, and they are at risk of becoming destitute mainly as a result of losing their jobs and being evicted as a result.

\section{Rural development}

Rural development can be regarded as a process whereby poor rural people achieve concrete improvements in their lives. While this process needs to be facilitated, it has to entail the transfer of power and control to the poorest and most marginalised groups. Energy policy therefore has to provide a framework for energy planning which is sensitive and responsive to the needs and priorities of rural people, particularly poor and marginalised people (including women). In addition, opportunities for increasing the control of rural people over energy-related initiatives need to be explored.

A future rural development policy is likely to give emphasis to matters such as land reform, raising the incomes of rural people, meeting basic needs, capacity building and establishing representative rural local government.

A land reform programme would entail the restoration of land to those who have been dispossessed, as well as generally redressing present inequalities in access to land. In very general terms, a land redistribution programme would result in a 'shift' in the rural population from the homeland areas to commencial farming areas. However, the actual decrease in the rural populations of the former homelands would also depend on factors such as the natural population growth in these areas and the process of urbanisation. The opportunities for improved service provision which may result from a land redistribution programme need to be considered. For example, people who acquire land for resettlement on electrified farms could be eligible for connections to the electricity grid.

Various strategies would be combined to raise the incomes of rural people, including public works programmes, targeted welfare transfers, the development of small-scale agriculture and businesses etc. The possibilities for income-generation through energy-related projects and activities should be explored to the full. These include opportunities for public works programmes (such as grid electrification), small business development (such as the maintenance of appliances) and employment in the provision of services (as, for example, social forestry extension workers). In addition, the constraints which a lack of energy services place on the development of small-scale agriculture, businesses etc would need tobe addressed.

A basic needs strategy would aim to meet the needs of rural people with respect to matters such as water, food, health, education, housing, sanitation, and transport. Although energy is generally not seen as a basic need in itself, it is included in a 
'package' of basic goods and services because of the crucial role played by energy services in the satisfaction of basic needs - for example food preparation, lighting, space-heating and water-pumping. A framework for service provision needs to be developed providing for a minimum level of service that would be provided to all rural people, and the possibility of acquiring a higher level of service through a process of negotiation and subject to certain conditions and constraints. Improving rural people's access to basic goods - such as foodstuff, building materials, paraffin - should also form part of a basic needs strategy.

The institutional and onganisational capacities in rural areas are for the most extremely limited, in spite of the plethora of organisations active in these areas. Capacity building in these areas will be aimed at the establishment of legitimate, accountable, effective and efficient local government structures, as well as the establishment of vibrant and democratic organs of civil society to represent the interests of the rural poor and serve as independent 'watchdogs' of local government. Opportunities for capacity building as part of energy-related initiatives should be explored, while keeping in mind the balance required between the delivery of improved services and the need to build capacity. However, this balance can only be achieved if it is actively sought.

The establishment of rural local government in the form of relatively autonomous composite government structures at a district level in all areas outside of what is regarded as the functional metropoles, is envisaged by the development community. The role of such district level administrations in energy service provision needs to be considered, including its role in electricity provision, as well as the implications of its possible role in coordinating development at this level.

\section{Energy services to meef development needs}

Energy is a pervasive element in all human activities. It is used for domestic purposes, in community facilities, and for economic activities. The EPRET project has focused mainly on domestic energy use, in addition to which considerable attention has been given to energy requinements for small-scale agriculture. The energy requirements of community facilities and economic activities other than agriculture have not received any significant attention.

There are important linkages between energy services and the ability of households to meet their basic needs. Fuel shortages can impact on basic needs satisfaction directly if cooking times have to be reduced for lack of fuel, as well as indirectly by reducing the time available to women for performing the range of tasks - including food preparation, cleaning, and income generation - that are necessary to meet the basic needs of their families.

The combined effect of fuel- and water-collection on the time available to rural women for performing other essential tasks, needs particular consideration. Energy is an important component of improved water supply, as pumping is generally required for the reticulation of water to convenient collection points. The energyrelated constraints (such as pump maintenance problems) on improved water supply therefore require greater attention.

Facilities in the rural areas like clinics, schools, community halls and venues for agricultural extension, could benefit greatly from the provision of electricity. However, the impact of electricity on the services provided will depend largely on the proper functioning and utilisation of these facilities.

The main constraints to agricultural and business development in the rural areas are probably of a structural nature rather than being energy-related. However, the latter also needs to be addressed. There is a need for flexibility and responsiveness in the provision of energy services to small-scale farmers and small businesses, which may require energy advice and support to be made available to them. 


\section{Domestic energy use by rural people}

Considerable limitations exist with regard to the information available on rural energy use, one of which is a lack of information required to develop a textured understanding of energy use by rural people. Energy surveys and analyses of energy use by rural people in South Africa have tended to focus on relating general trends in energy use, particularly trends in measurable aspects such as consumption rates, to some of the more visible and/or measurable factors that impact on energy use patterns, such as fuelwood shortages and household income. Generally the smallest unit of analysis employed has been the settlement, with little attention given to factors that operate at a household level. While this level of analysis is necessary, it has severe limitations, as it neglects important aspects of energy use and does not foster a real understanding of these matters.

Domestic energy use in rural areas is a matter of great complexity. Rural people are in need of particular energy services, such as cooking and water heating, and continually make decisions regarding the ways in which they will meet theseneeds - the type of fuel and appliance that will be used for a particular purpose, for example. These decisions are greatly influenced by particular needs and preferences, such as the need to complete cooking and water heating tasks speedily in the mornings.

The decisions made by rural people are influenced by a range of factors, of which the demands on women's time and the availability of 'free' fuelwood are probably the most important. Other factors of importance include household income and economic status, the cost and availability of fuels, and gender relations within households. The resulting patterns of fuel use and consumption in rural areas are characterised by the dominance of fuelwood, which contributes by far the most to energy consumption, and the widespread use of fuels like paraffin and candles.

Energy-related problems experienced by rural people include exposure to high levels of air pollution as a result of woodfires, fuel-collection over long distances, high fuel costs, and the ingestion of paraffin by children.

\section{Future rural energy demand}

A wide range of factors will impact on energy demand in rural areas in the future, most of which do not fall within the confines of the energy sector. Future energy demand in rural areas will depend to a large extent on the nature and impact of a rural development policy. In addition, the implementation of energy policies will also impact considerably on future energy demand.

It seems likely that rural electrification will occur on a significant scale in the future, but it is highly unlikely that electricity will become the dominant household energy source in rural areas within thenext 15-20 years. Rather, it is expected that fuel wood will continue to dominate energy use during this period. The extent to which this will happen will depend on factors such as the availability of fuelwood, as well as the availability, affordability and acceptability of alternative fuels for certain purposes, particularly the preparation of the main meal.

The future role of hydrocarbon fuels in rural areas will depend to a significant degree on factors such as the accessibility of fuelwood and electricity, as well as the incomes of rural people. However, demand for these fuels could also be affected greatly by reductions in the costs of these fuels, the greater accessibility of particularly LPG appliances, and real improvements with regard to the associated health and safety problems.

\section{Policy recommendations for energy provision in rural areas}

The formulation of energy policy for rural areas has been severely hampered by a lack of the information required to develop a textured understanding of energy use 
by rural people, as well as a lack of relevant experience with regard to the implementation of energy-related strategies in rural areas. It is these strategies by which policies are implemented at a local level, and the particular conditions at localities in rural areas, which ultimately determine the impact of policy on the lives of rural people.

\section{A framework for rural energy planning}

Integrated rural energy planning should occur within and/or in accordance with a framework of integrated rural development. Such an approach implies that household energy planning should be conducted in conjunction with planning for the other energy consumption sectors. Existing boundaries within sectors, such as the current distinction between farmworkers and other rural households, should also be transcended. In addition, energy planning should, where possible, address broad objectives and concerns of rural development.

The starting point for rural energy planning should be a systems-oriented understanding of the circumstances, needs and priorities of energy users. A people-centred approach is required, together with an understanding of the systems within which energy is utilised by rural people - for example, the system of food preparation in which fuel is but one component. Of equal importance are the socio-economic and political systems which operate in the society (including poverty and gender relations).

Rural energy planning should be responsive to the needs, problems and priorities of rural people. Flexibility should therefore exist within a national or regional energy development framework for the development and adaptation of energy-related implementation strategies at a local level, which should be actively facilitated. This is necessary to allow for the diversity in the specific needs, problems, conditions and resources in different areas.

Mechanisms need to be provided in the rural energy planning process to ensure that planners and policy makers are made accountable to rural people, and that the needs and concerns of rural people are addressed effectively at all levels. At the policy making and regional planning levels, this could be done by structuring the process to ensure real inputs to decision-making by representatives of rural communities. However, political representation is insufficient to ensure that the best interests of rural people, and particularly the poorest groups and women, are served. This can only be achieved if these people acquire effective control over decisions which affect them.

\section{Fuelwood supply}

The supply of fuelwood in rural areas would benefit from initiatives aimed at the management of natural woodland resources, and the promotion of tree planting through a national programme of social forestry, as well as the transport and distribution of local surpluses of fuelwood. It is necommended that innovative initiatives for the sustainable use of resources in communal woodland should be actively encouraged and supported, but that detailed policy guidelines on the management of indigenous woodland should be formulated at a later stage. A multi-sectoral social forestry programme, which include such diverse elements as homestead planting by individuals, reclamation forestry, community woodlots, commercial small-grower schemes etc, should be established as a matter of priority. A campaign to encourage farmers and foresters to allow easy access to surplus wood resources, should be conducted through the media, the agricultural unions and the extensions services to the commercial farming sector. 


\section{Hydrocarbon fuels supply}

The tack of information on the distribution of hydrocarbon fuels in rural areas limits the scope for policy formulation. The cost of paraffin and LPG to rural people could be reduced by shortening the distribution chains - if bulk tanks are installed and deliveries are madeby the oil companies to a larger number of points in rural areas. This would also enable the price of paraffin and LPG to be controlled up to this level. The National Bulk-buying Initiative may also provide a vehicle for the supply of fuels at reduced costs to a significant proportion of rural people. The service differential and the equalisation fund levy within the paraffin price, and the distribution cost differential in the case of LPG, should also be lowered to reduce the wholesale price. However, final recommendations regarding the pricing of paraffin and LPG will only be possible once the cost structures and appropriate delivery mechanisms in rural areas have been established. The most effective way to police the retail price of paraffin and LPG in rural areas may be to provide avenues by which transgressions of the regulated prices can be reported by consumers, and to actively inform consumers of the legislated prices and of the reporting avenues which exist.

\section{Rural electrification}

A national electrification policy and programme must be designed with a balance between electrification of urban and rural areas from the beginning in order to address the need for redistribution and the material needs of the poorest households. The national rural electrification programme should not be in conflict with the principle of maintaining a financially viable electricity distribution industry in South Africa. However, the government has a special role to play in fostering a more equitable access to electricity in rural areas.

Government policy, programmes and plans must be based on the principle of least-cost electricity supply, including both grid connections and non-grid systems of electricity provision. The tariff charged for electricity in rural areas should be equal to a national or regional household electricity tariff, based on the principle of a straight line tariff, implying a cross-subsidy from domestic consumers with higher average consumption levels to consumers in rural areas.

The rural electrification programme must from the start aim at electrification of a number of rural 'growth centres' (including electrification of both local community facilities and households), with an identified socio-economic potential and possibilities for the establishment of productive activities. The programme must also from the start emphasise the electrification of rural dense and rural scattered households, the former in particular, in addition to farmworker households on commercial farms.

\section{Health and safety aspects}

Energy use by rural people is associated with a variety of safety risks and detrimental effects on people's health. The establishment of a national programme with the aim to identify the areas of major health risk which result from energy usage by the urban and rural poor is therefore recommended.

The extent and the severity of the health problem in rural areas which result from air pollution from woodfires need further investigation. Strategies to reduce the exposure of rural people to air pollution also need to be developed, following a system-orientated and people-centred approach to the matter.

Government support should be given to a national low-smoke coal programme which would have as its main goal to facilitate the development and production of low-smoke coals in order to substitute for conventional bituminous coal used by households. The need and feasibility of introducing low-smoke coal in nural areas where coal is used by a significant percentage of the population should be investi- 
gated.

The prevention of paraffin poisoning should be regarded as a major area for public policy intervention. Education and publicity campaigns should be aimed at adults and older household members with the message to keep paraffin in safe containers and out of the reach of infants. The development of affordable child-resistant lids for the most commonly used paraffin containers, which may prove to have the most significant impact on this problem, should continue with more direct state support, and should continue to attempt to optimise the employment potential of this strategy.

The extent to which safety regulations regarding the installations and the equipment required, as well as the procedures which should be followed during the filling of LPG bottles, are implemented in rural areas needs to be investigated, and policy measures need to be devised to ensure that these measures are effectively extended to rural areas.

\section{Energy efficiency}

Access to efficient fuels and appliances, as well as information on fuel and appliance efficiency, are preconditions to the achievement of energy efficiency at a household level. In order to achieve this, it is recommended, among others, that appliances should be labelled to provide economic efficiency data in an accessible manner, that it should be possible to pay for appliances through the price of the fuel or a tariff, and that end-users should be encouraged through education and media campaigns, and economic incentives to use more efficient appliances.

Matters of particular concern in rural areas because of the inadequate infrastructure that exists in these areas include the availability and affordability of efficient appliances, the availability of maintenance services to ensure that the performance of appliances remain satisfactory, and the effective dissemination of accessible information on fuel and appliance efficiency to energy users. These matters require further investigation to enable the effective implementation of energy efficiency measures in these areas.

Energy efficiency in small-scale agriculture should also be improved, for example by promoting systems of cultivation which reduce energy requirements, particularly in relation to outputs.

\section{Energy goods and support services}

The distribution and cost-structure of energy goods, such as appliances and batteries, need to be investigated to assess their availability and affordability to people in rural areas, and to identify the areas where intervention is necessary and possible. Energy services which are required by rural people include appliance maintenance and adjustment, the installation and maintenance of RAPS systems, the dissemination of energy information, and an energy advisory service. The feasibility of extending the present services provided by rural service centres to include various energy-related services, should be explored as a possible mechanism to improve support services. In particular, the need for appropriately trained people who could facilitate this process requires attention. 


\section{CONTENTS}

Executive summary

$\begin{array}{ll}\text { CHAPTER 1: Introduction } & 1\end{array}$

CHAPTER 2: The rural areas and rural people 2

2.1 Introduction 2

2.2 Defining the rural areas 2

2.3 Rural people 5

2.4 Poverty in rural areas 6

2.4.1 Poverty in the homelands $\quad 8$

2.4.2 Poverty in the common area 10

2.5 Conclusions 11

CHAPTER 3: Rural development 12

$\begin{array}{ll}3.1 \text { Introduction } & 12\end{array}$

3.2 The need for rural development 12

$\begin{array}{ll}3.3 \text { Defining rural development } & 13\end{array}$

3.4 Rural development policy 14

3.4.1 Land reform 14

3.4.2 Raising the incomes of rural people 17

3.4.3 Meeting basic needs 18

3.4.4 Agricultural development 21

3.4.5 Management of natural resources 22

3.4.6 Developing institutional and organisational capacity 23

3.4.7 Rural local government 25

3.5 Implications for energy policy 26

CHAPTER 4: Energy services to meet development needs 27

$\begin{array}{ll}4.1 \text { Introduction } & 27\end{array}$

4.2 Energy for basic needs $\quad 27$

4.2.1 Food 28

4.2.2 Water 29

4.2.3 Health 30

4.2.4 Education $\quad 30$

4.3 Energy for production 31

4.3.1 Small-scale agriculture 31

4.3.2 Entrepreneurial activities $\quad 32$

4.3.3 Impact of electrification 32

4.4 Energy to improve the quality of life 33

4.5 Conclusions 33 
CHAPTER 5: Domestic energy use by rural people

5.1 Introduction

5.2 Problems with current information 34

5.3 Understanding rural energy use 35

5.4 Convergence in energy planning for all rural people 36

5.5 Domestic energy services 37

5.5.1 Cooking 37

5.5.2 Water-heating 39

5.5.3 Lighting 39

5.5.4 Space-heating 40

5.5.5 Other services 41

5.6 Quantitative end-use analysis 41

5.7 Fuel use and energy consumption 41

5.7.1 Study areas in the homelands/reserves 42

5.7.2 General trends in fuel use and consumption 43

5.8 Factors affecting rural energy use 45

5.8.1 Women's time and activities $\quad 45$

5.8.2 Fuelwood availability 46

5.8.3 Household income and economic status 47

5.8.4 Cost and availability of fuels and appliances 49

5.8.5 Gender relations 49

5.8 Problems related to energy use 50

5.9 Conclusions 50

CHAPTER 6: Future rural energy demand 51

6.1 General discussion 51

6.2 Future energy demand scenarios 52

CHAPTER 7: Policy recommendations for energy provision in rural areas $\quad 53$

7.1 Introduction 53

7.2 A framework for rural energy planning 54

7.2.1 An integrated approach 54

7.2.2 A people-centred and systems-oriented approach 55

7.2.3 Flexibility and responsiveness $\quad 56$

7.2.4 Accountability and participation $\quad 56$

7.2.5 Local energy planning $\quad 57$

7.3 Rural energy research 58

7.4 Supply of fuelwood 58

7.4.1 Management of woodland resources 59

7.4.2 National social forestry programme $\quad 59$

$\begin{array}{ll}\text { 7.4.3 Distribution of surplus fuelwood } & 60\end{array}$

7.4.4 Institutional requirements $\quad 60$

7.4.5 Financial implications $\quad 60$

7.4.6 Equity considerations 61

7.5 Distribution and pricing of hydrocarbon fuels 61

7.5.1 Paraffin, candles and LPG 62

7.5.2 Diesel 64 
7.6 Rural electrification 65

7.6.1 Principles to guide rural electrification 65

$\begin{array}{ll}\text { 7.6.2 Policy recommendations } & 67\end{array}$

7.6.3 Financial implications $\quad 68$

7.7 Health and safety aspects 68

7.7.1 Air pollution from woodfires $\quad 69$

$\begin{array}{ll}\text { 7.7.2 Air pollution from coal fires } & 70\end{array}$

$\begin{array}{ll}\text { 7.7.3 Paraffin poisoning } & 70\end{array}$

7.7.4 Safety of LPG bottles $\quad 70$

$\begin{array}{ll}7.8 \text { Energy efficiency } & 71\end{array}$

7.9 Energy goods and support services 71

7.9.1 Rural service centres 72

$\begin{array}{ll}7.10 \text { Conclusions } & 73\end{array}$

References $\quad 74$ 


\section{CHAPTER 1}

\section{Introduction}

The explicit aim of the Energy Policy Research and Training (EPRET) project has been to provide for the widening of access to basic energy services among the urban and rural poor. This paper is particularly concerned with rural people - how they can be given access to the energy services they want and need in a way that will make a significant difference to their lives.

It is notoriously difficult to ensure that rural people get an equitable share of resources and the benefits of development, or even just to ensure that 'development does not affect their lives adversely. Efforts to effect changes to the way people live, by, for example, introducing 'appropriate technologies', have often failed dismally as the realities of the lives of rural people have not been considered sufficiently. It is imperative that energy planners and policy makers take cognisance of these matters, if efforts at improving energy services are to benefit more than a few, and are to be successful in addressing the real needs and priorities of rural people. This paper is an attempt to begin to address these matters.

The purpose of the paper is threefold. In the first place it will attempt to provide a broad framework for energy provision in the rural areas, by considering present conditions in these areas, and the key aspects of a future rural development policy. Secondly, it aims to explore domestic energy use by rural people, and highlight some of the linkages between energy services and other aspects of development. Finally, it will serve to summarise the policy recommendations devised during the EPRET project that are applicable to rural areas, within a broad framework for rural energy planning.

The main characteristics of the rural areas of South Africa are outlined in Chapter 2, where an attempt is made to identify the poor and vulnerable people in rural areas and to analyse the nature of rural poverty. In Chapter 3 some rural development priorities and key aspects of a future rural development/restructuring policy are discussed. The implications of these for energy policy are also considered. Chapter 4 deals with linkages between energy services and development, including ways in which energy service provision can contribute to the achievement of development priorities, and constraints to development which result from a lack of appropriate energy services. In Chapter 5 attention is given to domestic energy use by rural people, with particular emphasis on the quantitative aspects of energy use, and the factors that impact on energy-related decisions by rural people. Future energy demand in rural areas is considered shortly in Chapter 6, and finally, Chapter 7 discusses the policy recommendations aimed at rural areas which have been devised during the EPRET project, as well as aspects of energy use and service provision which require more attention before meaningful policies can be developed. 


\section{The rural areas and rural people}

\subsection{Introduction}

In this chapter the main characteristics of the rural areas of South Africa will be outlined. An attempt will be made to identify the poor and vulnerable people in rural areas and to analyse the nature of rural poverty.

South Africa is presently characterised by a major division between the former homelands' ${ }^{1}$ and 'coloured reserves ${ }^{2}$ on the one hand, and commercial farm land and state-owned land on the other (see Figures 2.1 and 2.2). This has resulted from a long and complex historical process (Kassier \& Groenewald 1992) which is not dealt with in any great detail in this paper. The process was characterised by the progressive dispossession of black people with respect to land, their economic and political disempowerment and repression and the underdevelopment of black communities. It has led to substantial differences between these 'two rural areas' of South Africa. The discussion that follows will adhere to this division where necessary, although an attempt is made throughout the paper to deal with issues in a convergent manner, as the re-integration of these areas is imminent.

1. The term 'homelands' is used here to refer to all the 'self-governing territories' and 'independent states' that were created under apartheid policies, including Gazankulu, Kangwane, KwaNdebele, KwaZuh, Lebowa, Owaqwa, Bophuthatswana, Ciskei, Transkei and Venda.

2. There are 24 'coloured' reserves in total, most of which were established as mission stations in the nineteenth century (University of the Western Cape 1991: 13). The largest of these are situated in Namaqualand.

3. The term 'common area' is used by Bekker et al (1992) to refer to all parts of South Atrica outside of the homelands, including the 'white' commercial farming areas, the 'coloured reserves etc.

4 'Betterment' planning involved the replanning of rural settlements in the homelands. whereby house and garden plots were allocated in specific areas (villages) and arable land provided outside of

\subsection{Defining the rural areas}

The rural areas of South Africa are not easily defined. In the 'common area' 3 it can for the most be defined as those areas outside of proclaimed towns, namely the commercial farming areas where agriculture constitutes the main productive activity. The dominant settlement pattern in these areas are scattered homesteads of individual white farmers with clusters of farmworkers' homes closeby. However, there exist fairly dense settlements in some areas, particularly on 'black' freehold land (Cross 1991: 84) where agriculture is not the main source of income.

In the homeland areas the matter is much more complex. Only a very small percentage of households outside of proclaimed towns earn any significant income from agriculture (Bekker et al 1992). Most of the 'rural' areas in the former homelands therefore have a residential character with virtually no economic base. It is possible to define a range of settlement types in these areas, which probably constitute a continuum rather than being distinct types.

Firstly, there exist large fairly dense settlements in close proximity (daily commuting distance) to large urban or metropolitan areas in the common area. An example of this is Winterveld in Bophuthatswana, north of Pretoria, which has recently been given urban status. These peri-urban settlements form part of functional metropolitan or large urban areas, with a large percentage of residents relying on daily commuting to the urban centre to earn an income (Bekker et al 1992).

Secondly, there are large and fairly dense 'displaced' settlements in areas which are not linked specifically to a large urban centre. An example of this is the sprawling conglomerate in Gazankulu/Lebowa which borders on Acomhoek in the eastern Transvaal and includes the villages of Timbavati and Cottondale. A large percentage of residents in these areas derive income from migrant labour eamings, as is the case with the other groups discussed below (Lund et al 1993: D1).

The third settlement type is in the form of 'nucleated' villages which have resulted from so-called betterment planning. ${ }^{4}$ These settlements are not necessarily very dense or uniform - that is, they can consist of a number of smaller clusters of homesteads. 


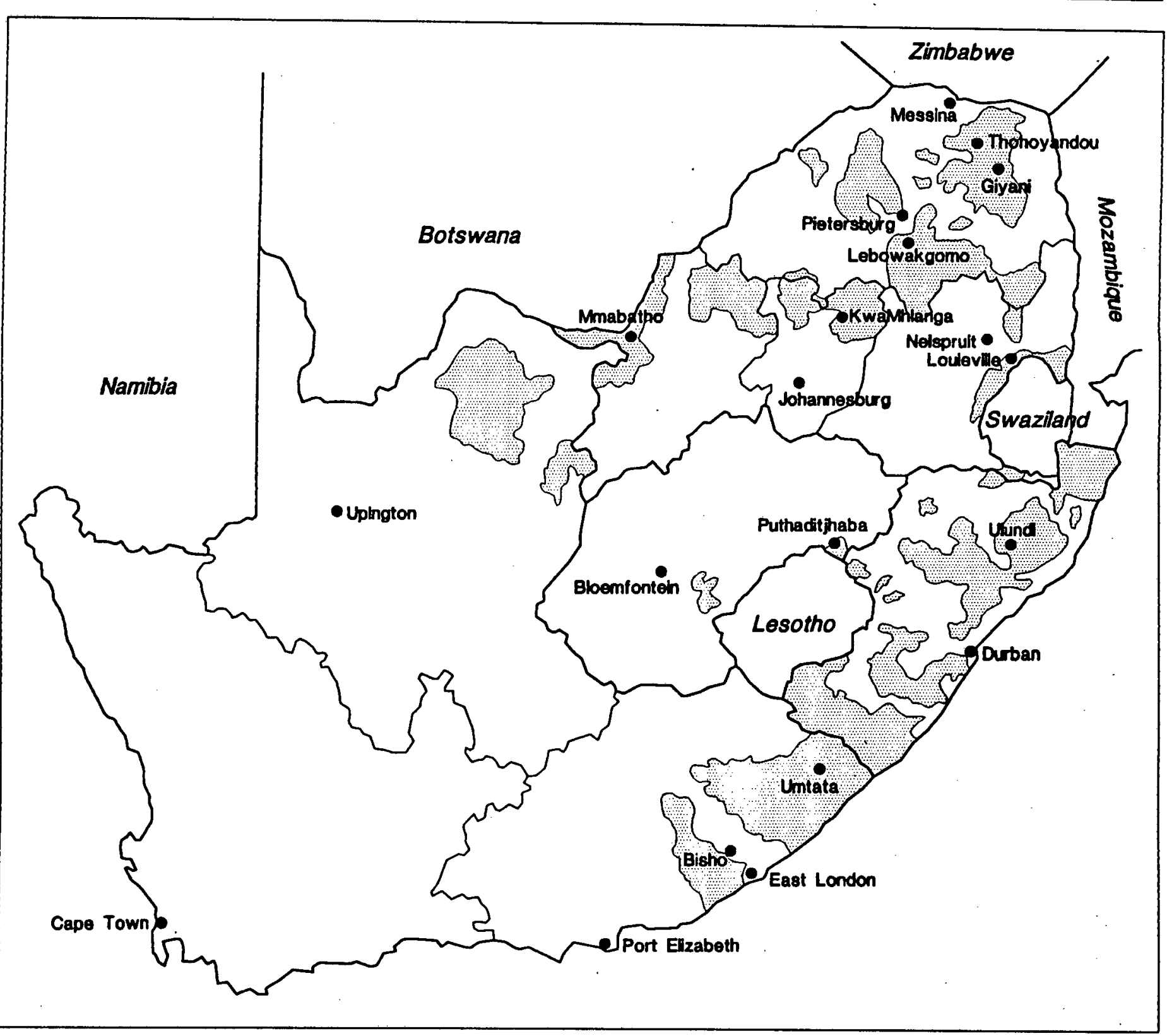

FGURE 2.1 Homeland areas in South Africa 


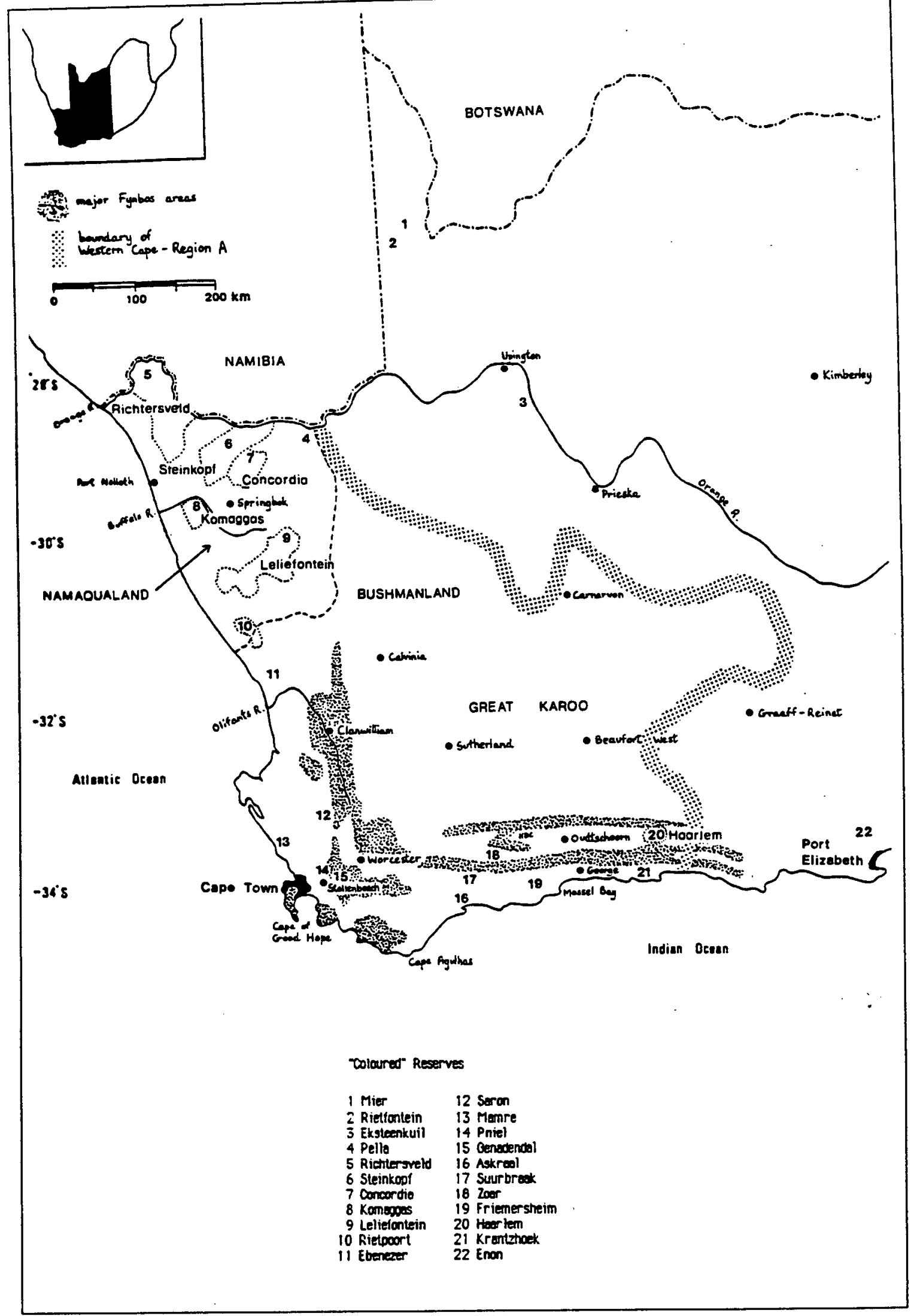

FIGURE 2.2 The 'coloured' reserves

Source: University of the Western Cape (1991) 
Finally, there exist scattered settlements, with individual or small numbers of homesteads separated from others by distances of hundreds of metres. This settlement type is found particularly in KwaZulu and the eastern part of the Transkei where 'betterment' planning has not been implemented successfully.

When considering these complexities, it is evident that it is not a simple matter to make a distinction between urban and rural South Africa. Only the first settlement type within the homeland areas that was discussed above can safely be classified as urban. For the purposes of this paper the rural areas of South Africa were therefore defined as all those falling outside of proclaimed towns and functional large urban and metropolitan areas. This corresponds to the definition used by Bekker et al (1992: 19).

Coupled with the uncertainties regarding the definition of rural areas, is the lack of accurate information on rural settlements. In order to cost service provision (such as grid electrification) to rural settlements more accurate information is required than the descriptions given above, including information on settlement sizes and densities. Some information on the settlement patterns among farmworkers has been obtained by Hofmeyr (1994). However, there exists no system of classification for the other rural settlements. In addition, the numbers of households that live in different types of rural settlements are unknown (see below).

\subsection{Rural people}

There is considerable uncertainty concerning demographic figures on South Africa, particularly with regard to rural areas. Based on information obtained from the Uman Foundation (UF) and the Development Bank of Southern Africa (DBSA), Trollip (1994) has estimated that the rural ${ }^{6}$ population in 1990 comprised 13.8 million people in the former homelands and 5.3 million people in the common area. For the purposes of the EPRET project, these figures had to be translated into numbers of dwellings or households. Bỳ assuming an average household size of six people, ${ }^{7}$ Trollip (1994) estimated the number of households in the rural areas to be 2.3 million in the homeland areas and 880000 in the common area.

The main group of rural people in the common area comprises farmworkers and their families who work and live in the commercial farming areas. Hofmeyr (1994) estimates that the total size of the farmworker community in the commercial farming areas is four million and the number of farmworker dwellings is 550000 , but points out that some estimates have placed the total population involved at six million. A small but significant group in the common area is the people in the 'coloured reserves'. The seven largest 'reserves', all of which are in Namaqualand, have an estimated total population of 31000 (University of the Western Cape 1991: 13).

\section{Personal communication with Protessor Bembridge, Uni- versity of Fort Hare.}

The rural population is subject to a number of distortions which have resulted from apartheid policies. It is therefore necessary to consider the composition of the rural population in greater depth. Table 2.1 is based on 1990 demographic information obtained from the DBSA (ANC Women's League 1993). From this it is clear that there is a significant difference in size between the male and female populations in rural areas, particularly in the income eaming age group (20-64 years). Approximately $53 \%$ of the total rural population is female, while this figure is as high as $57 \%$ in the income-earning age group. Moreover, children and teenagers comprise $58 \%$ of the total rural population compared to $41 \%$ in urban areas. The percentage of pensioners in the total population is approximately $4 \%$ in both rural and urban areas.

6. The definition of nural areas used in this case was the offcial one, namely all areas which fall outside of proclaimed towns.

7. It is recognised that the definition of a 'household' is not a simple matter. In South Africa this is particularly true because of the high occurrence of 'split households' as a result of labour migrancy, as well as 'com posite' households comprising a husband with more than one wife, or parents and married offspring. 


\begin{tabular}{|l|r|r|r|}
\hline & Rural males & Rural females & \multicolumn{1}{|c|}{ Total } \\
\hline Children/youth & 5533000 & 5643000 & 11176000 \\
\hline Working age & 3119000 & 4130000 & 7249000 \\
\hline Pensioners & 314000 & 428000 & 742000 \\
\hline Total & 8966000 & 10201000 & 19167000 \\
\hline
\end{tabular}

TABLE 2.1 Population figures for rural areas according to sex and age group

\subsection{Poverty in rural areas}

The vicious cycle of poverty and inequality is a reality that requires close examination in energy planning, as in any development planning (Bajracharya 1985: 13).

In this section an attempt is made to identify the main groups of rural people who are poor and to analyze the nature of rural poverty, drawing mainly on the draft report 'Rural poverty in South Africa' by Bekker et al (1992). As a first attempt to identify the rural poor, the cash income of households can be considered. Bekker et al (1992) define the rural poor as those households with incomes below the Minimum Living Level (MLL). ${ }^{8}$ Their findings on the rural poor, which utilised the income distribution model developed by the Urban Foundation (1991), can be summarised as follows:

In 1990 there were an estimated 17 million people in South Africa living in households below the MLL. Of these, 12 million were living in rural areas (Bekker et al 1992: 19). The rural poor therefore comprised approximately one third of the total population of South Africa.

- Of the rural poor $74 \%$ were black homeland dwellers and $19 \%$ were black people living in the common area. The rest (7\%) comprised mainly 'coloured' people in the common area, including both farmworkers and residents of the 'reserves'.

The poor in South Africa was therefore overwhelmingly black (95\%), largely rural (71\%) and mainly resident in the homelands, although significant groups are found in the common area.

Bekker et al (1992) analyzed the available income data from the UF and DBSA and concluded that the scope of rural poverty was greatest on the Eastern sea-board of the country, with Transkei and KwaZulu accounting for some $48 \%$ of the cases. This was followed by the three homelands in the Northern Transvaal, namely Venda, Lebowa and Gazankulu which together accounted for $23 \%$. Approximately $20 \%$ of the cases were found in the common area (Bekker et al 1992: 19).

Although it is convenient to use cash income to identify the rural poor, poverty is a much more complex phenomenon than this approach suggests. The analytic approach developed by Bekker et al (1992: 30) for identifying the poorest rural households and particularly those who are most vulnerable to increasing poverty, provides valuable insights into the nature of rural poverty. This approach focuses on the opportunities available to households and the capacities of households to make use of these opportunities.

8. The MLL was defined by the Urban Foundation (1991) as the minimum income required for subsistence in the short-term for a black household of average size'.
Households with formal cash incomes (wages, remittances and pensions) near or below the MLL generally do not have secure access to sufficient cash incomes to be confident that they will be able to cover their normal household expenses involving payments for basic needs, some savings and some level of social consumption (Bekker et al 1992: 33). Even in cases where the total level of income may be adequate, the timing with which income enters the household is often unsuited 
to the periodicy of domestic needs. For these households non-formal methods of support are vital to attempt to fill the shortfall of marginal, irregular or inadequate cash incomes. These non-formal options can be grouped as follows (ibid):

- production options aimed at home consumption (for example: home agricultural production for sale or consumption)

- informal enterprise (for example: informal production and/or distribution of goods and services)

- savings in money and assets for emergency use (for example: informal savings through investment in local savings groups)

- social network reciprocity and/or exchange relationships (for example: recourse to personal and family mutual support networks for gifts or loans)

- strategies for restructuring the household demographically to obtain a more economic configuration (for example: by shedding unproductive members or by taking in non-members in return for support contributions)

In order to utilise these poverty coping strategies households or individuals require access to basic resources. Some cash is normally required at the on-set to employ the more productive and effective options. Land is the alternative basic asset around which household support strategies can be organised, while successful responses to poverty also require control of household labour and/or social contact networks (Bekker et al 1992: 33).

Bekker et al (1992: 35) identify households which are deficient in two or more necessary assets in addition to formal cash income as the primary group vulnerable to rural poverty. Within this category of resource-poor households the very poor are those with very low formal income levels who rely significantly on coping strategies. Destitute households are those with no formal cash income wages, remittances and pensions) and therefore fully dependent on poverty coping options.

It was pointed out earlier that a low cash income constitutes just one aspect of poverty. However, the importance of cash incomes to the rural poor, also in pursuing poverty coping strategies, is clearly illustrated by Bekker et al (1992). In addition, they point out that securing a cash income is a priority among rural households, as it can be shown that households in aggregate put their labour resources into the job market as a first preference wherever this is possible.

An understanding of the poverty coping strategies employed by rural people and of the way in which these processes occur within households (e.g. who make the decisions, what are their priorities, what factors influence decisions) is vital to plan improved energy services in rural areas. If these matters are not taken into account sufficiently, it may well be that service provision is improved in an area, but that the people who are in greatest need of these improvements are unable to take advantage of them.

Finally, it is useful to consider the model of rural poverty developed by Chambers (1983: 112), which he called the 'deprivation trap'. This model very effectively illustrates that poor households do not only suffer from a lack of resources (on which the above analysis focused), but that there are other 'clusters of disadvantage' that impact on them. In addition to poverty, which can be defined as a lack of resources, these households suffer from powerlessness, isolation, physical weakness and vulnerability. Some of these were alluded to by Bekker et al (1992) and will be dealt with more specifically in Sections 2.4 .1 and 2.4.2. The interaction of all these factors serve to 'trap' poor households in their situation of poverty and deprivation. Any attempt to alleviate poverty therefore need to address all of these aspects if $i t$ is to nieet with any success. 
There is a danger that Chamber's model can foster an impression of rural people as passive victims of poverty and deprivation. This is incompatible with thenotion, discussed above, that rural people actively pursue strategies aimed at coping with poverty, often with great ingenuity. However, unless the complex network of factors which serve to entrench rural poverty is recognised and addressed, attempts at alleviating poverty will not meet with any success.

\subsubsection{Poverty in the homeland areas}

[B]lack rural dwellers live for the most part in poverty-stricken retirement and refugee settlements, where income is primarily dependent on remittances and pensions, households are largely headed by socially and economically weakened women, tenure is formally insecure, youth are poorly educated and unemployed, services are poor to non-existent, land is degraded, and governance is illegitimate and ineffectual (Lund et al 1993: D1).

One estimate of the incomes of rural people in the homelands during 1992 is presented in Figure 2.3. ${ }^{9}$ Assuming that the MLL in 1992 was approximately R850 per household per month, this indicates that the majority of households in the homeland areas had an income of less than half of the MLL. Bekker et al (1992) defined this group as the 'very poor'.

As mentioned before, rural people in the homeland areas mainly depend on remittances paid by family members who work in urban areas as well as state pensions (Bekker et al 1992). According to Bekker et al (1992: 55) the vulnerability of rural households in the homeland areas to poverty can be related to two key factors, namely the houschold's access to income transfers from urban areas, and the gender constitution of the houschold In addition, the spatial location of a household seems to be of major importance. Each of these will be discussed briefly, drawing substantially on the analysis presented by Bekker et al (1992).

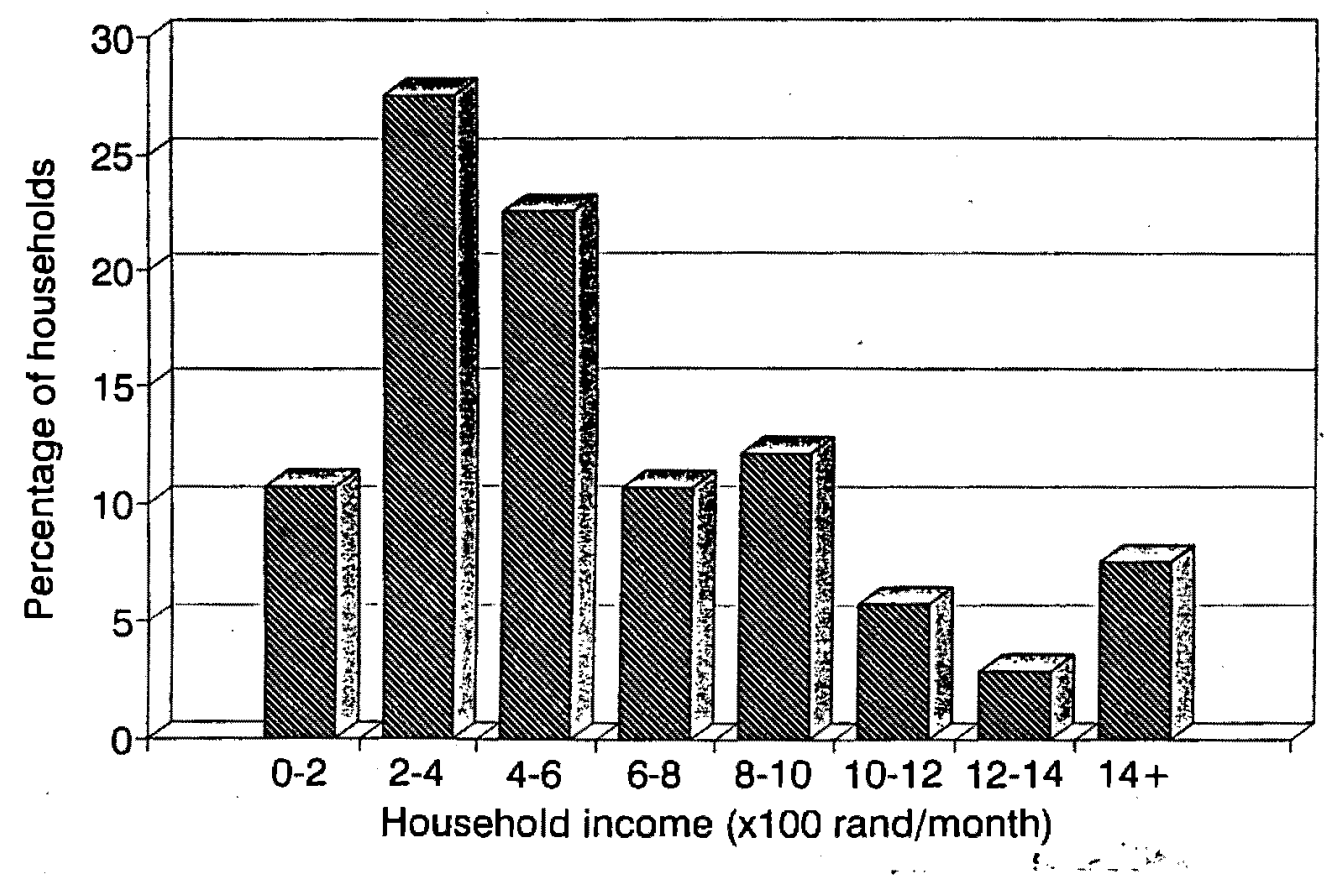

9. The income data for this purpose was obtained from Market Research Africa.
FIGURE 2.3 Household income distribution in the homeland areas (Data obtained trom Market Research Africa) 


\section{Access to urban income transfers}

Income transfers from urban areas can take the form of remittances by household members employed in urban areas, or social pensions received from the state. The ability of a household to earn income in urban areas depends to a large extent on the following (Bekker et al 1992: 32):

- The quantity and quality of its available labour, which is related to household size, age-structure, gender composition and health, as well as the education, training and previous experience of adults.

- The 'mobility' of the potential workers, which is influenced by the remoteness of the household, the availability of cash resources to finance travel and searching, its past employment history, its relation to information flows along kin and other networks and extra-local network connections which support urban job searches.

A household's access to state transfers depends firstly on its entitlement to pensions and grants, which is related to the age-structure of the household, and secondly on the ability of the household to secure access to these. The latter is largely dependent on the education of the household, its location in relation to urban centres, and its access to extra-local network connections which support dealings with outside bureaucracy (Bekker et al 1992: 36).

\section{Gender constitution}

The gender constitution of households impacts on their situation in the following ways (Bekker et al 1992: 32):

- Female-headed households are less able to ensure that remittances are received from 'distant workers', or to mobilise labour for local tasks.

- The ability of female members to earn incomes in urban areas (that is, their mobility) is restricted by the age of children, husbands' preferences, and the availability of grandparents or other surrogate parents.

- The administration of public process in general and of land tenure systems in particular tends to favour men over women. In outlying districts women have no access to public institutional proceedings in general, while in more urbanised areas their degree of access tend to be haphazard and unreliable.

\section{Spatial location}

The spatial location of a household is an important determinant of its access to income from urban sources (Bekker et al 1992: 55). Households spatially positioned so that employed members can commute daily or weekly appear to receive larger shares of the households' nominal wage income than those which depend on long-range migrants. These households furthermore have more urban contacts overall and tend to develop more effective urban networks. As a result of these and other factors, rural populations in the most isolated rural districts receive the lowest incomes from the general economy and tend to be thrown back on their local resources (Bekker et al 1992: 52).

This un favourable situation in remote areas is compounded by the fact that options other than gaining access to urban transfers are generally restricted (Bekker et al 1992: 54):

- In remote areas land options and contacts with the local power structure are more central to survival. However, the poor and the very poor are often unable to obtain effective access to administrative bodies and have tended to be marginalised in terms of access to land.

- While social networks in more remote areas are often more extensive and 
supportive than those in peri-urban areas, their potential to assist with poverty is limited by the low general asset base and the reduced cash flow found in these areas.

In addition, options related to the subsistence economy and social network connections are becoming less available to poor households under present conditions (Bekker et al 1992: 52).

\subsubsection{Poverty in the common area}

Hofmeyr (1994) discusses the circumstances of farmworkers and their families who work and live in the commencial farming areas in some detail. Attention will be given here mainly to some of the points raised by Bekker et al (1992) regarding the poverty among farmworkers.

The situation of farmworkers is characterised by low incomes and dependency on farmers (Bekker et al 1992: 56). They are almost totally reliant on wages for farm work, with minimal contributions obtained from home production and informal sector activities as well as pensions. Farmworkers' access to arable land and grazing has been declining since the early 1980 s, thereby reducing the possibility of agricultural production as support option (Bekker et al 1992: 58).

Wages are generally very low, with $57 \%$ of farmworkers earning between R1 000 and R2 999 per annum in 1991, and $17 \%$ earning less than R100 per annum (Bekker et al 1992: 51). A further 15\% earned between R3 000 and R4 999 per annum. However, while they remain employed, their income is relatively secure. A major exception is the mobile population of the Karoo migrant farmworkers of which $33 \%$ were found to be without a formal income (ibid).

Bekker et al (1992: 56) conclude that farmuorkers are vulnerable mainly in relation to the risk of job loss and consequent eviction. They are generally at a serious disadvantage when they have to compete in the off-farm labour market. According to Bekker et al (1992: 85) women are particularly at risk in this regard as 'women on commercial farms are isolated, have little experience of urban conditions and are cut off from obtaining significant income in their own right'.

There are considerable and increasing differences in the wages and living conditions of farmworkers in different regions, which correspond to a large degree with the financial state of the different farming sectors (Bekker et al 1992: 12):

Workers in the... Cape fruit industry have become relatively well-paid in the 1990s, and often receive substantial benefits in housing and services, with sugar, mixed farming and other sectors ranging away from this standard. In maize-growing regions of the northern interior, retrograde pay and conditions prevail on marginal farms.

The farming areas which have declined quite sharply in production during the 1980s are the Northem Cape and the Western Transvaal, while the Orange Free State and the Northem Transvaal have been stable in output (Bekker et al 1992: 50). In the other areas production has expanded. Approximately $60 \%$ of farmworkers are employed in areas where production is expanding. Full-time farmworkers were paid the highest wages in the Western Cape (R4 189 per annum in 1990, including both cash and kind), followed by the Pretoria-Witwatersrand-Vereeniging region (R3 225 per annum). In the other seven regions this varied between R2 939 per annum in the Eastern Cape/Border, and R2 487 per annum in the Westem Transvaal, where wages were the lowest.

Farmworkers are utterly dependent on the farmers who employ them. They have no security of tenure and their access to basic services is largely dependent on the attitudes of individual farmers. Access to education and training facilities in particular is generally wretched (Bekker et al 1992: 5). The resulting poor levels of 
education tend to trap farmworkers in farm employment.

Other groups in the common area that are vulnerable to poverty include labour tenants on commercial farms and 'black' freehold land, and residents of the 'reserves' and of small rural towns.

\subsection{Conclusions}

The rural areas of South Africa are characterised by a division between the former homelands and 'coloured reserves' on the one hand, and commercial farmland and state-owned land on the other. Poverty in these areas is both widespread and extreme in nature. In the homeland areas agricultural activity is very limited and people are mainly dependent on urban cash transfers for income. Households employ a variety of poverty-coping options to supplement their low and often unreliable incomes from urban sources. The population in these areas is skewed, with significantly higher numbers of women and children. Most incidences of extreme poverty are found in the former homelands.

In the 'white' commercial farming areas, on the other hand, farmworkers generally earn low but regular wage incomes, but their opportunities for off-farm income are severely restricted. Their situation of poverty is characterised by dependency on the farmers, and they are at risk of becoming destitute mainly as a result of losing their jobs and being evicted as a result. 


\section{Rural development}

\subsection{Introduction}

Considerable attention is currently given to the reconstruction of South Africa in the post-apartheid era. The need to address poverty and deprivation is widely recognised, as reflected by initiatives such as the Reconstruction and Development Programme (RDP) which has been launched by the Congress of South African Trade Unions (Cosatu) and others. There has also been considerable research activity in the field of rural development and restructuring during 1993. The latter is a phrase commonly used in South Africa at present, which reflects the need for fundamental structural changes to occur in the rural areas as a precondition for sustainable and equitable development. Initiatives such as the World Bank Rural Restructuring Programme generated a lot of information and debate on a range of matters relevant to rural development.

In this chapter some rural development priorities and key aspects of a future rural development/restructuring policy are discussed. The implications of these for energy policy are also considered.

\subsection{The need for rural development}

It is beyond the scope of this paper to argue the case for rural development to be made a national priority. The extent of rural poverty discussed in Chapter 2 should in itself be a powerful motivating factor. It is sometimes argued that urbanisation will solve the problem of rural poverty, particularly in the aftermath of the scrapping of apartheid laws, and that scarce resources should therefore be allocated to urban rather than rural areas. However, evidence suggests that no simple rural-tourban migration process is occurring in South Africa:

Rather, there is evidence of a complex set of circulatory migration streams between rural and urban areas as well as within urban and rural areas respectively. Although the number of black South Africans living in urban areas are increasing, there is a strong tendency to retain 'rural roots', e.g. in the form of ties with rural kin. (Bekker et al 1992)

According to Bekker et al (1992) these tendencies result from a combination of factors such as:

- household survival strategies balancing rural and urban advantages;

- increasing costs attached to life in urban informal settlements;

- push factors associated with violence; and

- cultural attachments to land.

It is likely that these factors will continue to play a significant role in the foreseeable future, particularly as the urban population is expected to grow considerably (Williams 1993). By comparison, the size of the rural population is generally not

10. Population projections by the Development Bank of Southem Atrica and the Uiban Foundation predict a small decrease and increase respectively in the rural population expected to change significantly over the next $15-20$ years. ${ }^{10}$

Another powerful argument for rural development is the potential of these areas to provide some social security and act as a welfare net in a country which is beset by poverty and unemployment, social disintegration and socio-political violence. It is evident from the above, and the discussion in Chapter 2, that the rural areas 
are already playing this role, in spite of the extreme poverty that exists. If the rural areas are further neglected, or destabilised through ill-informed policies, this role would be eroded, which could prove to be disastrous for the country as a whole.

During a workshop in August 1993 on 'Administrative requirements for rural restructuring' that was organised as part of the World Bank Rural Restructuring Programme, a number of field workers reported that urban dwellers are expressing a desire to live in rural areas. Anecdotal evidence was presented of people moving to rural areas, or sending their children to rural schools, to escape urban violence and instability. The views and aspirations of rural people clearly need to be considered in this regard.

\subsection{Defining rural development}

There are probably as many definitions of rural development as there are people involved in the field. Definitions have also evolved as theories of development were discredited and replaced by new ones (Jazairy et al 1992:5). However, the following definition by Chambers (1983) probably reflects the thinking of a large group of development workers:

Rural development is a strategy to enable a specific group of people, poor rural women and men, to gain for themselves and their children more of what they want and need. It involves helping the poorest among those who seek a livelihood in the rural areas to demand and control more of thebenefits of development. The group includes small-scale farmers, tenants, and the landless. (Chambers 1983: 147)

This definition places people at the centre of development. It emphasises the achievement of concrete goals, as well as the way in which these are defined and achieved that is, the process. Moreover, Chambers (1983: 147) emphasises that, although the initiative starts with outsiders, the aim is to transfer more and more power and control to the poor. Chambers argues that the primary development objective should be to enable the poor to obtain what they have identified as their needs, while other objectives such as greater productivity, equity and sustainability should follow. This matter has particular relevance for the EPRET project, of which the primary objectives are greater equity, efficiency and sustainability, with particular emphasis on equity considerations. The important point that needs to be made in this regard is that equity goals often are not achieved in rural areas unless special provision is made to involve poor and marginalised people directly in the planning and implementation of development initiatives. It can be concluded that, to be consistent with rural development objectives, and in order to achieve the main EPRET goal of greater equity, policy recommendations for rural areas would need to provide for an increased role for the poor in identifying and achieving their goals.

The approach to rural development outlined here emphasises the need for development priorities to be identified by the rural poor. Generally particular priorities will differ widely between different localities, households and also individuals, and it therefore follows that policy needs to allow for differences in priorities at a local level. This has particular implications for the planning of energy services. However, it is insightful to consider some of the points made by Chambers (1983: 145) regarding the priorities of the poor. He suggests that a secure and decent livelihood - an adequate and independent source of food and income - is of greatest importance to the majority of the rural poor. He therefore argues that, while basic goods and services are important, they may well be second to subsistence and security among the poorest.

A plate of basic needs does not whet the appetite while the prospect of a secure and plentiful livelihood according to the familiar pattern is an every- 
day motivation. (Chambers 1983: 146)

This can be compared with the results of a needs assessment study conducted in South Africa among farmworkers as well as rural homeland residents in the Transvaal (Pietersburg and Lebowa) and Natal/KwaZulu (Moller 1986: 18). Moller (1986: 18) concluded that employment was a top priority, followed by water for homeland dwellers and access to services (health, education and others) for both groups. Food and nutrition was another area that required attention, particularly among farmworkers. Lund et al (1993: D1) also indicate that 'jobs and services' are the needs most widely expressed by rural communities.

These findings would seem to confirm that the ability to provide for 'a secure and decent livelihood' (mainly in the form of a secure and adequate income) is of primary importance among rural people. At the same time it highlights the importance of basic services, particularly water supply, health and education, to the rural poor.

\subsection{Rural development policy}

There is an urgent need for the establishment of a single, transparent, and enforceable national policy for Rural Development. (Lund et al 1993: E1)

A future government is expected to create a body at national level which will be specifically charged with the formulation and implementation of a rural development policy (RDP). The location of such a body within the government institutions is a matter of debate. The main concern is that it may become marginalised - for example, if created separately it might have insufficient political power to ensure that rural development becomes and remains a national priority in the face of a strong urban bias. The possible domination of agricultural concerns if such a body is linked to a Department of Agriculture has also been raised. Arguments have been put forward in favour of linking it to a department which wield significant power at a national level, such as the Department of Finance.

The formulation of a policy framework for rural development, the setting of national priorities and the establishment of a national body charged with the implementation of a rural development policy should provide some much needed direction in this field, which should greatly facilitate the planning and financing of rural development activities. However, if rural development is to be an enabling process as discussed in 3.3 , there will be a need for considerable flexibility in the implementation of such a policy.

It is generally accepted that there is a need for a holistic and integrated approach to development, because of multi-dimensional nature of the problems in rural areas and the inter-relatedness of different aspects of development. It is therefore argued that aspects of development that complement one another should be linked to ensure that the greatest possible effect is achieved.

Some key aspects of a future rural development policy in South Africa are discussed in the sections that follow.

\subsubsection{Land reform}

There are advocates who maintain that under circumstances of sharp inequality, redistributive land reform is a necessary precondition for solving the energy crisis. (Bajracharya 1985: 13)

Present patterns of land ownership and access to land in South Africa are extremely skewed, as shown in Table 3.1. The need to restore land to those dispossessed in themore recent past, to address historical land claims, and to redress these inequali- 


\begin{tabular}{|l|r|r|c|}
\hline \multicolumn{1}{|c|}{ Region } & $\begin{array}{c}\text { Famland* } \\
\text { ('000 ha) }\end{array}$ & $\begin{array}{c}\text { Rural pop. } \\
\text { ('000) }\end{array}$ & $\begin{array}{c}\text { Farmland per } \\
\text { capita (ha) }\end{array}$ \\
\hline S Africa (non-homeland) & 82246 & 4537 & 18.13 \\
\hline Transkei & 4185 & 2638 & 1.59 \\
\hline Bophutatswana & 3979 & 1464 & 2.72 \\
\hline Venda & 639 & 446 & 0.70 \\
\hline Ciskei & 756 & 477 & 1.58 \\
\hline KwaZulu & 3277 & 2645 & 1.24 \\
\hline Lebowa & 2057 & 1718 & 1.20 \\
\hline Gazankulu & 544 & 477 & 1.14 \\
\hline KaNgwana & 354 & 338 & 1.05 \\
\hline KwaNdebele & 214 & 282 & 0.76 \\
\hline Owa-Owa & 60 & 160 & 0.38 \\
\hline TOTAL & 98311 & 15182 & 30.49 \\
\hline
\end{tabular}

* Crop land, natural grazing, wood and forests

TABLE 2 Farmland per capita of rural population in the homelands and common areas

Source: Kassier \& Groenewald (1992: 336)

ties in general, are widely recognised as some of the most critical issues on the national political agenda. The latter has also been the specific focus of the World Bank Rural Restructuring Programme (World Bank 1993). While there is agreement on the need to redress the inequalities in land ownership and access, considerable diffenences of opinion exist on the specific objectives, the beneficiaries and the mechanisms of a land redistribution programme. ${ }^{11}$ Fundamentally the different approaches to land reform stem from different views on the importance of the various functions of land. The most obvious functions of land are for productive purposes, that is, the harvesting or production of products for purposes of subsistence or to earn an income. ${ }^{12}$ Other important functions of land are related to its use for residential purposes (to provide security, for example) and as the basis for social relations and organisation.

As land is socially understood in African tenure, having it gives the holder sovereign standing, self-determination and an accepted place in the community.... On this principle, land is used to attract adherents, serving a basic resource to build up local organisation. (Cross 1991: 72)

The importance of land for residential and subsistence purposes, particularly in the case of the rural poor, is evident from the situation in the homeland areas. Although the use of land for agricultural production to earn a cash income is very limited (Callear et al 1993: 3), land is one of the primary resources required by rural people to employ some of the more effective poverty coping strategies, as discussed in $\mathbf{2 . 4}$.

These functions of land need to recognised as being as important as the use of land for production aimed at the 'market'. A land reform programme would therefore need to make special provision for poor rural people to gain more access to land for residential as well as productive purposes, and to obtain secure land rights. This view is held by many people in the rural development field, as expressed at the Land Redistributions Options Workshop in October 1993. Lund et al (1993: D16) summarise it as follows:

Land redistribution cannot be reduced to the need to create a black commercial farming class (although this is undoubtably necessary and must be

11. These matters are covered extensively in the papers preserted at the Land Redistribution Options Conference that was held in Johannesburg in October 1993 and was organised by the Land and Agriculture Policy Centre.

12. Shiva (1989) argues convincingly that 'subsistence' activitios (activitios aimed at sustaining the home which do not occur within the cash economy) should be recognised as 'productive' activities in their own right. 
facilitated). Poverty, and the lack of secure land rights, is most fundamentally the condition of the majority of black rural dwellers, whose ability to farm commencially is limited ... Opening spaces for land acquisition, under secure forms of tenure, accompanied by economic opportunity and services, is the imperative of land redistribution.

In addition, they suggest that the following principles, among others, should govern land reform:

Onus is ... on the state to make available state-held land, and to acquire further land for allocation to both individual and group applicants, either via secure forms of lease or via title, for both residential and farming purposes, within the context of viable and legitimate district-level development initiative. In this context, the state may also administer affirmative action subsidy for the purchase of commercial farming land by black farmers.... [L]and reform should be a facilitated, yet demand-driven process that improves local conditions, builds local decision-making and management capacity, and opens options for people to acquire land as groups or individuals, either within their vicinity or beyond, over a period of time.

The establishment of a Land Claims Court is necessary to arbitrate disputes over land in a manner that ensures that such lands will be held in a just and sustainable fashion. (D16)

\section{Land tenure reform}

The reform of land tenure systems will form an important part of a land reform programme. Current tenure systems in the homeland areas have provided for increased control of the land by influential elites; tribal authorities

are frequently forced to support their declining authority with patronage connections established by diverting resources to supporters among the influential elites in local communities. Land is the principle resource over which they have jurisdiction. (Bekker et al 1992: 54)

Under these systems the poor, and women in particular, have been disempowered in relation to land: 'Women's families in particular are now at an across-the-board disadvantage both in access to land and in obtaining autonomous control over it' (Cross 1991: 93).

Cross $(1990 ; 1991)$ discusses the current land tenure systems in the former homelands and other 'black' areas, some of the debates concerning land tenure, and some of the available alternatives for tenure reform in some depth. She dispels the notion that the productive use of land is linked to a particular tenure system (freehold), and suggests that land tenure reform in the homeland areas should focus on the introduction of 'some renovated form of indigenous tenure', which could also be implemented in other areas (1990: 557). This argument is supported by the proven resilience of 'indigenous' tenure systems in countries, including South Africa, where attempts have been made to replace these with more authoritarian or individual systems. Such attempts have often resulted in a situation where the legal records of land ownership do not correspond with the actual practices which continue to operate on former principles (ibid).

Equity considerations are also of importance in the land tenure debate. According to Cross (1990: 545)

freehold systems are acutely subject to the effects of rural differentiation. As a class structure of rich and poor takes shape, freehold makes it very easy to deprive the poor of all land rights without leaving them with any productive asset to compensate.... Unfortunately, the chances of obtaining a landless and destitute rural proletariat of the unemployable are high. The outcome in a 
weak economy with structural unemployment is more likely to be an acutely skewed income distribution than widely distributed economic growth.

Generally there is strong support within the development community for flexibility with regard to the forms of tenure that will be allowed in the homeland areas, 'reserves' and resettlement areas:

Initially, it is necessary to work within locally-chosen tenure systems, not to try to substitute these with an externally contrived blue-print for the nation. This implies the need for legal recognition of a wide variety of tenure types (both individual and group title, both freehold and leasehold, both local government-owned and private). Importantly, the law must allow for changes in tenure systems over time.... It is therefore imperative that the political space be opened for local systems and options to take shape. At the same time, legal mechanisms need to be in place to formalise the range of local choices when they emerge.... (Lund et al 1993: D16)

\section{Potential impact of a land reform programme}

A land reform programme of the nature described above could have a fundamental impact on the structure of rural society and the rural economy. However, it is impossible to make any predictions regarding its possible impact on rural incomes and poverty in general. This would depend largely on the manner in which land reform is implemented as well as parallel initiatives aimed at income generation and the provision of services in the rural areas. In very general terms a land redistribution programme would result in a 'shift' in the rural population from the homeland areas to commercial farming areas. There would be an increase in the rural populations outside of the former homelands, particularly in the Transvaal, Natal and Eastern Cape where the greatest concentrations of people are found. The actual decrease in the rural populations of the former homelands would also depend on factors such as the natural population growth in these areas and the process of urbanisation. The number of farmworker households living on largescale commercial farm land would decrease as a result of the reduction in the size of these areas. These people would probably become part of other rural communities.

\subsubsection{Raising the incomes of rural people}

In 3.3 the high priority given by rural people to attaining secure and adequate incomes was highlighted. Greater access to cash incomes will enable the poor to make use of some of the more productive and effective poverty-coping strategies discussed in 2.4 , and will improve their ability to provide for themselves generally. This matter is of particular importance in the light of the declining opportunities for subsistence production, even in remote rural homeland areas (Bekker et al 1992). A number of strategies which have been put forward as ways to increase the cash available to the rural poor will be outlined very briefly. Some of these are short-term strategies aimed particularly at relieving existing conditions of poverty. In the longer term, real and sustained increases in rural incomes will only be possible if a viable rural economy is established. The achievement of this goal would depend on the effective implementation of a rural development plan which incorporates land reform, service provision, etc.

\section{Targeted welfare transfers}

Social pensions are an important source of income to many poor rural households (Bekker et al 1992). Callear et al point out, however, that there are 'questions about the effectiveness of targeting of relief to poor households through a mechanism of largely providing pensions to the aged'. They argue that

the social security system has to be widened so that destitute people in categories other than the old can be assisted. In particular, this applies to 
households of single adults and young children with no outside support. (1993: 11)

Direct welfare transfer to the poorest and most vulnerable rural people is an attractive poverty relief option, particularly as it allows people to allocate their additional income in accordance with their needs and priorities.

\section{Public works programmes}

Callear et al argue that 'a large scale, on-going, well constituted rural public works programme (PWP)' should be a major component of a policy directed at the eradication of poverty:

The most conspicuous aspect of PWPs is their highly visible redistributive nature. Not only do they generate income, but they focus on generating wealth/assets (in) places that have been hitherto neglected.... [T] gramme must not only deliver relief where it is most needed, but also address the forces that are generating poverty. Amongst these forces are: poor skill-base within the community, absence of supportive infrastructure, and the lack of an integrated and consistent resource mobilization process. (1993: 13)

They make the following suggestions, among others, regarding the nature of a public works programme:

Broadly speaking, a rural PWP will consist of two programmes: one will be a programme for the provision of national or regional infrastructure; the other a community-driven set of projects that would address the local needs of the inhabitants (14).

In order to create a significant increase in the job opportunities per unit of expenditure, it would be essential for the public works programme to make extensive use of labour-intensive methods of production (Callear et al 1993: 15).

The need for such a programme is widely recognised. For example, it has been identified as an important component of the Reconstruction and Development Programme (Sunday Nation 1993: 14).

Other options for income generation and job creation

Agricultural development and the management and utilisation of natural resources in rural areas present opportunities for increasing rural incomes. These aspects of a rural development policy are discussed in 3.4.4 and 3.4.5 respectively.

The development of the small or 'informal' business, industry and service sectors in rural areas is receiving growing emphasis. These activities can be related to other sectors such as agriculture (for example, the milling of maize). The training and provision of support services, including small loan finance, to people who are currently involved in such activities as well as potential entrepreneurs are of particular importance.

The training and subsequent employment of rural people for the purposes of service provision in rural areas also provide some opportunities for increasing rural incomes. This include the employment of people as extension workers (in, for example, primary health care, agriculture and social forestry), as well as maintenance officers (in, for example, water supply and electricity provision).

\subsubsection{Meeting basic needs}

In 3.3 some of the priorities which have been identified by rural people were briefly considered. In addition to income, these revolved mainly around access to water, food, health and education services, which, together with shelter/housing, clothing and sanitation are generally grouped under the term 'basic needs' (Møller 1986:9). 
Streeten and Burki (1978: 413) define the following hierarchy of basic needs:

At the lowest level, basic needs are those that have to be met for bare survizal.... At the next level, basic needs may be defined as those that have to be met for continued survival and comprise a minimum of food and water, protection from fatal diseases and adequate shelter. At the third level, the satisfaction of basic needs covers continued productive survival and in addition protection from debilitating diseases, more food and some education. Finally, certain non-material needs may be added, like participation in making decisions affecting one's life and work, and the relative component of poverty.

However, it is not a simple matter to define the contents of a basic needs 'package', or the level of supply at which these needs are adequately met. For example, the need for leisure and recreation could be regarded as a basic human need, while access to electricity, transport, media and telecommunication services has become essential in the modern world.

The relationship between energy and basic needs is clearly of importance for the purposes of this paper. Energy is generally not regarded as a basic need in itself, but is included in a 'package' of basic goods and services because of the crucial role played by energy services in the satisfaction of basic needs, such as food preparation, space heating and water-pumping. This matter will be considered in greater depth in Chapter 4.

The poverty in the rural areas of South Africa is characterised by the lack of access to the basic necessities listed above. For example, Møller (1986: 14) found that people in the homeland areas she surveyed had inadequate access to water, education and health services, lacked proper nutrition, and were unable to save sufficient money. She identified fuel shortages as an area of major concern. Farmworker families were worse off, with inadequate access to clothing, housing, sanitation, fuel and health services, and very little leisure time. Areas of particular concem in this case were poor nutrition, poor access to education facilities and the lack of opportunity to save money.

A rural development policy which aims to meet the needs of people in rural areas therefore has to incorporate a strong emphasis on basic needs. Møller (1986: 9) points out that basic needs satisfaction is considered a necessary but not sufficient condition for economic development'.

A distinction can be made between basic services on the one hand (such aswater supply, health services), and basic goods on the other (such as food or other items required to satisfy basic needs). As will be evident from the discussion below, energy does not fall neatly within either of these categories.

\section{Provision of services}

It is generally agreed that the provision of basic services to rural people should form a key component of a rural development policy (Callear et al 1993: 3). The primary responsibility for the provision and financing of such services needs to rest with the state, as resources within these communities would be totally inadequate for this purpose. However, in some cases it may be possible to finance the provision of, for example, water and electricity from the revenue generated within these sectors.

The provision of basic services in poor areas would also provide opportunities for realising other development objectives: the creation of employment opportunities, the transfer of skills, the building of organisational and institutional capacity, etc. For example, the development of physical infrastructure could be done within the ambit of a public works programme (as discussed in 3.4.2). Another example relates to water supply projects in rural areas, which sometimes serve to develop technical, supervisory, organisational and even management skills among the local people. 
Various complexities exist regarding the provision of services in rural areas that need to inform the formulation of policies. These derive mainly from the fact that the homeland areas in particular are characterised by high population densities and settlement patterns which resulted from apartheid policies and generally bear no relation to economic viability or environmental sustainability. Some changes will undoubtably occur during the next 15-20 years, partly due to 'natural' rural-rural and rural-urban migration which is already apparent, and partly resulting from a land redistribution programme. While such changes could have a considerable impact on the nature of specific localities, it is generally agreed that the overall situation is unlikely to change significantly in the short term. This situation poses a number of questions. In some areas the provision of services could lead to the entrenchment of population densities and settlement patterns which are essentially unviable. It is also possible that services which are provided in some areas could be underutilised in the future if significant reductions in populations occur.

It is suggested here that these concerns should be given due consideration, but should not be allowed to override the imperative to provide basic services to all rural people. Rather, the concerns should be accommodated within a framework that provides for a minimum level of service ${ }^{13}$ to be provided to all rural people, and the possibility of acquiring a higher level of service through a process of negotiation and subject to certain conditions and constraints.

As the economic viability of rural settlements is of particular concern, the strength of the local economy could serve as one of the conditions for higher levels of services to be provided. However, the definition of 'economy' would need careful consideration, as 'informal' income-generating activities and activities which do not occur within the cash economy would also need to be considered. A typical constraint to the provision of higher levels of services would be the cost of the services per household.

Another matter of concern regarding the provision of services in rural areas, is the plethora of organisations that are currently involved in service planning, delivery and funding, which has resulted in confusion and the duplication of efforts (Lund et al 1993: D24). This matter needs attention to ensure more effective and efficient service delivery in the future.

Finally, it is useful to consider the principles formulated by Lund et al (1993: D25) for service provision in rural areas:

- Access of nural people to service deliverers is critical. It requires a functional decentralisation that places public administrators within reach of end users. It also requires a shift in attitude by the bureaucrats towards the people they should serve.

- Public institutions require clear functions and lines of accountability, and sufficient resources to implement.

- There is a need to regard service provision within the concept of 'soft boundaries', that is, service delivery that is not stopped at an administrative boundary, but is accessible to those who require it.

13. In the water supply and sanitation sectors different levels of supply have already been identified, including the minimum level of supply which is deemed to be acceptable (Personal communication with lan Pearson, Division of Water
- There is no necessary linkage between land tenure and services. This legacy needs to be overturned, and common standards set for South Africa.

\section{Provision of basic goods}

Modern-day commodities play a crucial role in meeting some of the basic needs of rural people. Such 'basic goods' include: foodstuffs and cooking utensils, cement and other building materials used for the construction of houses, and fuels such as candles, paraffin and batteries required to provide energy services. 
The importance of these goods in meeting basic needs is partly due to the high level of self-help in rural areas, where households have virtually no access to housing schemes and centralised services like electricity, sewage and piped water. The distribution of these goods is generally left to the private sector, and little attention is given to the problems of unavailability and high costs in rural areas. However, improving rural people's access to basic goods should form a fundamental part of a basic needs strategy.

A recent initiative which has begin to address the problem of the high costs of basic goods in rural areas is the National Bulk Buying Facility which was formed under the auspices of organisations like the:Natal Rural Forum, the Environmental and Development Agency (EDA) and the National Union of Mineworkers. It aims to negotiate discounts on certain goods with the suppliers at a national level, thereby enabling registered retailers in rural areas to supply the goods at considerably reduced prices to local customers. ${ }^{14}$

\subsubsection{Agricultural development}

Agriculture in the homeland areas and in the commercial farming areas differs substantially at present. The definition of a farmer in the homeland areas is not a simple task, and estimates of the number of farmers in these areas vary between 700000 and four million (Auerbach 1990: 41). However, a figure of 1.2-1.3 million seems to be fairly common; each of these farmers having, on average, access to approximately thirteen ha of land (including communal grazing land), of which between one and two ha are arable (Auerbach 1990; 41; Bembridge 1990:17-18). The majority of these farmers are women. Bembridge (1990: 21) identifies the following groups of farmers in the former homelands:

- market-oriented commencial farmers who make a living from farming ( $0.2 \%$ of the rural homeland population);

- progressive small-scale landholders who sell some produce and/or livestock, but generally do not produce enough food for their families (13\%);

- small-scale landholders with below subsistence production levels who generally do not sell any crops or livestock ( 56\%).

In addition, he indicates that approximately $31 \%$ of the rural population in these areas had no access to arable land and own no large livestock. The average household in the homeland areas earns very little from agricultural activities (Callear et al 1993: 3).

The commercial agricultural sector, on the other hand, comprises approximately 50000 white farmers ${ }^{15}$ (Auerbach 1990: 41) who are generally involved in largescale capital-intensive farming operations. On average each of these farmers owns 1700 ha of land, of which 286 ha is arable. Auerbach (1990: 41) identifies the following groups of farmers in this sector:

- the $6 \%$ most successful farmers who produce $40 \%$ of the total agricultural output;

- the $20 \%$ reasonably productive farmers who produce $40 \%$ of the total output;

- the remaining $74 \%$ of farmers who produce only $20 \%$ of the total output.

More than 1.2 million people are employed on these farms on a regular basis (Hofmeyr 1994).

In addition to the striking difference in access to land between the two groups, farmers in the former homelands generally have poor access to agricultural inputs, implements, markets, research and extension services and credit, while 'much of the success of commercial farming in South Atrica can be attributed to ... institu-

14. Personal communication with Bill Kaye, Natal Rural

Forum.

15. Bembridge (1990: 17) estimates the number of white commercial tarmers as 62000 . 
tional support and services' (Bembridge 1990: 19). According to Auerbach (1990: 41) each of the white farmers received on average about fifty times more assistance than a black farmer.

However, in recent years many white 'commercial' farmers have found themselves in increasing financial difficulties due to a combination of inflated input prices, stagnant prices for raw products and the removal of government subsidies (Auerbach \& Gandar 1994). It is now widely recognised that there is need for a fundamental restructuring of the commercial agricultural sector, in addition to the need to the address the inequalities in present land ownership patterns and the allocation of resources.

It is generally agreed that small-scale agriculture needs to be the focus of agricultural development in the future, in the homeland areas as well as the commercial farming areas. Future agricultural development will be closely related to the land reform programme that is implemented. As discussed in 3.4.1, the development community is calling for a demand-led land redistribution programme that will enable people to acquire land for various purposes, rather than a programme which focuses on the establishment of a small black' commercial farming sector.

The provision of support services to farmers is an important aspect of agricultural development. Such services need to be appropriate to the particular needs of different groups of farmers (Land and Agriculture Policy Centre 1993: 2).

The energy requirements related to small-scale agricultural development have received particular attention in the EPRET project with the aim to identify and begin to address these needs. This matter is discussed in depth by Auerbach and Gandar (1994), and will be considered in Chapter 4.

\subsubsection{Management of nafural resources}

The sustainable management of natural resources, which includes its utilisation, is an essential part of a rural development strategy. The natural resource base in rural areas is particularly important for the purposes of this paper, because of its present and potential role in providing in the subsistence needs of rural people (such as food, water and fuelwood) and providing people with a source of income (from, for example, the sale of medicinal plants, ecotourism and agriculture). The presently degraded condition of the land and vegetation in many rural areas (for example, around settlements in the former homelands) is therefore of considerable concern.

The management of natural woodland is particularly important for energy planning purposes. This matter is discussed in depth by Gandar (1994). He estimates that more than two-thirds of the roughly ten million tons of wood used as domestic fuel annually, is obtained from natural woodland. The savanna woodland regions in particular are the main source of fuelwood in South Africa. Current land-use in the savanna regions is mainly geared to livestock production, both in the commercial farming areas and the homeland areas, and is unlikely to change markedly in the future (Gandar 1994). According to Gandar, wood use in these commercial ranching areas is negligible compared to the abundance of wood. Wood is mostly used by resident farmworker families, while limited quantities are 'exported' to other areas. In woodland areas in the former homelands, however, wood is often a scarce resource. Here, trees are utilised for a variety of purposes, including construction material, medicines, fruits, dyes, and fuel. It is of interest to consider some of the mechanisms used in the past and present to control the use of wood in these areas.

Gandar (1994) points out that, under pre-colonial indigenous land tenure systems, numerous practices existed which had the effect of regulating the utilisation of indigenous common resources. Some had a deliberate conservation intention, of 
which the most important were tenurial regulations and/or usufructuary rights controlling access to resources. In addition, various social taboos, seasonal and social restrictions and the existence of technical limitations inadvertently served to regulate utilisation. Tenure of trees was the strongest customary regulatory mechanism controlling the harvesting of trees. Trees in communal areas traditionally belonged to the chiefs or headmen. The gathering of dead wood for firewood was freely allowed, but harvesting of live trees was forbidden unless specific permission was obtained from the chiefs. When an area of land was allocated to an individual for residence or cultivation, the trees on it became the property of the user of the land, together with the rest of the biotic component.

However, the changes imposed on these tenure systems since colonial times have resulted in the undermining of the traditional role of the chiefs as custodians of the natural resource base. Gandar points out that the traditional controls on the cutting of live trees have fallen into disuse in much of KwaZulu, and probably in many other areas. In Gazankulu and Bophuthatswana, this function seems to have been taken over to some extent by the authorities responsible for activities like nature conservation. There is evidence, though, that people in these areas are cutting live trees in spite of the legal restrictions, because of the prevailing wood shortages (Griffin et al 1992: 59). According to Gandar (1994) wood-gatherers will generally go to considerable lengths to collect dead wood before resorting to the cutting of live trees. In many areas, therefore, this occurs only to a limited extent or not at all.

Clearly the management of woodland resources under these circumstances is not a simple matter. Gandar (1994) claims that the management of communal rangelands has 'continually confounded rural developers'. However, international experience has indicated that the control and management of indigenous woodland and forest resources need to be decentralised to village level institutions and individual farmers, while management strategies should be built on local traditions and practices.

\subsubsection{Developing institutional and organisational capacity}

\section{Present situation}

At present there is a serious lack of both institutional and organisational capacity in rural areas, particularly at a local level. The local administrative structures provided for in the former homelands were the tribal authorities (TAs), which comprised the local chief, headmen and tribal elders nominated by the chief. This structure also served to represent the locality in the political hierarchy of which the highest body in each homeland was the Legislative Assembly. In a report on rural local govemment (University of the Western Cape 1992: 43) the TA system is criticised on account of the extensive but vague powers allocated these bodoes, the confusion of roles that resulted, the lack of democracy and accountability, and the gender inequality in the system, the lack of capacity and the financial unviability of the structures, etc. In some areas the TAs had ceased to function altogether.

Homeland government ministries which have been primarily responsible for service provision in the rural areas, have generally been ineffective (Lund et al 1993: D23). This is evident from the inadequate service provision in these areas (see 3.3). In recent years organisations such as the Joint Services Boards in Natal/KwaZulu have become more involved in service provision, but the impact has been minimal (Lund et al 1993: D24).

In the commercial farming areas, provincial administrations have mainly been responsible for services such as transport and health, while farmers generally provide their own water and services like sanitation. However, no responsibility has been allocated with regard to the provision of services to farmworkers. Their access to services has therefore depended entirely on the goodwill of individual farmers. This has led to the current situation in which farmworkers generally have 
poor access to most services (Hofmeyr 1994).

Thenon-governmental service sector in rural areas mainly comprises small support organisations operating in particular areas-so-called non-governmental organisations (NGOs). They have experience mainly in community and organisational development and in providing support services, although some have been involved in infrastructural development (such as water supply):

Rural-focused NGOs have.... mostly emerged from the resistance years, some concentrating on the defence and promotion of land and democracy rights, others on farm support, or water provision, or primary health, or savings/credit activities. Few NGOs have a history of wider-perspective rural development planning and implementation. (Lund et al 1993: D26)

The capacity of rural NGOs is generally limited, and most rural communities do not have access to the services provided by such organisations.

Community-based organisations (CBOs) in rural areas can comprise a whole range of structures, such as civics or residents' associations, farmers'/agricultural associations, women's groups, youth organisations, water committees, savings clubs, clinic/health committees, religious groupings, literacy organisations and others. The capacity of these organisations is generally limited:

For the most part, CBOs are locality specific structures, many having been bom out of resistance or out of low-level attempts at survival.... CBOs in different localities remain largely isolated from one another.... Rural CBOs are often politically powerful and regarded as widely legitimate in their areas. However, minimal resources, infrequent access to funding, poor management skills, and low levels of education greatly restrain their ende[a]vours.... Women are generally not prominent in CBOs. (Lund et al 1993: D27)

In some cases, however, the level of organisation has evolved considerably.

Only a small number of NGOs and CBOs are operative in farmworker communities, mainly as a result of their physical isolation and the attitudes of farmers. In some areas farm workers are served by advice offices, while a number of farmworkers' unions and associations have evolved in recent years (Hofmeyr 1994).

\section{Capacity building}

Two long-term goals have been identified within the development community in response to the situation described above (Lund 1993: 2). The first is the establishment of legitimate, accountable, effective and efficient local government structures in rural areas (see 3.4.7). The second is the establishment of vibrant and democratic organs of civil society to represent the interests of the rural poor and serve as independent 'watch-dogs' of local government. The achievement of these goals in the long-term will be the objective of a capacity building process in rural areas.

While capacity building is a long-term process, there is clearly a need to meet the basic needs of rural people and increase rural incomes in the short-term. In her address to the Social Forestry Workshop organised by the Biomass Initiative in July 1993, Susan Lund (1993) summarised the tension between these two aspects as follows:

I am convinced that development projects are doomed to fail in rural South Africa unless there is a balance - and it is a delicate one - between the slow process of organisational development, and the rapid delivery of tangible improvements to people's daily lives.

She gave the following guidelines for incorporating capacity building in national development programmes, such as a national social forestry programme: 
- $C B O s$ need to beengaged in planning the design of the programme at local level. This should not be done in the way of 'consulting' them to get approval of a design formulated elsewhere, but to design with the $\mathrm{CBO}$ a programme that is appropriate to local conditions within the framework of a nationally flexible programme. This means that development practitioners need to work intensively with $\mathrm{CBOs}$, and not to dismiss them as inefficient and unreliable, with the aim to build up their planning and management skills.

- Where NGOs are working, liaison with them should start as early as possible in the investigation phase. NGOs usually have sound working knowledge of community dynamics, and most will be keen to be involved in some capacity especially in facilitating $\mathrm{CBO}$ planning for the programme and in training for local management.

- As a priority, CBOs should be trained to manage the programme's finances, schedules, monitoring, etc. This need not happen immediately, but should be built into the plan with the aim to equip local leadership to take responsibility for managing community development.

- Women and young people should be central to all initiatives, and it should be ensured that they benefit from the programme, by being involved in the planning, and learning to manage and maintain it.

These strategies therefore aim to equip rural people with the necessary skills to serve on local government structures, or to engage such structures in a meaningful way. Particular attention is given to the involvement of women and other marginalised groups, who are in danger of being excluded from the process.

\subsubsection{Rural local government}

There seems to be strong support within the development community for the establishment of relatively autonomous composite government structures at a district level in all areas outside of what is regarded as the functional metropoles. The following recommendations in this regard were made by Lund et al (1993: E1):

Relative autonomy needs to be devolved to district level, which implies the need for 1) financial security; 2) the ability to provide and/or access services; and 3) powers to address local needs and issues.

- A public administration at district level is necessary for implementation.

- District residents should elect District Councils.

- District councils should be represented at regional level.

- District boundaries need to take account of 1) the integration of existing racial administration; 2) the integration of town and country areas; 3) social cohesion; 4) the potential economic base; and 5) natural resource assets and constraints.

- District Councils should be responsible for at least certain functions and services which they may provide directly, or access from elsewhere. These are specified, and include primary health care, primary and secondary education, and bulk and reticulated water supply.

- Localities within districts could take many administrative forms, including town municipalities, tribal authorities, and returnee groups, all of which will require access and powers at district level. These should be matters for district level negotiation, and systems may need to change over time.

- Weaker constituent groups within districts, particularly women, will require special attention to ensure participation in, and appropriate benefits from, district decisions. NGOs and CBOs will play a pivotal role at this level. 
Recommendations were also made regarding the functions of the central state and regions. The former includes provision for fiscal allocations to regions and districts in line with policy.

It is envisaged that District Councils would be established through a negotiating process at the local/district level within a framework provided nationally. One of the matters that would need to be negotiated is the position of traditional leaders. It is conceivable that such leaders with some local standing could enjoy ex officio status on the structures that are put into place.

Lund et al (1993: E2) specify a wide range of functions that should be the responsibility of District Councils, including land use planning and zoning. It therefore seems likely that these bodies would take responsibility for overall development planning, as well as the coordination and integration of development efforts in districts. It should be noted that these recommendations are unlikely to be implemented in the short-term. Implementation in the longer term will be dependent on the extent to which the development community can canvass support for these proposals.

\subsection{Implications for energy policy}

Some of the implications for energy policy of the approach to rural development and the priorities of a rural development policy that were discussed above, are the following:

- Energy policy should provide a framework for energy planning which is sensitive and responsive to the needs and priorities of rural people, particularly poor and marginalised people, as well as women. In addition, opportunities for increasing the control of rural people over energy-related initiatives need to be explored.

- The opportunities for improved service provision which may result from a land redistribution programme need to be considered. For example, people who acquire land for resettlement on electrified farms could be eligible for connection to the electricity grid. In addition, people who acquire land for resettlement in well-wooded areas may have better access to this resource than before.

- Energy services which contribute to basic needs fulfilment and those which support productive activities are both crucial to rural development. In a particular area the constraints which a lack of energy services places on the achievement of different development objectives would need to be considered to determine priorities.

- The possibilities for income-generation through energy-related projects and activities should be explored to the full. These include opportunities for public works programmes (such as grid electrification), small business development (such as the maintenance of appliances) and employment in the provision of services (for example, social forestry extension workers).

- Opportunities for capacity building as part of energy-related initiatives should be explored, while keeping in mind the balance required between the delivery of improved services and the need to build capacity. However, this balance can only be achieved if it is actively sought.

- The role of a district level administration in energy service provision needs to be considered, including its role in electricity provision, as well as the implications of its possible role in coordinating development at this level. 


\section{CHAPTER 4}

\section{Energy services to meet development needs}

\subsection{Introduction}

In this chapter the ways in which energy can contribute to development are considered in the light of the development priorities discussed in Chapter 3. The effects of energy shortages receive attention, as does the extent to which a lack of appropriate energy services constitutes a critical constraint to development.

Energy is a pervasive element in all human activities. It is used for domestic purposes like cooking), in community facilities (such as schools) and for productive purposes (such as ploughing). The EPRET project has focused mainly on domestic energy use, in addition to which considerable attention has been given to energy requirements for small-scale agriculture (Auerbach \& Gandar 1994). The energy requirements of community facilities and productive uses other than agriculture have not received any significant attention. This approach could have resulted from the way in which integrated energy planning (IEP) has been conceived:

Through disaggregated end-use analysis, major consumption sectors, such as households, commerce, industry, mining, transport and agriculture are defined. These consumption sectors are then broken down into subsectors such as rural and urban households which are, in turn, divided into end-uses. (Eberhard 1992: 17)

This analytical framework may be appropriate for urban areas, but is incompatible with an integrated approach to rural development, as discussed in Chapter 3 , which recognises the central importance of enhancing rural incomes and meeting basic needs. The provision of energy services in rural areas could only contribute significantly to these objectives if its potential for improving other services (such as water supply, education) and enhancing income generating activities are fully explored.

\subsection{Energy for basic needs}

As discussed in Chapter 3 , one of the priorities of a future rural development policy will be to meet the basic needs of all rural people. In this section the role of energy in meeting basic needs will be considered.

Women in rural areas are mainly responsible for meeting the basic needs of their families, including most of their energy needs (Cecelski 1985: 13). The resources available to poor women for this purpose are mainly their own time, as well as limited cash resources. Cash availability is further limited by the fact that women often do not control household budgets (Cecelski 1985: 19) (also see 5.8.5).

Some essential household tasks done by women are water collection, fuel collection and preparation (such as chopping wood), cooking (including preparing food and tending the fire), washing, cleaning, child feeding and care (for example, preparation of special infant foods), food gathering (leafy green vegetables, for example), and taking children to the clinic (Cecelski 1985: 30; James 1993: 93). In addition, they are involved in agricultural and other activities. James comments that:

Unless women are frail their leisure time is small. Even though women may rest during the day, especially at midday, this rest time is not devoid of responsibility, with children to care for and food to watch over. Many women spend their resting periods making handcrafts, such as mats. (98) 
All the tasks performed by women are interdependent, and an increase in the time required for one task such as fuel collection will reduce the time available for other essential tasks. If the time required for fuelwood collection in the homeland areas is considered (see 5.8.1), it seems highly likely that this activity has begun to impinge on the ability of rural women to provide in the basic needs of their families. However, very little attempt has been made in South Africa to date to establish the extent to which this is the case.

A similar point needs to be made about the cash resources available to rural people: demands on cash resources to meet energy needs will have an impact on the extent to which basic needs can be met. Again it seems likely that expenditure on energy (see 5.8.3) is affecting the ability of people to meet their needs.

\subsubsection{Food}

Food is a basic necessity for survival. As most foods, and particularly the whole grain and legume staple foods on which most rural diets are based, are inedible when raw, cooking generally forms an essential part of food preparation. An estimated $60-70 \%$ of the energy used in rural areas of underdeveloped countries is for cooking (Morse et al 1984: 477). Both the quantity and nutritional value of food are important. It is therefore necessary to consider the impact of fuel shortages on both of these. A reduction in the number of hot meals prepared daily has been reported in areas of fuel scarcity (Cecelski 1985: 36; Morse et al 1984: 477), with an impact particularly on children:

The number of meals prepared daily is especially critical for small children where staple foods are starchy. Because of their small stomachs, children cannot obtain enough calories from one starch meal per day to avoid malnutrition, but three or four small meals each day can be sufficient. (Cecelski 1985: 38)

Eberhard (1986: 59) observed that most households in the six settlements he surveyed cooked at least once a day. The majority of households cooked more than once a day, with significant differences in the frequency of cooking between different areas. The largest number of households $(90 \%)$ who cooked three times a day were found in Manzimahle (Transkei), while $90 \%$ of households in Mokumuru (Lebowa) cooked twice a day. However, a significant percentage (about 5-7\%) of respondents in Lujiko (Ciskei), Cottondale (Gazankulu) and Mokumuru (Lebowa) cooked less often than once a day. Unfortunately the reasons for this were not analysed in any depth.

Food may be cooked in bulk and served either cold or slightly reheated (Cecelski 1985: 38). In such cases the food may become unfit for consumption, as rural people generally do not have refrigerators. It has also been found that people resort to greater consumption of undercooked or raw food in areas of fuel shortages (Cecelski 1985: 37). Again it is children who are mainly affected:

Serving food undercooked or raw can be damaging to the health of small children in particular, who need well-cooked food for proper digestion. (Cecelski 1985: 38)

Nutrition may ... suffer from decreased availability of protein and sometimes calories in uncooked or partly cooked foods. (Morse et al 1984: 477)

Toxicity and diseases which would be destroyed by cooking may become a problem. Many legumes for example when raw or under-cooked contain substances that are indigestible or antagonistic to digestion if not actually poisonous), which are eliminated by extended heat. (Cecelski 1985: 38)

Eberhard (1986: 38) found that fuel shortages prevented the preparation of meat and vegetables with the staple mealie meal. This would result in the reduced intake 
Reductions in the frequency and duration of cooking can in somecases be attributed particularly to fuel shortages (Cecelski 1985: 38). However, it is generally not possible to separate the effects of fuel shortages on cooking patterns from that of a lack of food and a lack of time (see 4.2).

\subsubsection{Water}

Domestic water is often the highest development priority in the rural homeland areas. In many areas the average consumption of water is of the order of 10-20 litres per person per day. ${ }^{16}$ This can be compared to the World Health Organisation's recommended daily minimum of $\mathbf{5 0}$ litres per person per day. Energy is often required to pump water to meet domestic needs. The following water supply systems are found in the rural areas of the former homelands (Water and Sanitation 2000 1991):

\section{- Protected local sources}

An example of this is spring protection whereby the water from a spring is made available at source before it can be contaminated; or the covering of a shallow well and installation of a suitable pump to prevent contamination of the well water.

- Grounduater extraction by means of handpumps on boreholes

In this case handpumps are installed on shallow and medium depth boreholes. Water has to be collected from the boreholes.

\section{- Local water supply schemes}

Water is extracted, treated if required, and distributed to the community by means of communal or household taps. Possible sources include boreholes equipped with either a windmill, a diesel pump, or an electric pump; a spring protection scheme with a distribution pipe network; or water extracted from a stream or dam. The source of water is, by definition, within close proximity of the residential area.

\section{- Centralised uater supply schemes}

Regional schemes consist of large reservoirs supplying water to a central treatment works. The water is subsequently pumped via long pipelines to a number of rural communities. The individual communities then obtain water from a local storage reservoir and distribute it further.

The energy requirements for water-pumping therefore vary considerably. At present human energy contributes significantly to domestic water provision in poor rural areas, as the use of handpumps is common in many areas and water generally has to be fetched at considerable distances or along steep slopes, as in KwaZulu. For example, Eberhard (1986: 70) found that average distances which had to be travelled to collect water (retum trip) ranged from 0.7 to $1.8 \mathrm{~km}$. Women assisted by children are mainly responsible for water collection. Eberhard (1986: 70) found that the average time spent by women on a single trip to collect water was between 0.6 and 2.3 hours, while the majority of households in four of the six areas surveyed collected water three times a day. The demands made on the time of women for water collection could have a significant impact on the ability of rural households to meet their basic needs, as discussed above.

Energy is also required to heat water for a variety of purposes, which mainly aim to ensure personal and household hygiene, as Cecelski (1985) points out:

Cleanliness is one of the most basic health practices for maintaining a germ-free environment and preventing the spread of diseases. Hot water is needed for washing clothes, cooking utensils[,] and people. Scabies and other skin diseases become prevalent if it is not possible to wash frequently. Availability of hot water for washing and clean clothes is especially important for small infants, who are more vulnerable to infection. (32).

16. Personal communication; lan Pearson, Division of Water Technology, CSIR. 
The heating of water for some of these purposes, particularly bathing, is common in the rural areas of South Africa (see 5.5.2). However, water shortages are probably a greater constraint to hygiene at present than the availability of fuels for heating the water. Nevertheless, this is an important energy service which needs more attention, particularly in areas where household water connections are being provided.

Water can also be boiled to disinfect it before drinking, which is necessary in many rural areas where people have no choice but to use water from polluted sources. However, this is not necessarily the best alternative available for the disinfection of water, and is not commonly practised.

\subsubsection{Health}

The role of energy in the provision of nutritious food and clean water, both of which are prerequisites for good health, are discussed above. In addition, energy can play an important role to improve the quality of health services in rural areas. Energy services which may be required by clinics are refrigeration (for vaccines), sterilisation (by means of heat), lighting, cooling and so on. Furthermore, clinic staff are sometimes housed on-site and require energy for domestic purposes.

A major programme to electrify schools and clinics in rural areas, funded by the Independent Development Trust (IDT), is currently being implemented. This is expected to generate considerably more information on the energy requirements of clinics and schools than is available at present. It should be noted, however, that energy may not in all cases be the critical constraint to improving health services: 'Lack of medicines and qualified medical staff are usually far greater constraints on health services than the absence of a public supply of electricity for lighting or refrigeration' (Foley 1990: 101). An improved energy supply to clinics could have a significant impact on health services only if other elements of the health system function well.

In addition to the contributions which can be made by energy to health, energy use can also have very particular negative health impacts. These are discussed in depth by Van Horen (1994a).

\subsubsection{Education}

Energy can contribute to education in rural areas in a number of ways. At a household level, lighting is often used to enable children to study in the evenings (see 5.5.3). Improved lighting, such as that provided by electricity, is therefore welcomed particularly as it provides for easier studying. In schools the use of audiovisual aids which require electricity could improve the quality of education. Lighting in schools could enable the use of the facilities for studying in the evenings (for adult literacy training etc), while it would also improve the visibility in classrooms on rainy/cloudy days. Laboratory and domestic science facilities at schools also require energy services, particularly heating and refrigeration.

Again it should be noted that energy services may not be the main constraining factor in this regard, as Foley comments: 'with evening classes and adult education courses, shortages of teachers, books and equipment tend to be far more critical than the lack of electric light (1990: 101). Improved energy services would have the greatest impact on education if the facilities are properly utilised by well-trained teachers, of which there is a serious shortage in rural areas. 


\subsection{Energy for production}

As discussed in Chapter 2, the rural economy of South Africa is for the most extremely depressed and fragile. Any contribution which could be made by energy services to the development of productive activities, both for purposes of subsistence and income generation, should therefore be explored. Energy is a necessary input to many productive activities. The unavailability of suitable energy sources and/or equipment, or the high cost of what is available, can severely limit their viability. The energy requirements of small-scale agriculture and related activities are discussed below, followed by other entrepreneurial activities.

\subsubsection{Small-scale agriculture}

The energy requirements of small-scale agriculture are discussed in depth by Auerbach and Gandar (1994). Only the main points will be outlined here.

Auerbach and Gandar (1994) point out that energy merely comprises one of the inputs to agricultural development, which is subject to various constraints of a structural nature (some of which were discussed in Chapter 3). For example, while the underutilisation of arable land may seem to be a consequence of the lack of available tractive power, underlying factors concerning land tenure and alternative options in the labour market have an important impact on the situation.

Different categories of small-scale agricultural activity can be identified, each of which have particular energy requirements. Subsistence and sub-subsistence activities typically involve the extensive grazing of livestock, dry or arable cropping, or gardening on a plot, which can be at the homestead or in a community garden. Various other activities, such as more intensive livestock production, may be included. Most of the people involved in small-scale agriculture in the future will probably be in this group, if a land redistribution programme is implemented as discussed in Chapter 3 . The main energy requirement is to provide draught power for ploughing and other agricultural operations (Auerbach \& Gandar 1994) (see below). Energy is also needed for water-pumping, particularly for irrigation purposes in communal gardens and for the watering of livestock in arid areas where surface water is insufficient.

Communal gardens are generally between one and three hectares in size (Auerbach \& Gandar 1994), usually divided into individual plots. More than $\mathbf{4 0} 000$ families benefit from such gardens, mainly in the homeland areas. Most gardens are situated near a surface water source from which water is carried by hand to water the crops.

A further use of energy is for the processing of food, such as the shelling and milling of maize. Maize is usually shelled by hand, while dry bean crops are commonly beaten with sticks. Milling is done by various means, which include hand mills, trading store millers, PTO-driven hammer mills and commercial milling facilities.

The second category in small-scale agriculture comprises small-grower schemes. These generally involve the production of a single crop, typically a raw material for processing such as sugar cane, cotton or timber, by small farmers who are contractually bound to sell the crop to the company involved in the project (Auerbach \& Gandar 1994). Typically energy is required for haulage to transport the bulky raw material to the processing plant or mill.

Finally, settler schemes typically take the form of intensive agricultural operations in which groups of farmers are involved. Irrigation often constitutes a major use of energy, and energy may also be required for processing. However, the viability of such schemes are in question because of their capital and managerial intensiveness. Energy is generally required for purposes of agricultural extension, training and organisational development, particularly in the form of electricity to operate audiovisual aids and provide lighting in suitable venues. It is also necessary to be responsive to diverse and very localised energy needs. 


\section{Draught power requirements}

Auebach and Gandar (1994) focus mainly on draught power requirements, as this has been identified as a critical area of need. They consider the presently cultivated land in the homeland areas and the draught potential in these areas from animals as well as tractors, and conclude that shortages of traction could be expected both at a local and regional level.

In addition, they find that animals presented a greater potential traction source than tractors at present. However, considerable constraints exist with regard to the use of animal draught power, including skewed ownership patterns with regard to cattle, the poor condition of these animals generally and a shortage of appropriate implements. The use of tractors in these areas is constrained by factors such as the difficulties involved in purchasing tractors, inadequate maintenance of existing tractors and inadequate access to diesel. The latter is of particular concern for the purposes of this paper. Auerbach and Gandar (1994) point out that diesel generally has to be obtained from towns in the homeland areas. This poses serious difficulties to many tractor owners who do not have access to a light delivery vehicle or a trailer that can be used for this purpose. While it is theoretically possible for a tractor contractor to obtain a bulk tank, this has proven to be extremely difficult to arrange in practice.

\subsubsection{Entrepreneurial activities}

Very limited information is available on the energy requirements of small businesses and industries in rural areas. Indications are that a significant percentage of rural people are involved in informal income-generating activities. May et al (1993) found that almost a fifth of all respondents in their study in Natal/KwaZulu were involved in entrepreneurial activities: The production of soft goods (knitling, sewing and the preparation of foods) was by far the most commonly reported business activity overall' (22). Street hawking and 'other retail activities' were also common. Smaller percentages of households were involved in the running of spaza shops or shebeens, ad in the production of 'hard goods' (21). The majority of these people earned less wian $R 200$ per month from their businesses.

In Mabibi (Northern KwaZulu) James (1993: 20) observed that it was 'not uncommon to find that households are involved in several different income generating activities'. These included building, selling prepared food, and running shebeens, churches and tuck shops from the homesteads. Other activities requiring energy which have been observed in rural areas include the baking of bread. beer-brewing, brick-making and pottery making. Very little is known about the energy requirements of these activities. May et al (1992: 25) observe that the brewing of traditional beer increased fuelwood consumption considerably. The energy services required by rural entrepreneurs clearly need more attention. As in the case of agricultural activities, there is a need to be responsive to the individual needs of small entrepreneurs. The provision of energy advice and planning services to rural entrepreneurs as an integral part of a package of support services, should be investigated.

\subsubsection{Impact of electrification}

It is necessary to consider briefly the impact of electricity on productive activity, as it is often claimed that electricity has a profound effect on economic development. Foley (1990: 89) discusses this matter in depth and draws some important conclusions. In the first place, he finds that electricity at times seemed to trigger new economic activity:

it appears as if rural electrification is particularly effective in stimulating activity in the services sector, an extremely important area of the economy as far as off-farm job creation is concerned.... [T] he arrival of an electricity 
supply in certain areas seems to be a crucial factor in precipitating decisions by local entrepreneurs to invest in a variety of productive enterprises or improvements to existing businesses (91).

However, there were also many examples where rural electrification had very little impact on development. This leads him to conclude that the supply of electricity in itself was not sufficient to cause development. Rather, the impact of electricity seemed to depend on the existing level of development in an area (93).

Thus, rather than rural electrification bringing about increased wealth, economic dynamism, and increased literacy, it is arguably the presence of these which permits rural electrification programmes to be successfully implemented.... The confusion between cause and effect arises because after an electricity supply is brought to areas which have reached such a stage of what might be called 'electrification readiness', the form of their subsequent development is profoundly influenced. (94)

Foley concludes that 'the availability of an electricity supply can therefore be seen as a necessary but not sufficient condition for development beyond a certain point'.

\subsection{Energy to improve the quality of life}

In addition to the above, energy services can contribute to improvements in the quality of life of rural people in numerous ways. For example, outside lighting could lead to a greater feeling of safety/security; radios and television sets could provide more entertainment and communication options; lighting provided in community centres could increase the opportunities for social and other community activities; and, finally, people's morale and attitude to life can be greatly affected by the advent of electricity, as discussed by Foley (1990: 158). These may be of great importance to the people in need of such services, and should therefore be given due consideration in energy planning.

\subsection{Conclusions}

From the above discussion it is clear that there are important links between energy services and the ability of households to meet their basic needs. Fuel shortages can impact on basic needs satisfaction directly if cooking times have to be reduced for lack of fuel, as well as indirectly by reducing the time available to women for performing the range of tasks, including food preparation, cleaning, income generation, that are necessary to meet the basic needs of their families.

The combined effect of fuel and water collection on the time available to rural women for performing other essential tasks, needs particular consideration. Energy is an important component of improved water supply, as pumping is generally required for the reticulation of water to convenient collection points. The energyrelated constraints on improved water supply (such as pump maintenance problems) therefore require greater attention.

Facilities in the rural areas like clinics, schools, community halls and venues for agricultural extension, could benefit greatly. from the provision of electricity. However, the impact of electricity on the services provided will depend largely on the proper functioning and utilisation of these facilities.

The main constraints to agricultural and business development in the rural areas are probably of a structural nature rather than being energy-related. However, the latter also needs to be addressed. There is a need for flexibility and responsiveness in the provision of energy services to small-scale farmers and small businesses, which may require energy advice and support to be made available to them. 


\section{Domestic energy use by rural people}

\subsection{Introduction}

In Chapter 4 the energy needs in the rural areas of South Africa that relate to rural development were discussed in fairly general terms. In this chapter specific attention will be given to domestic energy use by rural people, as this has been the main focus of the EPRET project.

As discussed in Chapter 2, the two main groups of rural people considered in this project havebeen farm workers and their families who live on commercial farm land and people who live in the former homelands and 'reserves'. Domestic energy use by farmworkers has been covered comprehensively in a parallel paper by Hofmeyr (1994). Unfortunately an equivalent paper on rural people in the homeland areas and 'reserves' has not been completed. An attempt is made in this chapter to fill this gap to some extent, by presenting some detailed information on energy use by this group. However, because of the scope of this paper and the limited resources available to the author, a comprehensive analysis of energy use by rural people in the homeland areas and 'reserves' cannot be presented here.

\subsection{Problems with current information}

A major concern when attempting to construct a national picture of energy use by rural people, is the limitations regarding the information that is available on the matter. ${ }^{17}$ There are a number of facets to this problem. Firstly, efforts at data collection have been limited. An estimated total number of 5500 households (approximately) in the former homelands and 'reserves' have been surveyed in the past, while an additional 2500 households (approximately) have been surveyed during 1993 as part of the Biomass Initiative. ${ }^{18}$

The quality and reliability of the available information vary considerably. For example, methodologies have in some cases been inappropriate, sampling techniques questionable, sample sizes inadequate, or measuring techniques (for measuring consumption, for example) not suitable. Inadequacies exist in some studies which reduce the potential value of the collected data. For example, important information has in some cases not been collected (such as incomedata); information on the methodologies used is not always provided; the data is in some cases interpreted incorrectly; or the available data is not analysed adequately (for example, disparities exist between aspects covered in the questionnaires and the re ported data). Finally, the biases evident in some studies (such as their being assessments for electrification purposes) have distracted from their potential value. Meaningful comparison and collation of information is often difficult because of differences in aspects covered by studies, the methodologies and conventions used and the ways in which information is presented. There is clearly a need for a consistent survey methodology and questionnaire and report format to be developed for energy surveys.

The available studies do not cover South African rural areas in a statistically representative manner. Studies in the homeland areas have included settlements which were located in different homelands (such as Eberhard 1986), scattered within a homeland or grouped in a particular district (such as Griffin et al 1992). A recent study in Natal/KwaZulu (May et al 1993) constitutes the first attempt to provide a picture of energy use in a whole region. However, as a result, the information has limited value at a sub-regional level. The survey conducted as part
17. Personal communication with Sarah Ward, Energ Development Research Centre, University of Cape

18. The Biomass Initiative is an inter-departmental govemment programme in which the Departments of Mineral and Energy Atfairs, Water Atfairs and Forestry, and Agriculture are involved, among others. 
of the Biomass Initiative is expected to address this matter to some extent. By contrast, studies of energy use by farmworkers have mainly been conducted at a national level. In some cases particular regions have been covered, but generally very little information is available on regional and particularly sub-regional differences (Hofmeyr 1994). It has therefore been very difficult to collate data on farmworkers and other households in a meaningtul way.

Finally, there is a dire lack of qualitative information on rural energy use at a household level - information which is required to develop an understanding of energy use by rural people (see 5.3). Only two in-depth studies on enengy use in rural areas have been conducted, both in northern Kwazulu, by May et al (1992) and by James (1993). Unfortunately the former does not achieve the depth of analysis that is found in the study by James as well as the in-depth studies which have been conducted in informal urban settlements by Annecke (1993), Ross (1993) and Van Gass (1993).

These limitations should be kept in mind in the discussion that follows.

\subsection{Understanding rural energy use}

As discussed in earlier chapters, energy use by rural people needs to be considered within the broad framework of rural poverty, neglect and underdevelopment, as these conditions have to a large extent determined current patterns of energy use. Nevertheless, there are a large number of factors operating within this broader context that affect energy use more directly, and some of these will be discussed in this chapter. In order to set out the approach followed, these factors are listed briefly:

- Factors of a general socio-economic and socio-political nature

These include the poverty which afflicts the majority of rural people, the particular circumstances of farmworkers which is characterised by dependency on farmers, and gender relations in society.

- Factors which impact on people living in a particular geographical area, region or district

Examples of these factors are the economy of the area which impacts on the financial situation of farmers and the job opportunities of rural people, attitudes and traditions which are prevalent in the area, bioclimatic factors (for example, vegetation type and ambient temperature), and the proximity of coal fields.

- Factors of a local nature which impact generally on households in a particular settlement

These include the proximity of the settlement to centres of economic activity, its location in relation to major transport routes, the nature of the settlement (such as settlements pattems, population density), and local preferences, attitudes and traditions.

- Factors concerning the position of households within settlements

Examples of these factors are the location of a household in a particular settlement, its social status, its access to power and resources, and the gender of the household head.

- Factors that operate within households

These include the nature of the household's income and other resources, demands on its resources, household structure, decision-making processes, processes of allocating time and cash resources, linkages between food and fuel use, needs and priorities, options available, and gender relations. 
Analyses of energy use by rural people in South Africa have tended to focus on only some of these factors, mainly in the first three categories. The emphasis has been on relating general trends in energy use, particularly trends in measurable aspects such as consumption rates, to some of the more visible and/or measurable factors that impact on energy use patterns, such as fuelwood shortages and household income. Generally the smallest unit of analysis employed has been the settlement, with little attention given to factors that operate at a household level. Clearly this level of analysis is necessary. However, it has severe limitations, as it neglects important aspects of energy use and does not foster a real understanding of these matters. Its limitations are particularly evident when strategies and policies have to be formulated to address energy problems and/or manage energy use.

A different approach will be followed in this chapter, which attempts to place at the centre the people who need energy and are continually making energy-related decisions to meet these needs. Their decisions are influenced and determined by the complex interaction of the factors listed above. However, it is recognised that their needs and actions constitute the core of observed energy use practices and patterns. The emphasis is therefore on gaining an understanding of the decisions that people make under particular circumstances, the ways in which they use fuels to meet their needs and how energy use is affected by other aspects of their lives. This approach is motizated by the conviction that a proper understanding of these matters is an absolute necessity if strategies to improve energy service provision are to make a significant impact on the lives of nural people. Unfortunately the extent to which this approach can be followed is limited by the lack of qualitative information that is currently available on rural energy use in South Africa.

\subsection{Convergence in energy planning for all rural people}

In the EPRET project the two main groups of rural people have been dealt with separately because of the significant differences in their general circumstances which have important implications for energy policy (see 2.4). However, the structure of this chapter does not reflect the same degree of differentiation between the two groups. Rather, an attempt has been made to integrate the material presented, as it is necessary to start developing an integrated approach to energy planning which encompasses all rural people. There are a number of reasons why an integrated approach is required:

- There are important similarities in energy use by the two groups generally, which relate, among other things, to the extreme poverty that afflicts most rural people. An example of this is the widespread dependency on fuelwood.

- There are factors of a geographical nature which impact on the energy use of both groups in particular areas, although not necessarily to the same extent. Examples of these are the availability of coal, vegetation type, and ambient temperatures.

- The proximity of commercial farmland and homeland areas presents possibilities for improvements in energy service provision in some areas, by, for example, moving fuelwood from areas of surplus to areas of deficit.

- There are many people who do not fall within either of the above categories, but who need to be provided for in energy planning. Examples of such groups are labour tenants on privately owned land, including commercial farmland and black' freehold land.

- As discussed in Chapter 3, the current distinction between commercial farm land and the homeland areas and 'reserves' is likely to diminish in future, particularly if land reform is implemented on a large scale. One of the results of 
such a programme would be to increase the population densities in some areas of what is presently called commercial farm land. The implications for energy service provision in such areas can be considerable: for example, the availability of wood resources and the possibility of utilising existing infrastructure for electricity provision.

\subsection{Domestic energy services}

Fuels and energy sources are not used for their own sake, but to provide certain energy services. This discussion is therefore structured primarily around the different domestic energy services that are commonly acquired by rural people. People often have specific requirements with regard to the services they want and, as a result, prefer to use particular fuels for certain purposes and utilise these in very particular ways. An attempt will be made here to highlight some of these complexities. Generally the aim is to explore the way in which people use fuels to provide their energy needs, as well as the constraints which determine the way in which they use it.

Cooking, heating and lighting can be regarded as the most basic energy services which are obtained by even the poorest people.

Among the poorest families in most developing countries, cooking (and heating) accounts for $90-100 \%$ of fuel consumption, the remainder being for lighting. (Leach \& Gowen 1987: 58)

Most attention will, therefore, be given to these services.

\subsubsection{Cooking}

Cooking is a complex activity which forms an integral and important part of the cultural existence of human beings. This is beautifully illustrated in books such as that of Coetzee (1982) which is subtitled 'Roots of traditional African food culture'. From a practical viewpoint cooking can be seen as a 'system' which comprises at least the following elements (Leach \& Gowen 1987: 66):

- the kind of foods prepared (for example, mealiemeal porridge);

- methods of food preparation (for example, grinding);

- cooking methods (for example, boiling, frying);

- cooking utensils/equipment (for example, three-legged pots);

- fuels and appliances (for example, paraffin and a primus stove);

- the location and structure of the cooking site (for example, a hearth at the centre of a room);

- ways in which the fire or appliance is utilised and managed (for example, tending the fire);

- ways in which the cooking devices are used (for example, the use of lids).

No attempt will be made here to deal with all these elements in any depth, as variations in cooking practices in the rural areas of South Africa are likely to be considerable. Suffice to say that attempts to provide in people's energy needs for cooking purposes need to take these matters into consideration.

In the rural areas cooking is mainly done on open woodfires, which may be located indoors at the centre of 'the cooking hut' or outside. Outside fires are commonly shielded or made in special cooking shelters. Terblanche (1993: 23) found that a variety of such shelters, with different ventilation characteristics etc, were used by farmworkers. In addition to wood, fuels such as dried dung, crop residues, coal, paraffin and gas are used for cooking purposes, but generally to a much smaller degree. Farmworkers in particular are reliant on fuelwood (Hofmeyr 1994). 
often highly specific preferences. They list as reasons for particular choices of fuels and cooking appliances: 'ease of handling and lighting, flame quality and temperature, ability to secure fire from young children, smokiness and the taste imparted to food, as well as relative prices and availability of fuels' (65). In a town in Sierra Leone they found that people preferred to use woodfuels for reasons of 'food tastes, safety, and the wider range of cooking methods that are possible with an open fire' (65). Strong preferences for cooking with fuelwood were expressed by respondents in Mabibi:

Attitudes towards wood as a good fuel are consistently grounded in the fact that it is cheap and therefore can be used every day and that it is the habit of people of the area to use wood as their mothers and fathers did.

The number of people in the household and the utensils used also influences women's positive attitudes towards cooking on an open fire.

Doubt was expressed as to whether [they] would stop using wood and replace it with other fuels such as gas and paraffin. (James 1993: 43)

Eberhard (1986: 57) also found that wood was the preferred fuel for cooking in the four villages surveyed in the Transkei and Ciskei. Coal came a close second in two of these villages. In the five villages surveyed by Griffin et al (1992: 85) wood was the second choice after electricity as preferred fuel for cooking, but trailed behind considerably in most cases (for example, rating $19 \%$ compared to $66 \%$ ).

It is of interest that only a small percentage of people prefer paraffin as a cooking fuel, although it is commonly used (Eberhard 1986: 57; Griffin et al 1992: 13). In Mabibi gas was more commonly used than paraffin which reflected the expressed preferences of people; it 'is chosen above paraffin as a cooking fuel because it is quicker and easier to use and does nor release fumes, as paraffin does' Uames 1993: 45).

Fuel preferences are often related to particular cooking tasks, reflecting the specific requirements for the preparation of different foods:

Many surveys have found that woodfuels are used primarily for cooking staples which may take on an oily taste on a kerosene stove; while kerosene is strongly preferred for quick snacks or boiling small amounts of water for hot drinks. (Leach \& Gowen 1987:65)

James observed the following relation between food and fuel in Mabibi:

Another central factor influencing the preference for wood for cooking is that it suits the type of food which is prepared. All respondents claimed that it was especially good for samp and beans, which forms a large component of every household's diet, as they command a long cooking time. The cost of cooking these types of food on gas or paraffin are prohibitive for all households in the sample. (1993: 43)

May et al (1992: 17) found that fuels other than wood were used to prepare specific foods, such as fried food, in Ingwavuma.

A particular requirement under certain circumstances is the reduction of the time required to complete cooking (and heating) tasks. James (1993) found that 'alternative fuels are used to aid households when time demands that tasks, at certain times of the day, are performed quickly' (45):

It is at this time (early in the morning) that those households with alternative fuels used them so as to ensure that their children were not late for school. (89)

May et al (1992: 19) observed similar behaviour in Ingwavuma:

Households with school-going children have to rise earlier, and need to 
speed up the preparation of breakfast and hot water. As a result, they are more likely to use paraffin or gas.

Griffin et al (1992: 16) also found that one of the most important advantages of both paraffin and gas was the speed of cooking (and heating) that these fuels provided. It is likely that the total time required for these activities rather than the cooking time only is of importance, as the preparation and lighting of a fire can add considerably to a task of relatively short duration.

In addition to cooking for domestic purposes, there are a number of informal income-generating activities employed by rural people that are related to cooking. These include the preparation of food, baking bread and brewing beer for sale (see 4.3.2). It may be very difficult to separate the consumption of fuel for these purposes from domestic consumption. One of the reasons for the significantly higher consumption of fuelwood in the foothills of Ingwavuma compared to the plains (May et al 1992: 24) may be the use of fuelwood on a fairly regular basis for baking and brewing, particularly for home consumption but also in order to sell these products.

\subsubsection{Water-heating}

In his survey covering six areas, Eberhard (1986: 63) found that water was commonly heated for purposes such as making tea and for bathing and washing dishes. Hot water was generally not used to do thelaundry. Water was mostly heated early in the moming as well as in the evening:

Water is heated primarily for bathing and washing dishes in the morning, often with the same water. Hands and faces may be washed again in the evening with the dishes and pots. (Eberhard 1986: 63)

The average quantity of water heated per day for washing varied between 10 and 49 litres, which is clearly insufficient to ensure adequate personal and household hygiene (see 4.2.2). May et al (1992: 15) found that hot water was only used for personal washing in the moming. None of the respondents in the foothills area of Ingwavuma heated water for washing clothes. In the plains area, however, people sometimes heated water to do the laundry:

Water for washing is boiled in a kettle over an open fire. Because up to 251 may be used for one wash, this is a time consuming and laborious task which consumes a great deal of fuel. (15)

On the other hand, James (1992: 66) observed that none of the respondents in Mabibi used hot water for personal washing. In this area water was only heated to make tea, while the hot water that remained was sometimes used to wash dishes.

Eberhard (1986: 63) found that both wood fires and paraffin stoves were used extensively for heating water. The fire made for cooking purposes was 'invariably also used for heating water' (ibid). Paraffin stoves were more commonly used for heating tea water than heating water for washing. According to May et al (1992: 15) two thirds of the respondents in Ingwavuma used paraffin and gas stoves to boil water in the mornings to reduce the time required for this purpose. Eberhard (1986: 57) also found that more households preferred the use of gas and paraffin for heating purposes than for cooking. The reason for this seemed to be that heating can be done more rapidly with the hydrocarbon fuels. This tendency is similar to that which has been observed for cooking (see 5.5.1).

\subsection{3 lighting}

Leach and Gowen (1987: 73) suggest that lighting is of considerable importance to poor rural people:

low and middle income families view improved lighting as a high priority in the achievement of better living standards.... As a result, energy consump- 
tion for lighting normally increases quite rapidly with income above a certain threshold level.

Eberhard (1986: 67) observed that most families in the six areas he studied used lighting from sundown to approximately $21: 00$ or 21:30. However, some families lighted their houses for the entire night because they are afraid of evil spirits or tsotsis'. May et al (1992: 17) found that families generally retired between 19:30 and 21:30.

The main reported purpose of lighting is to enable children to study in the evenings (May et al 1992: 18; James 1993: 100). Other reading activities appear to be limited. People also commonly listen to radios in the evenings (James 1993: 100; May et al 1992: 18), in which cases lighting is required. No reference was found to incomegenerating activities which required lighting in the evenings. The open fire provides lighting for entertainment and social purposes, for example, for parties (May et al 1992: 18) and for 'sitting and chatting' around the fire (Eberhard 1986: 63).

Candles and paraffin are the fuels most commonly used for lighting purposes (Eberhard 1986: 67; Griffin et al 1992: 13). In addition, lighting is provided by the open fire, torches, gas and electricity (May et al 1993: 73). In different areas strong preferences for the use of candles, paraffin and electricity for lighting purposes have been expressed (Eberhard 1986: 58; Griffin et al 1991: 87). It is of interest that gas generally rates low as a preferred lighting fuel. An exception to this is the observation by May et al (1992: 21) that by far the most popular form of lighting in this region [plains area in the Ingwavuma district] is the gas mantle lamp, as the light it gives off is far brighter than either a candle or a paraffin lamp'. However, only one of the households included in the study owned a gas lamp. Even in Namaqualand (Borchers et al 1991: 43), where gas is used extensively for cooking and water-heating, and in the areas of KwaZulu where gas use is not uncommon Uames 1993: 45; May et al 1993: 68), its use as lighting fuel is limited. This corresponds to international experience as reported by Leach and Gowen (1987: 75). Finally, a significant pencentage of farmworker households (18\%) use grid electricity for lighting (Hofmeyr 1994).

Lighting is often the only energy service which involves cash expenditure by (very) poor households (Leach \& Gowen 1987: 73) who use collected fuelwood to meet their other basic energy needs. James (1993: 50) found that the households in Mabibi who were unable to afford any appliances or the fuels required to use them, still spent a small amount of money every month on candles, which were the only energy sources purchased by them. One family with a total income of R20 from informal activities, spent the equivalent of one packet (R1.95) on candles during the month of monitoring. According to James (1993:50) these households bought fuels only when they felt they could afford to do so, which meant that they sometimes bought one candle at a time.

The candles bought by these families were primarily used for purposes such as reading the bible and studying by the children, while light for other activities was derived from the open fire. Very poor families are therefore severely restricted with regard to access to adequate lighting services.

\subsubsection{Space-heoting}

As discussed by Thome (1994) energy requirements for space-heating are influenced by climatic factors as well as housing design. Space-heating requirements can vary considerably as a result of differences in climate; for example it accounted for $4 \%$ of biomass energy consumption in the coastal region of Kenya, compared to $20 \%$ in the cooler Rift Valley (Leach \& Gowen 1987: 58). In addition, it has been found that energy consumption in winter can in some cases be as much as double that in summer, for example, Tanzania and Lesotho (Leach \& Gowen 1987: 83). 
Open woodfires are generally used to heat the homes of rural people, and are also preferred for this purpose (Eberhard 1986: 64) (May et al 1992: 20). Woodfires often serve a number of purposes at the same time, such as cooking, water-heating and space heating. However, it is of interest that a greater percentage of respondents in Eberhard's (1986: 61) study reported using the open fire for space-heating than for cooking and water-heating, which indicates that it was used exclusively for spaceheating in some cases.

\subsubsection{Other services}

Other domestic services commonly required by rural people include ironing and the use of radios, and to a lesser extent radio/cassette recorders (Eberhard 1986; Griffin et al 1992; May et al 1993). Ironing is usually done by heating a metal iron on a fire or stove, and a variety of fuels are used for this purpose, including wood, coal, paraffin and gas. Radios and similar items are usually operated from dry-cell batteries.

Households may also acquire hi-fi's, television sets and fridges. The first two are usually operated from lead-acid batteries, and less often from petrol generators. Only a small percentage of households are able to afford lead-acid batteries, and very few can afford generators. Fridges are usually paraffin-or gas-operated.

\subsection{Quantitative end-use analysis}

The integrated energy planning (IEP) methodology that was used in the EPRET project reflects an end-use approach to some extent, as energy consumption data need to be disaggregated in terms of end-use, such as lighting, cooking and space-heating. However, the use of this methodology for planning purposes is constrained by the lack of information available on the fuel use related to various services - for example, the quantities of paraffin used for lighting and cooking purposes respectively. Longitudinal data on energy consumption for different purposes, which reflects changes over time, is also non-existent. Generally energy studies in South Africa have dealt inadequately with these matters.

The measurement of energy consumption for particular end-uses is complicated by the fact that different energy services can be derived from the same energy source or fuel. For example, fuelwood used in an open fire or stove can fulfil the functions of cooking, water-heating, space-heating and even lighting, while paraffin can be used in a primus for cooking, water-heating and ironing and in a lamp for lighting. Electricity is the most varied source of energy, with a wide range of appliances which can provide different services, but in this case it is possible to measure consumption by particular appliances by technical means. The case of fuels such as wood and coal is particularly complex, as these provide various services at the same time (such as cooking and space-heating), making it virtually impossible to assess the energy requirements for different services. Nevertheless, a general pattern for the use of biomass fuels in rural East Africa has been suggested (Leach \& Gowen 1987: 58) in which cooking accounts for 55\% of fuel use, waterheating for $20 \%$, space-heating $15 \%$, and ironing and other minor uses for $10 \%$. This breakdown cannot, however, be applied universally, as substantial differences exist between countries as well as regions and localities.

\subsection{Fuel use and energy consumption}

In this section an overview is given of the domestic fuel use and energy consumption of farmworker families as well as rural people in the former homelands and 'reserves'. The data on the homeland areas and 'reserves' is presented in a very specific manner, partly because of the short-comings of the available data as 
discussed in 5.2, as well as the limited time and resources available to the author for this purpose. 19

A small number of 'study areas' were identified, each of which include a number of settlements which had been surveyed as part of a single study deemed to be of acceptable quality. One of the study areas falls within the 'coloured reserves' (Borchers et al 1991), while the other four are located in different parts of the former homelands (see below). As the study areas were selected on the basis of existing studies, they have not been defined in a uniform manner. For example, the study by Griffin et al (1992) was conducted in one magisterial district of Gazankulu, while that by Eberhard (1986) included a settlement in the Ciskei as well as three settlements in different parts of the Transkei. ${ }^{20}$ The study by May et al (1993), on the other hand, aimed to be representative of the whole of KwaZulu.

This approach was regarded as more meaningful than the alternative of obtaining average figures for each region or homeland/reserve by extrapolating from the available data. Significant assumptions would have been required to do the latter, which would have increased the uncertainty attached to the data considerably.

\subsubsection{Study areas in the former homelands/'reserves'}

The study areas are briefly described here in terms of settlement patterns, vegetation type, climate, income profiles etc. It should be noted that considerable variation was found within study areas, which cannot be adequately reflected here. More over, it would have been impossible to interpret energy use patterns in a meaningful way.

\section{Westem and centrol Bophuthatsuana (Eberhard \& Dickson 1991)}

Eight rural settlements were included in the survey. The natural vegetation in the area covered is classified as Kalahari thornveld and shrub bushveld, with the former being more dominant in the west and the latter in the east. Annual rainfall varies from $200 \mathrm{~mm}$ in the west to $500 \mathrm{~mm}$ in the east. Population densities in the settlements varied between five people per square kilometre in Ganyesa (west) to 34 people per square kilometre in Ditsobotla (east). The average household income was R223 (1990) ${ }^{21}$ per month, ranging from R148 in Dinokana to R361 in Loopeng. This was the poorest of all the study areas considered.

\section{The Mhale district of Gazankulu (Griffin et al 1992)}

Five rural settlements were included in the survey, together with a refugee settlement in the area. The study area is located in the lowveld and the natural vegetation is classified as bushveld. Annual rain fall in the different settlements varies between 560 and $850 \mathrm{~mm}$, with higher rainfall in the southern and western parts. The settlements range from smaller isolated ones (Athol, Welverdiend) to larger, more closely settled ones adjacent to major transport routes (Okkerneutboon, Rolle). Household incomes are generally higher than those in Bophuthatswana, ranging

19. The author was assisted in this by Sarah Ward as well as Yaw Atrane-Okese, both of EDRC.

20. The settlements in the Transvaal that were surveyed by Eberhard (1986) were not included in the 'study area' defined for the purposes of this paper.

21. All the income figures presented here have been converted to 1990 Rands for comparative purposes. from R623 (1990) per month in the case of Rolle to R218 per month in the refugee settlement, with an average of $\mathrm{R} 438$ per month for the six settlements.

\section{Trunskei and southern Ciskei (Eberhard 1986)}

Three areas in the Transkei and one in the Ciskei were included in the survey. Lujiko in the Ciskei and Nkanga in Pondoland (Transkei) are located within coastal areas where thomveld, valley bushveld and coastal forests are found. Manzimahle and Clarkebury in the Transkei are located inland in grassveld areas. Average annual rainfall varies from $1000-1200 \mathrm{~mm}$ in Lujiko to $600-700 \mathrm{~mm}$ in Clarkebury. Settlement types range from the large sprawling village of Manzimahle, a betterment" village at Nkanga, to small village clusters in Clarkebury. No income figures were provided in the report. 
KuaZulu (May et al 1993)

Eight magisterial districts of KwaZulu were included in the study, which covered a variety of bioclimatic zones. Settlement densities varied considerably from 60 to 211.5 people per square kilometre. Settlement types include relatively dispersed traditional settlements, dense 'betterment' villages and dense settlements along major transport routes. The mean household income was found to be R607 (1990) per month, varying between R326 in Nkandla and R990 in Ezingolweni.

\section{'Coloured reserves' (Borchers et al 1991)}

Six of the Namaqualand 'reserves' were included in the study. The region is very dry, with rainfall ranging between $70 \mathrm{~mm}$ and $250 \mathrm{~mm}$. The vegetation type is mostly desert, succulent karoo and karoo. The population mainly live in small towns and villages, which can be located at great distances from one another, or grouped close together. Settlement densities vary considerably. The mean household income was R733 (1990) per month, ranging from R456 in Leliefontein to R1 140 in Komaggas. This was therefore the study area with the highest income of those considered here.

\subsubsection{General trends in fuel use and consumption}

Information on fuel use and energy consumption by rural people is summarised in this section. Figure 5.1 shows the percentage of rural households in the different study areas that use particular fuels. This provides a general picture of fuel use in the homeland areas and 'reserves', although it does not represent all areas. It is evident that the most widely used fuels and energy forms among rural people in the homeland areas and 'reserves' are fuelwood, candles and paraffin, and to a lesser extent dry-cell batteries. The use of fuels like dung, crop residues and liquefied petroleum gas (LPG) is significant in particular study areas. Although not reflected here, coal is widely used in particular areas, such as some districts of KwaZulu (May et al 1993: 49). Generally the use of petrol/diesel generators, lead-acid batteries and grid electricity by rural people in the homeland areas is very limited.

The total mean monthly net energy consumption by all households surveyed in the different study areas is presented in Figure 5.2. From this it is evident that fuelwood is by far the greatest contributor to household energy consumption in the homeland areas and the 'reserves'. However, there is considerable variation in the contribution by fuelwood in different study areas, with Gazankulu households consuming an average of $5500 \mathrm{M}$ ) of fuelwood per month, while households in Namaqualand and Bophuthatswana consumed 3060 and $3300 \mathrm{MJ}$ per month respectively. The low wood consumption in these areas is to some extent compensated for by the increased use of gas (as in Namaqualand) or dung (as in Bophuthatswana and the Transkei). The energy contributions of paraffin and candles are similar in all the study areas.

The use of fuels by farmworkers as reported by Hofmeyr (1994) is summarised in Tables 5.1 and 5.2. Paraffin use seems to be significantly less common than in the homeland areas, particularly for cooking and heating purposes. Another significant difference is the relatively high percentage of farmworker households that have access to grid electricity. 


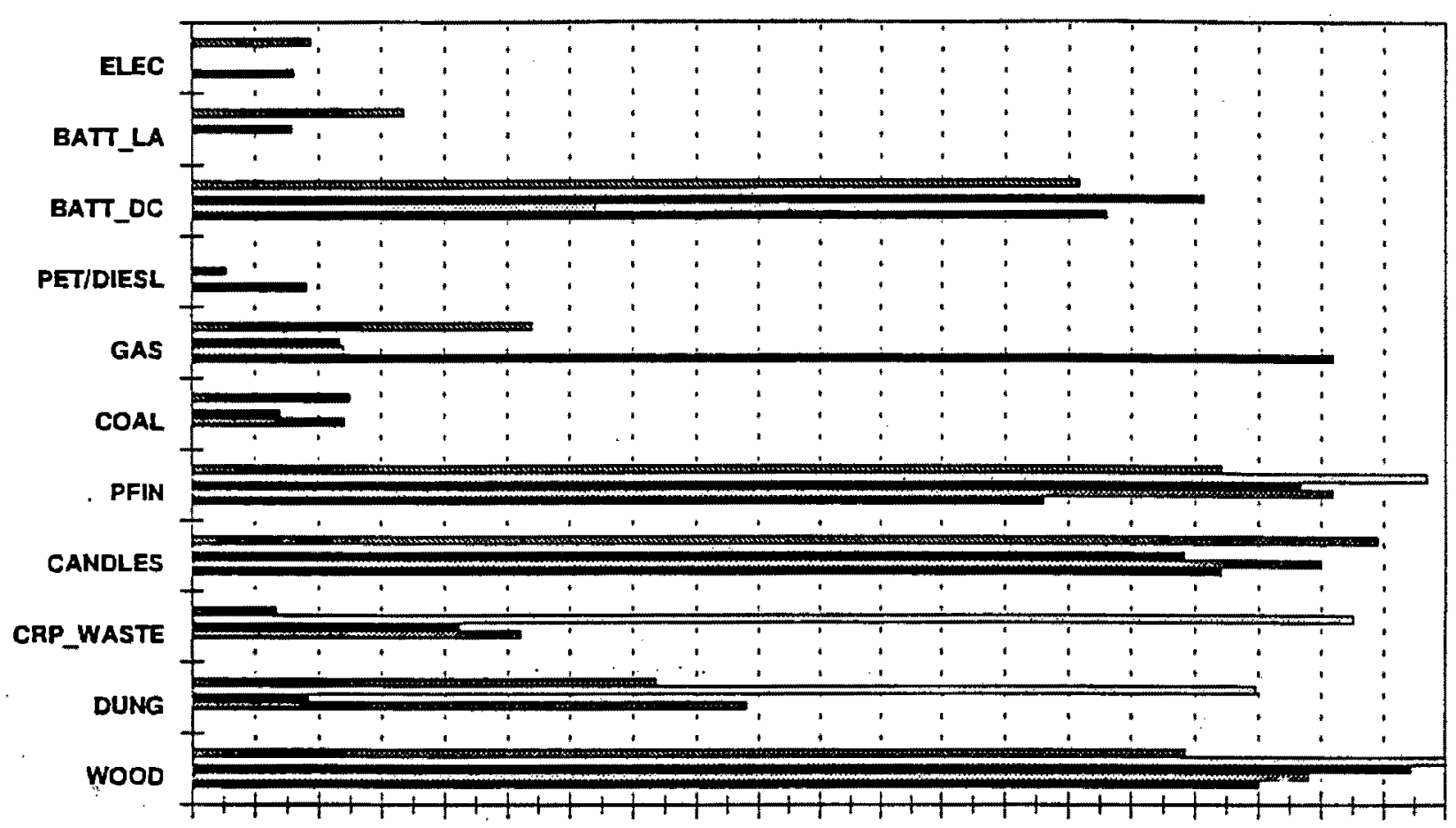

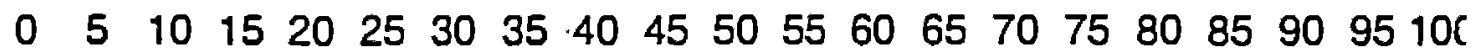

\section{Namaq Bop Gaz Trans Kwaz}

FIGURE 5.1 Percentage of households using different fuels in five study areas in the former homelands Source: Epret database

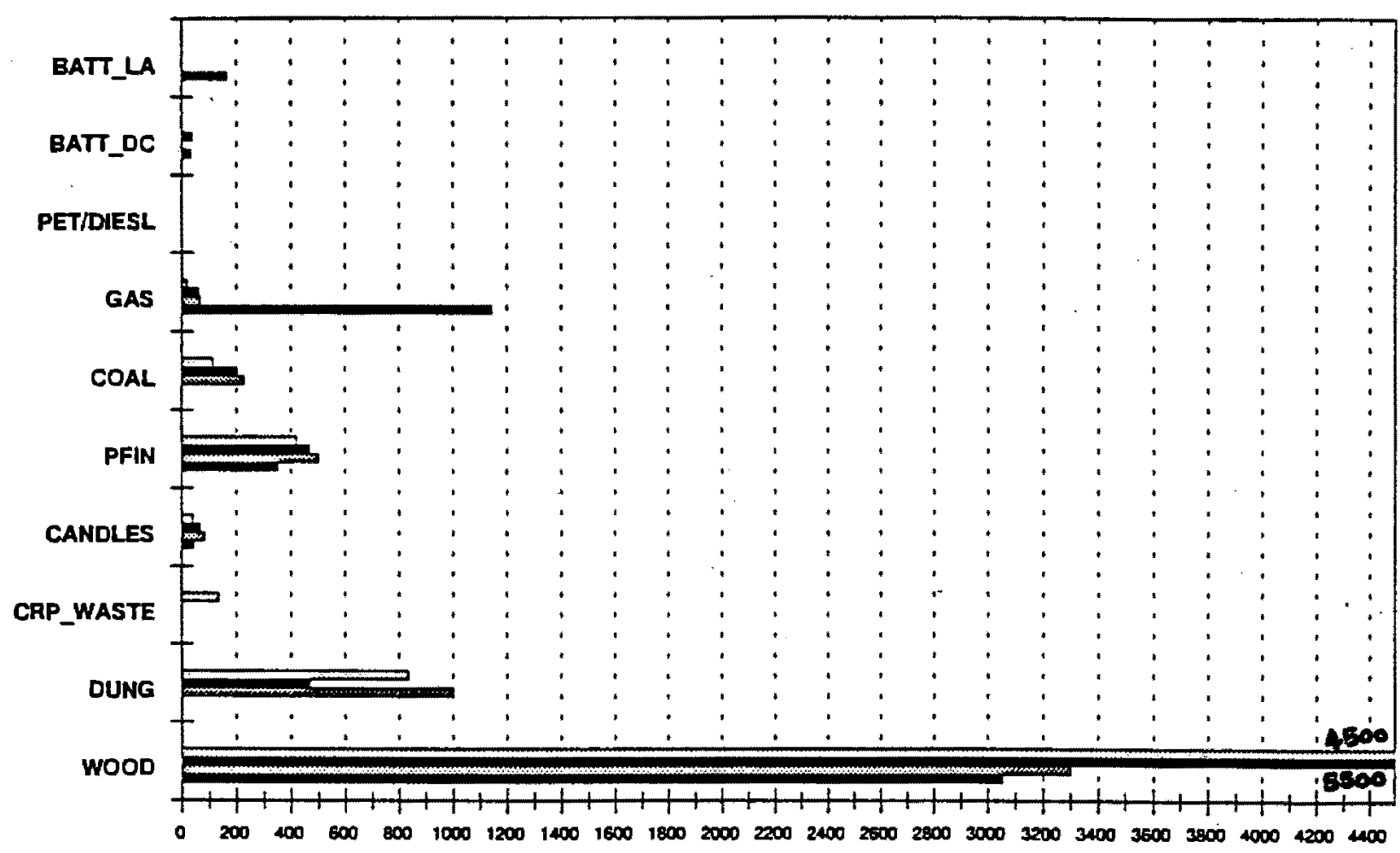

\section{Namaq Bop Gaz $\quad$ Trans $\mathrm{Kwaz}$}

FIGURE 5.2 Mean monthly household income in five study areas in the former homelands Source: Epret database 


\begin{tabular}{|c|l|r|r|r|r|r|c|}
\hline \multicolumn{1}{|c|}{ Surveys } & \multicolumn{6}{c|}{ Percentage of households using fuels } \\
\hline $\begin{array}{c}\text { Sample } \\
\text { size }\end{array}$ & \multicolumn{1}{|c|}{ Ruelwood } & $\begin{array}{c}\text { Agric. } \\
\text { residue }\end{array}$ & Coal & Paraffin & LPG & Electricity \\
\hline 299 & NE-TVI, Natal & 88 & 34 & 17 & 42 & 2 & 2 \\
\hline 382 & National & 97 & 4 & 5 & 19 & 9 & 4 \\
\hline 45 & W-OFS, E/C-Ntl, S-TVI, W-Cape & 88 & 8 & 8 & 25 & - & 6 \\
\hline 530 & W-OFS & 86 & 59 & 8 & 9 & 1 & 0 \\
\hline 200 & E-OFS, S-TVI, N-Cape, Nt1-Cst & 88 & 9 & 8 & 25 & - & 8 \\
\hline 100 & W/N/E-Cape, W/E-NtI, S\&C-TVI & 73 & 0 & 14 & - & - & - \\
\hline 948 & W/E-TVI, Natal & 96 & 4 & 0 & - & - & - \\
\hline Weighted average & 91 & 20 & 6 & 21 & 4 & 3 \\
\hline
\end{tabular}

TABLE 5.1 Percentage of farmworker households using different fuels for cooking and heating Source: Hofmeyr (1994)

\begin{tabular}{|c|l|c|c|c|c|c|}
\hline \multicolumn{2}{|c|}{ Surveys } & \multicolumn{5}{c|}{ Percentage of households using fuels } \\
\hline $\begin{array}{c}\text { Sample } \\
\text { size }\end{array}$ & \multicolumn{1}{|c|}{ Region } & Candles & Paraffin & LPG & Electricity & Fug/wood \\
\hline 299 & NE-TVI, Natal & 90 & 67 & 2 & 10 & 5 \\
\hline 382 & National & 14 & 65 & 3 & 14 & - \\
\hline 45 & W-OFS, E/C-Ntl, S-TVI, W-Cape & 46 & 37 & - & 25 & - \\
\hline 530 & W-OFS & 91 & 68 & - & - & 5 \\
\hline 200 & E-OFS, S-TVI, N-Cape, Nt1-Cst & 56 & 37 & - & 35 & - \\
\hline 100 & W/N/E-Cape, W/E-Ntl, S\&C-TVI & 25 & & & 22 & 6 \\
\hline 948 & W/E-TVI, Natal & 96 & 0 & - & 27 & - \\
\hline Weighted average & 75 & 62 & 3 & 18 & 5 \\
\hline
\end{tabular}

TABLE 5.2 Percentage of farmworker households using different fuels for lighting Source: Hofmeyr (1994)

\subsection{Factors affecting rural energy use}

Some factors that affect the use of energy for particular purposes were discussed in 5.5, including preferences related to cooking practices and the need to reduce the duration of cooking and water-heating activities at times. Here attention will be given to some of the key factors which affect fuel choices and consumption rates.

\subsubsection{Women's time and activities}

In 4.2 some of the demands made on women's time in rural areas and its affect on their ability to meet the basic needs of their families were considered. According to Tyler (1991: 471) it is increasingly being recognised that the availability of women's time is one of the most important factors which determine household decisions on fuel use. The average duration of fuelwood collection trips which have been recorded in the rural areas of South Africa varies between 2.5 and 6.2 hours, and these trips are generally made two or three times per week (van Horen 1994a). Fuelwood collection therefore absorbs a considerable amount of the time available to rural women. Moreover, indications are that the time required to collect fuelwood is increasing because of its increasing scarcity (ibid). Griffin et al (1992: 53) found that the average number of working hours spent on fuelwood collection per month by each household varied between 50 and 85 hours during the study period. In one of the settlements it was as high as 178 hours during winter. 
Cecelski (1985: 24) maintains that women's decisions on fuel use are based on a comparison of the time and expense involved in the use of different fuels, as well as the convenience offered by the different fuels, with consideration of particular preferences. The time in consideration is the total time spent on, for example, the collection and preparation of firewood, lighting the fire, and tending the fire while cooking. In the case of commercial fuels, the time required to purchase these fuels would be considered. However, if another member of the family is available to take on such tasks, it would clearly change the equation.

Interactions within the household determine a 'total systems efficiency' of fuel procurement and use to optimise labour and cost, which is not the same as 'fuel efficiency' as normally considered in energy accounting. (Cecelski 1985: 19)

Decisions based on time considerations are complex. Women may choose to use dung and crop residues in spite of their inferior properties, and the fact that the fire needs constant tending, because of its greater availability than fuelwood (Cecelski 1985: 24). On the other hand, women may sometimes prefer to spend more time or money to obtain higher quality fuels which requires less cooking time and attention.

The need to reduce the time spent on cooking can also outweigh the need to save fuel (Cecelski 1985: 25). For example, women may choose to attend to other work in stead of tending the fire, which could lead to increased fuel use. Fuel consumption is therefore determined by the total time budget of women, which might reflect bottlenecks at particular times of the day. Some of these effects are evident in the study by James (1993:

Participation by the woman (of one particular household) in the labour market has caused a decrease in time available to perform domestic work. Although her work as a teacher has not relieved her of her domestic duties, the purchase of a primus stove and a gas cooker have ensured that she is able to perform in both arenas more efficiently. (49)

Collection [of wood] from around the homestead is generally made when time is short and the woman cannot afford to make a trip to the forest (56).

In one household:

the stress on the female household head to ensure her household's survival clearly influences the wood consumption rate.... Meals are prepared once a day when her daughter returns from school and then only when there is food available. The log book revealed that there were often days when no food was cooked. (67)

When women are involved in activities which take up time which would otherwise be spent on domestic work their fuel consumption rates are affected.... In [one household] the umakoti (daughter-in-law) goes to night school. On these days she prepares and cooks the evening meal at midday. In the evening the grandmother makes another fire to reheat the already cooked food, thus increasing the amount of wood used. (69)

The time pressures on women in this area are therefore varied, as are the effects on their energy use. However, the fact that fuelwood can be collected relatively easily is an important underlying factor in this area. It is vital that similar studies of women's activities and demands on their time in relation to energy use are conducted in areas of greater fuelwood scarcity.

\subsubsection{Fue/wood availability}

An important reason for the continued and extensive use of fuel wood in rural areas is the fact it is possible to collect wood at no cash expense. This is particularly true in the case of farmworker households (Hofmeyr 1994). Even in the former home- 
lands and 'reserves' where the scarcity of fuelwood around settlements has generally led to its partial commercialisation, the collection of fuelwood is still common. For example, wood is collected by approximately $61 \%$ of all households in the Bophuthatswana study area, ${ }^{22}$ while approximately $82 \%$ of households in the Gazankulu study area collected wood (Griffin et al 1992: 52).

The impact of fuelwood scarcity on energy use among very poor rural households can be clearly observed in the Bophuthatswana study area (see 5.7.1). Not only is the percentage of households who use wood $(89 \%)$ in this area,lower than in Gazankulu (97\%) and the Transkei (100\%), but the fuelwood consumption by households is also considerably lower. This can be attributed to the desperate shortage of fuelwood in this area (Eberhard \& Dickson 1987:22), which has lead to its increased commencialisation, coupled with the extreme poverty in the area. Approximately $28 \%$ of all households in this area relied almost exclusively on bought wood, compared to the approximately $15 \%$ of households in Gazankulu. ${ }^{23}$ Moreover, the mean household income in this area was only R223 (1990) compared to R438 in Gazankulu. These factors have lead to a high consumption of dung in this area relative to the other study areas considered (see 5.7.2).

Fuelwood scarcities can mainly be related to a combination of bioclimatic factors (the vegetation type and climate) and settlement patterns (the number of settlements, their sizes and densities). The combined effect of these factors can be seen very clearly in Bophuthatswana (Eberhard \& Dickson 1987: 23). A greater degree of woodland denudation and resulting fuelwood scarcity was observed in the Ditsobotla region compared to the Ganyesa region which has a lower rainfall and a sparser vegetation type than the former. This can be attributed to the higher population density in Ditsobotla ( 34 people per square kilometre compared to five in Ganyesa).

Eberhard and Dickson (1987: 25) suggest that the process of fuelwood commercialisation has a varying impact on fuelwood consumption. As the distance at which the wood is collected increases, consumption drops at first, until it becomes viable for entrepreneurs to collect and sell wood, after which consumption increases again. However, a further increase in fuelwood scarcity results in price increases which curtail the demand once more.

\subsubsection{Household income and economic stafus}

Household income has an important impact on energy use, as it enables households to exercise a wider range of fuel choices. May et al (1993:62) illustrate the relationship between income and fuel choice by comparing the mean income of households using particular fuels or energy sources with those who do not. For example, they found that the mean household income of wood users was R755.50 (1992) compared to R1 $\mathbf{0 5 6 . 1 8}$ for non-wood users. Similarly, the mean income of users of candles, dung and crop residues, was considerably below that of households not using these fuels. The difference was particularly pronounced in the case of candles.

It is interesting that paraffin users on average earned only slightly less income than non-paraffin users. In fact, paraffin, dry-cell batteries and coal in particular, showed very little difference between users and non-users. On the other hand, gas users were found to have a much higher income than households who do not use gas. Significant differences in the incomes of people using car batteries and generators and those who did not were also found. While the incomes of households with grid electricity was also higher than those without it, this difference was less pronounced than in the case of car batteries and generators.

Estimates of the average percentage of household income spent on fuel in different settlements and areas vary between 5.7\% and 15.4\% (May et al 1993: 49; Eberhard 1986: 56; Griffin et al 1992: 91). In addition, the trends in energy expenditure and energy consumption in relation to increasing income can be considered. Eberhard

22. Calculation based on information reported by Eberhard and Dickson (1987: 23).

23. Calculation based on information presented by Eberhard and Dickson (1987: 26) and Grittin et al (1992: 49) respectively. 
and Dickson (1987: 39) found that the amount spent on energy tended to increase as the income of households increased. This corresponded to a decrease in the percentage of income spent on energy. The two poorest groups of households, which earned less than R50 per month and R50-R100 per month respectively, spent approximately $36 \%$ and $20 \%$ of their income on fuel. A similar situation was found in the Namaqualand 'reserves' (Borchers et al 1991: 49) as shown in Figure 5.3.

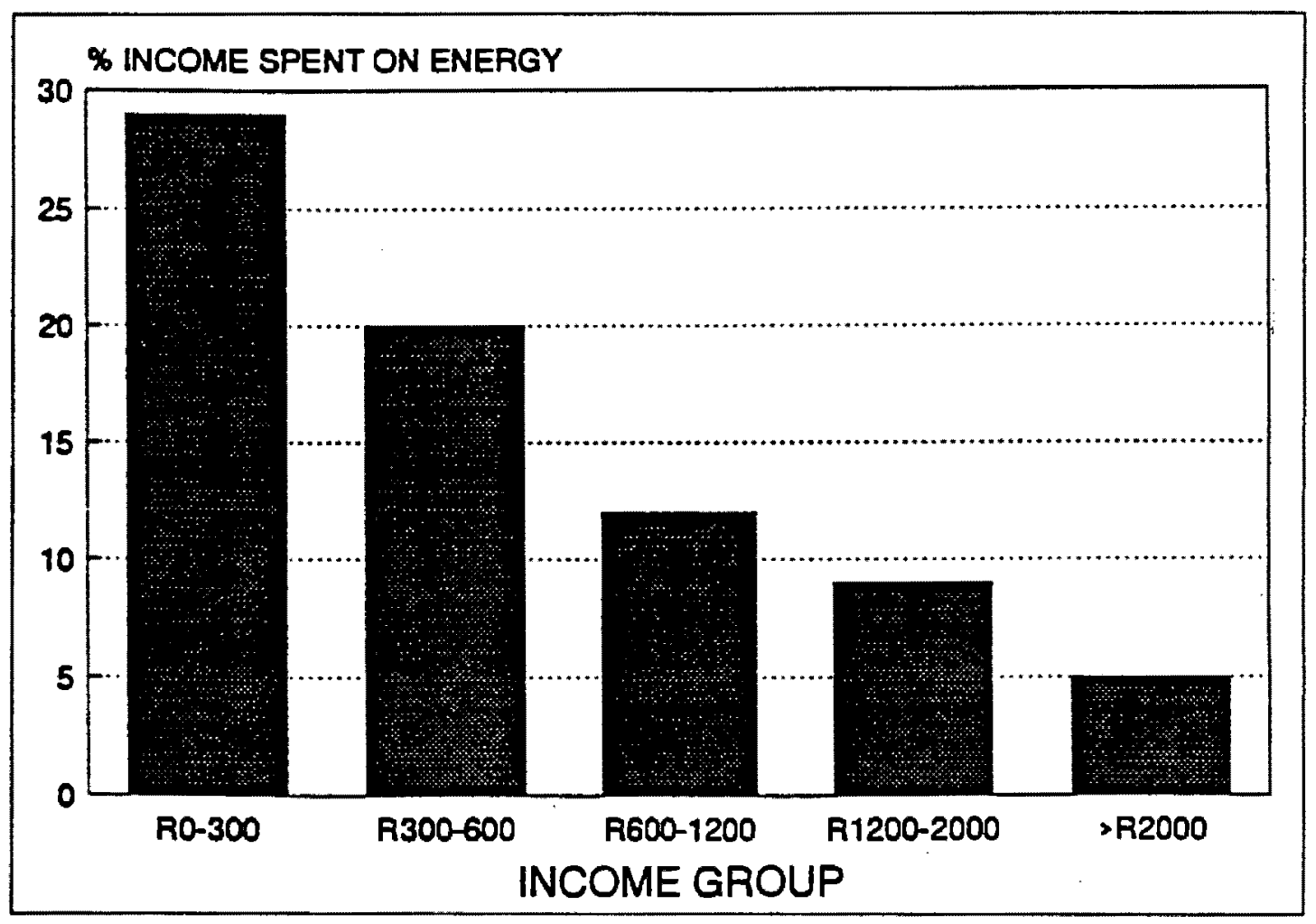

FIGURE 5.3 Energy expenditure as percentage of income in the Namaqualand 'reserves'

Source: Borchers et al (1991: 49)

It should be noted, however, that fuel use is not determined by income in itself. For example, James (1993: 49) found that, while

those that do enjoy a relatively high and secure income are more able to use fuels such as gas, paraffin and batteries, it is very often the case that they choose not to.... [A]lthough their income was the deciding factor in enabling the purchase of appliances and the running of them it was the activities which the members are involved in that determine their fuel use and expenditure.

This point is well-illustrated by the complex fuel use patterns in relation to income that were observed in some of the 'reserves' in Namaqualand (Borchers et al 1991: 51). On the other hand, fairly definite patterns of energy use in relation to income could be observed in other areas.

In addition to the absolute amount earned by households, the nature of the income - that is, whether or not it is obtained from a regular and secure source - also impacts on energy use. James (1993: 49) found that households with unreliable incomes tended to buy fuels only when they could afford it. On the other hand, households with secure incomes should be able to purchase food and fuel on a more regular basis. 


\subsubsection{Cost and availability of fuels and appliances}

The cost of fuels and appliances clearly restricts people with relatively low incomes from using particular fuels, as discussed in 5.8.3. In many instances fuel choices are motivated by cost considerations, as is illustrated by the widespread use of collected wood. Fuels such as wood, dung and crop residues provide services such as space-heating, cooking and water-heating at very low cost (Thorne 1994). On the other hand, the life-cycle costs of fuels such as candles and paraffin are in many cases extremely high (Thorne 1994). Nevertheless, these fuels are the most widely used in rural areas after fuelwood, in spite of the fact that paraffin is not a preferred fuel among rural people. It would appear that these fuels are used mainly because they meet particular needs (see 5.5), while their use is facilitated by the following: - candles and paraffin are widely available in the rural areas;

- the basic appliances required to use paraffin are relatively inexpensive;

- these fuels can be purchased in small quantities, and therefore involve little expense at a particular time.

Hofmeyr (1994) points out that the availability of fuels has a major impact on fuel use by farmworker households. For example, fuelwood is relatively easily available in the commencial farming areas compared to the homeland areas. On the other hand, commercial fuels, including paraffin and candles, usually are bought in town and are therefore not easily available to farmworker households who generally lack transport: A smaller percentage of farmworker households therefore use these fuels compared to households in the homeland areas (see 5.7.2).

\subsubsection{Gender relations}

James (1993) found that gender relations impacted on energy use in a number of ways. In the first place, decision making with regard to the purchase of appliances is greatly determined by relations between women and men in the household.

In some households the decisions as to what to buy were made jointly, either between spouses or head and adult children.... In most cases, however, after the initial joint decision to buy some form of appliance, the decision of what type, eg gas or paraffin, lies with the man, whether he be husband or son.... In cases where women's lives may be made easier by the purchase of a stove of some sort it often happens that a conflict of interests results and the man's need is met before that of the woman's, eg as in the case of household 13 where two televisions were purchased before a much needed gas cooker. (James 1993: 42]

James (1993: 42) cites two cases where men control the use of the gas cookers owned by the household. In the one case the women of the house only have access to the gas cooker when they prepare tea for the husband. In the second, the gas cooker accompanies the husband who spends one week at a time with each of his wives. He also found that fuel expenditure is affected by the power relations between men and women.

All the households with high battery expenditure have in their households young men who listen to taped music.... [W]hen one examines the ownership and right to the radios and hi-fi's it becomes clear that these are the domain of the men. Decisions to buy batteries lie in their hands even if they are the sons of the household and earn no money.... [W]ives and daughters (unless they eam their own money) do not control the purchase of batteries and very often do not have the right to these appliances. (52)

Energy use is also influenced very generally by gender relations because of the division of labour between men and women, which means that it is mainly the demands on women's time which affect energy use (see 5.8.1). 


\subsection{Problems related to energy use}

The safety, health and environmental problems experienced by rural people in relation to energy use are discussed in great detail by Van Horen (1994a). These include the following:

- Air pollution

High levels of pollutants resulting from the use of woodfires have been found in the homes and cooking areas of farmworker households in South Africa (Terblanche 1993). Van Horen (1994a) concludes that indoor pollution among rural households seems to be a major environmental health problem which warrants considerably more research attention and resources than it has received in the past.

- The increasing scarcity of fuelwood

In many rural areas the increasing scancity of fuel wood leads to an increase in the distances covered by women to collect wood, while the weight of headloads also appear to increase (van Horen 1994a). The combined effect of these two factors places considerable stress on the physical well-being of rural women. Moreover, it is possible that spine damage could occur in extreme cases.

- The ingestion of paraffin by children

Paraffin poisoning occurs when children inhale or drink paraffin, which is commonly sold in soft-drink bottles. Effects may range from coughing and choking, to diarrhoea and vomiting, and possibly death (van Horen 1994a).

Some other energy-related problems which have been discussed in this chapter include the demands made by fuel collection on the time of rural women (5.8.1), and the high percentage of income spent on energy by the poorest groups in rural areas (5.8.3).

\subsection{Conclusions}

Domestic energy use in rural areas is clearly a matter of great complexity. Rural people are in need of particular energy services, such as cooking and water-heating, and continually make decisions regarding the ways in which they will meet these needs. These decisions are greatly influenced by particular needs and preferences - the need, for example, to complete cooking and water-heating tasks speedily in the mornings.

The decisions made by rural people are influenced by a range of factors, of which the demands on women's time and the availability of 'free' fuelwood are probably the most important. Other factors of importance include household income and economic status, the cost and availability of fuels, and gender relations within households. The resulting patterns of fuel use and consumption in rural areas are characterised by the dominance of fuelwood, which contributes by far the most to energy consumption, and the widespread use of fuels like paraffin and candles.

Energy-related problems experienced by rural people include exposure to high levels of indoor pollution, fuel collection over long distances and the ingestion of paraffin by children. 


\section{Future rural energy demand}

\subsection{General discussion}

A wide range of factors will impact on energy demand in rural areas in the future, most of which do not fall within the confines of the energy sector. The extreme poverty prevalent in rural areas has probably resulted in a high degree of suppressed demand, both in terms of the types of energy services that are acquired and the consumption of fuels to provide these services. At the same time, the lack of access to affordable energy services has also contributed to rural poverty by diverting household resources (such as labour and cash) from other essential needs, such as food, education and health. An improvement in the provision of energy services in rural areas under present conditions will therefore not necessarily lead to an increase in household energy consumption, but would enable households to reallocate 'released' resources to priority areas, of which energy may be one. In this way improved energy service provision could make a small but important contribution to the alleviation of poverty.

Future energy demand in rural areas will depend to a large extent on the nature and impact of a rural development (RD) policy, comprising strategies aimed at land reform, job creation and income generation, basic needs satisfaction, capacity building, etc (see Chapter 3). Of particular importance will be the effect of land reform policies on population distribution, and, together with natural resource management strategies, on resource availability, the impact of a RD policy on real incomes and food security in rural areas, as well as changes in the status of women and the nature of gender relations in the society, the improvements in infrastructure, delivery mechanisms and services that are achieved, and the degree to which integrated rural development is implemented.

In addition, the implementation of energy policies will also impact considerably on future energy demand. Rural electrification is gaining importance as a national development priority, and it seems likely that rural electrification will occur on a significant scale in the future. However, it is highly unlikely that electricity will become the dominant household energy source in rural areas within the next 15-20 years. In the first place, the high costs of electricity connections in rural areas will render it impossible to provide all rural households with an electricity supply during this time. Secondly, the experience in low-income urban areas which have been electrified indicates that households continue to use fuels other than electricity for some purposes, particularly the more energy-intensive services such as 'slow' cooking, and space-heating. There are various factors which contribute to this situation, of which cost savings to the household is one, and the ownership of appliances another. In rural homes which have been electrified, similar tendencies have been observed (Gandar 1994). For these and other reasons, fuels such as fuelwood, paraffin and LPG are likely to continue to satisfy the bulk of household energy demand in rural areas in the foreseeable future.

It is expected that fuelwood will continue to dominate energy use in rural areas during the next 15-20 years. The extent to which this will happen will depend on factors such as the availability of fuelwood, as well as the availability, affordability and acceptability of alternative fuels (see below) for certain purposes, particularly the preparation of the main meal (see 5.5.1). A number of initiatives aimed at improving woody biomass resounces in rural areas are being mooted, such as a national social forestry programme and the improved distribution of firewood from areas of surplus. Increased demand for fuelwood in rural areas, where the population is expected to remain of the same order of magnitude (see 3.2), may 
occur if there is a reduction in the costs of fuelwood, or a real increase in incomes in rural areas, as suppressed demand would be met to some extent. On the other hand, if real incomes would decrease, without significant improvements in the availability of fuelwood at very low cost, demand would be suppressed even further.

The future role of hydrocarbon fuels in rural areas will depend to a significant degree on factors such as the accessibility of fuelwood and electricity, as well as the incomes of rural people. However, demand for these fuels could also be affected greatly by reductions in the costs of these fuels, the greater accessibility of particularly LPG appliances, and real improvements with regard to the associated health and safety problems. Indications are that particular needs (such as 'fast' cooking and water-heating) of rural people are best met by hydrocarbon fuels rather than fuelwood. Hydrocarbon fuels can also play a major role in providing services such as lighting, refrigeration, and water heating where these cannot be provided by means of electricity. As it is unlikely that electricity connections in rural areas will generally make provision for water-heating devices such as geysers, a fuel like LPG could play an essential role in providing this service.

\subsection{Future energy demand scenarios}

Two scenarios on future trends in energy use have been developed during the EPRET project. They were used to analyse the financial and economic impacts of the policy options which were devised (Van Horen 1994b). The first comprises a 'business-as-usual' (BAU) scenario, which assumes that current trends in the energy sector continue into the future. The integrated-energy-planing (IEP) scenario assumes that the principles of IEP are applied, and particularly that the policy recommendations devised during the EPRET project are implemented (see Chapter 7). Detailed discussions of the scenarios for particular supply sectors are provided by Horvey and Dahl (1994), McGregor (1994), and Gandar (1994), while van Horen (1994b) provides an overview of the two scenarios.

The IEP scenario envisages considerably more emphasis on rural electrification compared to the BAU scenario. Assuming that the number of rural households remain constant during the period involved, it is predicted that about $90 \%$ of farmworker houses, and about $60 \%$ of other rural houses would be electrified by the year 2010 - that is, a total of $66 \%$ of all rural houses (Horvey \& Dahl 1994). This can be compared to figures of $59 \%$ for farmworker houses, $44 \%$ of houses in dense settlements, and $27 \%$ of houses in scattered settlements (a total of $43 \%$ of all rural houses) projected by the BAU scenario. The initial consumption of rural households has been assumed as $60 \mathrm{kWh}$, reaching a peak of $150 \mathrm{kwh}$ after 4 years (ibid).

The IEP scenario also makes provision for strategies which would provide an additional 1.25 million tons of fuelwood per year in the homeland areas (Gandar 1994). This can be compared to the currently estimated annual consumption of 6.6 million tons of fuelwood, and the estimated 5.8 million tons of fuelwood which is available through sustainable harvesting from woodland in these areas (ibid). Under the BAU scenario it is envisaged that policy efforts such as the Biomass Initiative would continue, but that its impact would be limited (van Horen 1994b).

The projected demand for hydrocarbon fuels under the two scenarios are presented by McGregor (1994), but no distinction is been made between rural and urban areas. The IEP scenario predicts that the demand for both paraffin and LPG will decrease, with the decrease in the case of paraffin being particularly pronounced. This can be compared with predicted increases in the demand for both these fuels in the case of the BAU scenario. The increase in the demand for coal is also expected to be less pronounced under the IEP scenario compared with the BAU scenario. 


\title{
Policy recommendations for energy provision in rural areas
}

\begin{abstract}
A first important step is recognising that every energy supply intervention will have some impact on rural poor households, and all too often these effects will be negative, though unintended. (Cecelski 1985: 47)
\end{abstract}

\subsection{Introduction}

The formulation of energy policy for rural areas during the EPRET project has been severely hampered by a lack of the information required to develop a textured understanding of energy use by rural people, as well as a lack of relevant experience with regard to the implementation of energy-related strategies in rural areas. It is particularly important that policy aimed at rural areas should be informed by an in-depth understanding of conditions there, the complex and fragile nature of rural people's lives, and their efforts to secure their livelihood, and how these matters impact on energy use, as well as practical solutions which have been crafted under the difficult circumstances that prevail, and which have been proven to have the desired impact. It is these strategies by which policies are implemented at a local level, and the particular conditions at localities in rural areas, which ultimately. determine the impact of policy on the lives of rural people. As the quotation from Cecelski at the head of this chapter suggests, energy supply strategies can have a negative effect on poor rural people. Policies could also fail to have any real impact because of the lack of physical and institutional infrastructure in rural areas. Poor rural people are particularly vulnerable in this regard, as they generally lack access to the power required to ensure that resources are allocated in their favour (see Chambers (1983) for a discussion on the powerlessness of the poor).

This paper has been particularly concerned with the need to ensure that rural energy policy improves the lot of poor rural people generally. An attempt has been made to deal with the realities in rural areas and the circumstances of rural people, particularly in discussions of the nature of rural poverty (see 2.4), the relationship between energy services and basic needs fulfilment (see 4.2), the requirements of rural people with regard to the energy services they need (see 5.5), and the factors which impact on energy use, including the demands on women's time and gender relations (see 5.8). However, it has not been possible to explore these matters adequately, mainly because of the lack of in-depth information on energy use in South Africa, as well as resource limitations during the EPRET project.

Experience with the implementation of energy-related strategies in the rural areas of South Africa is relatively limited, while much of the experience has not been well-documented. Some experience has been gained in the realm of social forestry and other fuelwood supply strategies, such as woodlot development, which have been made possible with funding from the Department of Mineral and Energy Affairs (DMEA) and the Biomass Initiative during recent years. Similarly, some recent experience has been gained in rural electrification (Horvei and Dahl 1994). Other efforts have often centred around the introduction of 'appropriate' technologies such as woodstoves, biogas plants, solar cookers, and solar water heaters, while the provision of battery charging services, and the dissemination of photo-voltaic systems (Davis, Borchers, Dickson et al 1994) have also been investigated. 
An attempt will be made in this chapter to summarise the policy options for the provision of energy services in rural areas which have been developed during the EPRET project, as well as the institutional requirements and financial implications of these policies. This discussion will draw heavily on the recommendations which have been developed in other EPRET papers - those, for example, on the various supply sectors (Gandar 1994) (McGregor 1994) (Horvei \& Dahl 1994), on different user groups (Hofmeyr 1994) (Gandar and Auerbach 1994), and on energy-related issues (van Horen 1994a) (Thome 1994). In addition, a range of matters will be highlighted which require further investigation before meaningful policies can be formulated. Areas which have been dealt with inadequately during the EPRET project will also be highlighted.

\subsection{A framework for rural energy planning}

In the past, energy planning in South Africa has taken the form of centralised supply-oriented planning which was conducted separately for the different subsectors such as liquid fuels and electricity. In addition, planning was focused on matters of strategic importance to the government which faced a range of economic sanctions. The needs of the poor, and particularly rural people, were not considened to any significant degree during this planning process.

A new approach to national energy planning - integrated energy planning (IEP), which is discussed in great depth by Eberhard (1992) - has been developed internationally during the last two decades. This approach is characterised by a focus on energy end-use analysis, and

involves a detailed and comprehensive analysis of the energy sector, interaction between energy subsectors, and linkages with the rest of the economy. More importantly, it also involves formulating and evaluating appropriate policies and implementing strategies to manage the demand and supply of energy to achieve desired objectives. (Eberhard 1992: 16)

The EPRET project constituted an attempt to implement the IEP methodology, although this was severely hampered by the lack of information on critical aspects such as energy end-use, as well as various other aspects of rural energy use (see 5.2). While the IEP methodology provides a useful tool for the analysis and planning of the energy sector, it is not adequate as a framework for rural energy planning. In this section an attempt will be made to begin to develop such a framework.

Energy planning can be seen as a number of inter-related processes, one which occurs at a national level, which is essentially a policy-making process, drawing on information and experience which are generated at the local (or implementation) level, while the coordination of programmes occurs at a regional level. This discussion will give particular attention to the planning process at a local level, as this is crucial to the development of sound policies, and the successful implementation of these policies. Drawing on previous discussions, various elements have been identified as essential to a framework for rural energy planning and are discussed below.

\subsubsection{An infegrated approach}

Integrated rural energy planning should occur within and/or in accordance with a framework of integrated rural development. This is required to ensure that appropriate energy resources are developed and that these are optimally utilised, and that the development of energy services contribute to other aspects of development. Such an approach implies that household energy planning should be conducted in conjunction with planning for the other energy consumption sectors, such as the agricultural, small business and public services sectors. Existing boundaries within sectors, such as the current distinction between farmworkers and other rural households, should also be transcended. 
In addition, energy planning should, where possible, address broad objectives and concerns of rural development such as basic needs satisfaction, employment creation, skills devélopment, organisational and institutional development, improvement in infrastructure and basic services, improvement in the status of women, and improvement in the living conditions and opportunities of the poorest people. At the same time, it is necessary to take full cognisance of the constraints to development in the form of the shortage of skills and resources in rural areas, and the lack of infrastructure and delivery mechanisms, as well as the opportunities presented by available skills and resources which could be developed and utilised for energy service delivery. Formal linkages between energy and other sectors should be established where necessary. Bajracharya (1983: 8) makes the following comments regard integrated energy planning:

[R]ural energy planning cannot function as an independent entity, but has to be part of the entire process of rural development planning, based on such widely discussed principles as satisfaction of the basic needs of the neediest, atto inment of looal self-reliance, local participation in decision-making, local control in the implementation of innouations, redistribution of economic and political power, and so forth. (emphasis added)

At a local level, it is of particular importance that needs assessments should be conducted in an integrated manner, thereby forming the basis for integrated planning. Needs assessments which are conducted by a particular supply agency, such as Eskom, tend to be of limited value for the purpose of integrated planning, and are therefore often wasteful of scarce resources.

\subsubsection{A people-centred and systems-oriented approach}

The starting point for rural energy planning should be a systems-oriented understanding of the circumstances, needs and priorities of energy users. A peoplecentred approach is required, together with an understanding of the systems within which energy is utilised by rural people, and particularly rural women, including the system of food preparation in which fuel is but one component, the way in which fuels are utilised to meet needs, and particularly the role(s) of the woodfire, the demands on women to meet a variety of needs, the way in which resources such as cash and labour are obtained, allocated and utilised to meet needs, the impact of changes in energy service provision on their livelihoods, gender relations within households, and how these impact on energy use, the priorities of women and the implications for energy service provision, etc.

In the past there has been a tendency to follow a technocratic rather than a people-centred and systems-oriented approach to energy problems in rural areas. An example of this was the focus on woodlot development as a way to address fuelwood shortages, which has now been replaced by the focus on social forestry, with a smaller role being allocated to woodlots. This change in approach reflects an improved understanding of the utilisation of trees by rural people - that is, the context in which fuelwood is harvested and utilised. Another example of a technocratic approach to a problem is the common response to the high air pollution in rural homes resulting from woodfires, which focuses on the introduction of woodstoves to alleviate this problem. A more meaningful approach would be to develop an understanding of the system of cooking (see 5.5.1) in which the woodfire plays a central role - the context in which the fire is used.

Of equal importance are the socio-economic and political systems which operate in the society, such as the trappings of poverty and the poverty-coping strategies employed by people, power dynamics in rural communities, including gender relations, the difficulties of ensuring that benefits of development do not only accrue to the more powerful and affluent in these communities, and, in the case of farmworkers and other such groups, the relationships of dependency which generally exist between farmers or land-lords on the one hand, and farm employees or 
tenants on the other.

It is essential that a gender-sensitive approach is adopted in rural energy planning: the socially constructed relations between men and women (gender relations) must be considered explicitly. As Rathgeber points out:

Besides providing a precise conceptual analysis, the exploration of gender relations allows one to explore constraints on women's ability to participate in development projects as well as suggest ways in which women can and do become agents of change rather than passive recipients of development assistance. (Quoted by James 1993: 3)

\subsubsection{Fexibility and responsiveness}

Rural energy planning should be responsive to the needs, problems and priorities of rural people. Flexibility should therefore exist within a national or regional energy development framework for the development and adaptation of energy-related implementation strategies at a local level, which should be actively facilitated. This is necessary to allow for the diversity in the specific needs, problems, conditions and resources in different areas. Bajracharya (1983: 8) comments on this:

The present emphasis on cental macro-level planning and decision-making in many Asian countries may need to be diminished and effectively combined with the micro-focus that is emerging as a prerequisite to effective problemsolving [author's emphasis]. This shift is made clear by the increasing awareness of the diversity in socio-cultural contexts, problem situations, and especially the differences in priorities, options, resource availabilities, local organizations and local capabilities. Only through local assessment and internalization of the problems does it become possible to identify realistically which needs and whose needs ought to be satisfied, and also by which means and within what framework of organization, space and time.

Mechanisms should also be provided to ensure that local experiences in implementation inform regional planning as well as policy making at a national level, which should be seen as an on-going process. The independent evaluation of energy projects should therefore form an integral part of the energy planning process at a local level, to generate the information required for this purpose.

\subsubsection{Accountability and participation}

Mechanisms need to be provided in the rural energy planning process to ensure that planners and policy makers are made accountable to rural people, and that the needs and concerns of rural people are addressed effectively at all levels. At the policy making and regional planning levels, this could be done by structuring the process to ensure real inputs to decision making by representatives of rural communities.

Auerbach and Gandar (1994) make the following recommendations with regard to the representation of the small-scale farming sector in energy planning:

- The development of representative organisations for small-scale farmers with the influence to lobby effectively on their behalf is a priority. Furthermore, particular interest groups within the small-farm sector, such as tractor operators and millers, need to have a voice. Provision must be made for such organisations to influence energy planning at local and regional levels.

- Since advocacy and lobbying will be an important function of the interest groups, they should be established outside of government structures. The existing networks of development NGOs could play an essential facilitating role.

However, political representation is insufficient to ensure that the best interests of rural people, and particularly the poorest groups and women, are served. This can 
only be achieved if these people acquire effective control over decisions which affect them. At a local level the energy planning process should therefore be structured to enable the participation by various groups who would be affected by energy-related decisions, such as women's groups and farmer groups, with the aim to facilitate joint decision-making by these groups. This would clearly not be a simple process, as rural communities are by no means homogeneous in nature. The analysis of key issues and problems, as well as possible opportunities and solutions, would need to be conducted by these groups in cooperation with planners, and complex matters would need to be communicated effectively to all groups involved, to enable them to make informed decisions. Again it is enlightening to consider the view of Bajracharya (1984: 279) in this regard:

The problems that develop in implementation generally stem from a process of externalization, that is, activities such as identification of nural development issues, determination of priorities, conceptualization and planning of action programs, all take place outside the purview of the people for whom the programs are intended [author's emphasis]. Even though some rural development theorists recognize how important people's participation is, the 'blueprint approach' continues as the basic dogma in rural development efforts, energy-related activities being no exception. The control and decision mechanisms remain foreign to the local populace At best, local people's interests and needs are intellectualized by the planner and plans that supposedly embrace people's needs are assumed to be 'appropriate'. (emphasis added)

Bajracharya (1984: 303) reported on the successful implementation of local control in decision-making during energy projects. Morse et al (1984:6) commented as follows on these experiences:

The significance of these village decision sessions can be generalised by stating that the motizations, needs, and constraints of rural people constitute the foundation of rural change and development and set the context for defining rural energy issues. Small- and medium-scale farmers, marginal and subsistence farmers, landless families, large-scale farmers, agro-processors, traders, artisans, teachers, and community leaders - all may see these issues somewhat differently. (emphasis added)

In South Africa some of the social forestry projects which have been implemented in recent years have incorporated a significant degree of local participation and decision-making. ${ }^{24}$ In some cases representatives of rural communities have also reportedly been involved in decision-making concerning rural electrification projects (Horvei \& Dahl 1994).

\subsubsection{Local energy planning}

If an integrated and participatory approach to local energy planning is adopted, a wide range of energy-related functions would need to be fulfilled at a local level. Energy planning at the local level could possibly be fulfilled by district-level authorities responsible for development planning and coordination, as discussed in 3.4.7. Considerable investigation is required to develop appropriate models for the implementation and institutionalisation of local energy planning. The development of integrated energy plans for areas such as the Umvoti River valley atStanger in KwaZulu/ $\mathrm{Natal}^{25}$ could provide valuable experience in this regard. It is suggested that the creation of the position of 'energy development coordinator' at a district level should be investigated as one possible model.

24. Personal communication with Fiona Archer and Tim Fenn, both of whom are private consultants involved in social forestry projects.

25. Personal cormmunication with Mark Borchers of the Energy Development Group. 


\subsection{Rural energy research}

As discussed, current information on energy use by rural people is fraught with problems, and inadequate for the purpose of developing a textured understanding of energy use. In order to address this situation, it is recommended that future research should give particular attention to the following matters:

- Analysing and collating available information, including statistical information, information of a quantitative nature which cannot be analyzed statistically, and qualitative information.

- Generating energy end-use information - that is, particular requirements people have with regard to energy services, and the quantities of fuels used for particular purposes. In particular, a distinction should be made between domestic uses of energy, and energy used for home-industries such as baking.

- Developing a systems-oriented understanding of intra-household factors which impact on energy use, such as the demands on women's time, decision-making processes, gender relations, the interdependence of food, water and fuel needs, the cooking system, particularly as related to the woodfine, etc.

- Developing a systems-oriented understanding of energy-related problems, and all the factors which contribute to these, including exposure to air pollution as a result of woodfires, high paraffin prices, and so on.

- Generating longitudinal data on energy use - that is, information which reflects changes over time.

- Generating information on the energy requirements of community facilities, public services and small entrepreneurial activities in rural areas.

The development of a conceptual framework on rural energy, which draw particularly on quantitative aspects of energy use, is essential to ensure that the information generated during research is relevant and comprehensive. It is recommended that more research should be conducted which focuses around particular issues attempting to address particular problems or to improve understanding on particular matters. However, this should be done within the context of a systems-oriented approach to the issues concerned, to ensure that a narrow and possibly technological focus is not adopted.

It is also recommended that a framework for rural energy research should be developed to guide the manner in which research is conducted by different organisations and consultants. Some of the aspects that would need to be considered in such a document, are the following:

- the need for research activities to be non-exploitative and linked to implementation;

- the utilisation of participatory and action research approaches where appropriate;

- the need to include all significant groupings among rural people, such as farmworker households, in research activitie;

- the need for a gender-sensitive approach to rural energy matters.

\subsection{Supply of fuelwood}

Gandar (1994) deals extensively with measures to improve the supply of fuelwood in rural areas, and the framework he suggests for approaching fuelwood problems shows close correspondence with the suggested framework for rural energy plan- 
ning which was discussed in 7.2. He indicates that:

A new intellectual and analytical framework is needed for the so-called fuelwood crisis. It is necessary to understand the nature of the problem. It is not simply a resource shortage requiring narrow supply-side or demandside interventions. The fuelwood issue must be placed in the wider context of rural poverty, and of the coping mechanisms and livelihood strategies of rural people. Thus the targets for interventions are constraints rather than shortages. The fuelwood problem may thus take on a different complexion in different situations.

The above framework has two main implications for biomass policies. Firstly, interventions must be co-ordinated with and integrated into regional rural development strategies and integrated energy planning. A multitude of intersectoral linkages are required to effect this. Secondly, adaptive and participatory approaches to planning and implementation are necessary. It is necessary to understand the local best-practice responses to fuelwood shortages, and to build on these as appropriate.

Gandar identifies three broad areas of intervention aimed at improving the fuelwood situation in rural areas: the management of natural resources, promoting tree planting through a national programme of social forestry, and the transport and distribution of local surpluses of food.

\subsubsection{Management of woodland resources}

Gandar (1994) recommends that 'innovative initiatives for the sustainable use of resources in communal woodland should be actively encouraged and supported', but that detailed policy guidelines on the management of indigenous woodland should be formulated at a later stage. He points out that it is important to understand and build on local and traditional practices which regulate the utilisation of natural resources', recognising that traditional practices have changed in response to external influences, which have often resulted in the erosion of these practices. Finally, he recommends that the role of Resource Management Areas (communal areas which are set aside specifically for conservation and controlled utilisation) should be explored.

\subsubsection{National social forestry programme}

The bulk of Gandar's recommendations are concerned with the establishment of a national social forestry programme as a matter of priority. He makes the following recommendations in this regard:

- That such a programme should include such diverse elements as homestead planting by individuals, reclamation forestry, community woodlots, commercial small grower schemes, institutional woodlots etc, which should be implemented at appropriate locations.

- That the programme should be truly multi-sectoral, with firm and formal links established between the various sectors involved, within an overall coordinating structure.

- That a specialist extension service in social forestry should be established, but that the programme should rely to a large degree on extension workers in related disciplines, particularly agriculture. Moreover, that all the existing disparate branches of extension in rural areas should be brought under a coordinating structure which could facilitate cooperation.

- That training in social forestry should be provided at all levels from the rural village level to tertiary professional training, and that the planning and coordination of training should rest with a body established for this purpose. 
That support services should be provided to NGOs and service organisations which support social forestry initiatives on the ground, including access to information and technical advice, supplies and basic infrastructure, etc.

Hofmeyr (1994) has recommended that farmworker households should be included in a national programme of this nature, although they have been excluded from the Biomass Initiative.

Gandar (1994) points out that the direct involvement of the energy sector in a social forestry programme would be limited, and suggests that it could play a role in the initiation of the programme and its co-ordination, in planning and policy formulation, and in research insofar as it relates to fuel wood'.

With regard to the relationship between commercial forestry and social forestry, he recommends that these sectors should be brought together in a single coherent policy framework, pointing out that there are important areas of overlap, which include commercial small-grower schemes, the sharing of nursery facilities, and the use of plantation residues for fuelwood.

\subsubsection{Distribution of surplus fuelwood}

Gandar (1994) recommends that a campaign, to encourage farmers and foresters to allow easy access to these resources, should be conducted through the media, the Agricultural Unions and the extensions services to the commencial farming sector. In addition, the integration of fuelwood harvesting into farm management plans should be encouraged. He also suggests that assistance might be given to wood merchants in the form of finance, advice, and assistance with the formation of associations to negotiate directly with land owners.

\subsubsection{Instifutional requirements}

Gandar (1994) points out that institutional capacity is required at the national, regional and local levels, for purposes such as policy making and overall coordination at the national level, the operationalisation and integration of programmes at a regional level, and the planning, implementation, coordination and assessment of projects at the local level. He makes the following recommendations in this regard:

- That the Forestry Branch of the Department of Water Affairs and Forestry (DWAF) is the best positioned to provide an institutional base for a national programme of social forestry and woodlot development.

- That a committee should be appointed to review the institutional location and status of Forestry, as its current position as a directorate within the DWAF is under question.

- That a national advisory and coordinating Forum for social forestry should be convened, which should set up working groups on matters such as policy, education and training, extension and support services, and research.

- That an institutional framework would need a clear entry point for funds and demonstrably effective mechanisms for delivery of these funds to where they are needed, which should include mechanisms for directing funds to NGOs and CBOs.

\subsubsection{Financial implications}

Gandar (1994) developed scenarios for each of the interventions discussed above, corresponding with the IEP scenario that was discussed in 6.2 . He estimates the costs that would be incurred, and the potential additional fuelwood yield that would be achieved for each of the strategies, and draws the following conclusions: 
From a purely energy perspective, investment in firewood distribution systems has by far the best marginal returns in terms of increasing fuelwood availability. The actual cost of transport and distribution is passed on to the consumer. However, the strategies must not be evaluated in energy terms alone. The interventions aimed at tree planting have a broad spectrum of benefits for development and environmental management. Since these strategies exit only as integrated packages, it is not possible to isolate the energy component from the other components. (Gandar 1994)

\subsubsection{Equity considerations}

In his discussion on fuelwood pricing policies, Gandar (1994) raises the question of equity in access to fuelwood: that fuelwood should be affordable to the poorest people who are dependent on it for energy purposes. He points out that this consideration has translated into political pressure in the Transkei where fuelwood is sold below production cost at woodlots run by the Department of Forestry.

This question is of particular importance in the light of the concerns raised in this paper with regard to poverty and the impact of fuel shortages and high fuel costs on people's ability to meet their basic needs (see 4.2). It is therefore necessary to consider what will be the impact of the interventions discussed above (which are aimed in part at improving the supply of fuelwood in rural areas) on the situation of the poorest people in these areas. For this purpose some criteria would have to be identified by which the nature and extent of the impact could be established, such as the following:

- Are the poorest people able to meet their basic energy requirements?

- Does the increased commercialisation of fuel wood provide incomes to the poor?

- Does the improved supply of fuelwood lead to a reduction in the cost of fuelwood to users?

- Do social forestry and other efforts lead to the greater availability of fuelwood which can be collected free of charge or at minimal cost?

The impact of interventions on the poorest people would have to be assessed as part of the structured evaluation of social forestry and other projects. This monitoring role could be fulfilled by the energy sector, which would be responsible for the development of policies to ensure that the poorest people are able to meet their basic energy needs. One possible strategy could be the issuing of 'fuel stamps' together with 'food stamps' to targeted groups. This could prove to be a more effective strategy to ensure food security than the issuing of 'food stamps' alone, which has been suggested as a possible option in a future agricultural policy. As discussed in 7.2.4, it would be essential to involve the poorest groups in society, and women in particular, in decision making regarding appropriate strategies to alleviate problems of fuel wood unavailability at particular localities.

\subsection{Distribution and pricing of hydrocarbon fuels}

The fuels considered here include domestic fuels such as paraffin, candles and liquid petroleum gas, as well as diesel which is mainly used for agricultural purposes. The hydrocarton fuels supply sector has been discussed in some detail by McGregor (1994). Information is mainly available on the formal distribution of these fuels as well as urban retail networks. 


\subsubsection{Paraffin, candles and LPG}

Relatively little is known about the distribution of these fuels - particularly candles and paraffin - after they leave the formal networks (the oil company depots in the case of paraffin). Indications are that rural people in the homeland areas buy paraffin and candles from a range of outlets, including formal trading stores, service stations and informal or 'spaza' shops. However, no clarity exists on matters such as the percentage of sales from these different outlets, the number and the nature of the intermediaries in the distribution chains, the nature of price increases along the chains, and so on. Rural energy surveys often provide some information on the outlets at which fuels are purchased, but this is generally of a limited nature. For example, May et al (1993: 61) found that paraffin and candles were bought mainly from formal traders as opposed to informal outlets in the rural areas of KwaZulu. (Less than $15 \%$ of the sample bought candles at informal traders, while about $22 \%$ bought paraffin at informal traders). However, no indication was given of the reasons for this, such as a possible difference in the costs of the fuels at different types of outlets. According to McGregor (1994), there are service stations in the Transkei which sell more paraffin than petrol.

Only one in-depth study of the distribution of hydrocarbon fuels in rural areas has been conducted by the Palmer Development Group, the findings of which will be available during 1994. This study has focused on four areas in the Transvaal, and particularly the northern part of the Winterveld. According to Richard Palmer, ${ }^{26}$ all the retail outlets which were included in the study stocked paraffin and candles. He indicated that the distribution chains in rural areas appear to be fairly short.

It would appear that LPG is mostly purchased from formal traders in rural areas, probably because of the safety precautions necessary, and the equipment required to fill gas bottles. May et al (1993) found that only $2.2 \%$ of their sample in the rural areas of KwaZulu indicated that they filled gas bottles at informal traders. Their conclusions in this regard are somewhat ambiguous, on the one hand stating that this did not indicate the 'non-favouring' of informal dealers but rather that the latter did not provide this service. On the other hand, they pointed out that the results revealed how cautious people are about the buying or refilling of gas bottles, as it appeared that they generally did not trust informal traders.

The maximum price of paraffin is legislated to the retail level, but is only effectively controlled to the wholesale level (that is, at the depots) as it has been impossible to police the retail price (McGregor 1994). Only limited information is available on the price of paraffin in rural areas, but indications are that it is considerably higher than the legislated price. For example, Griffin et al (1992: 12) found that the retail price of paraffin was between R1.38 and R1.56 per litre in the Mhala district of Gazankulu, while a mean retail price of R1.58 per litre was found in KwaZulu (May et al 1993: 65). This can be compared to the legislated price (at the coast) of approximately R1.09 in April 1993 (McGregor 1994).

It is unclear where the major price mark-ups occur in the distribution networks, or whether it merely results from the number of intermediaries involved. Studies conducted by the Palmer Development Group (1993), mainly in urban townships, indicate that significant price increases occur both at wholesale and retail levels, and similar tendencies are expected in rural areas.

Significant reductions in the costs of paraffin to users has reportedly been achieved in areas where community controlled wholesalers and satellite depots have been set up as part of the National Bulk-buying Initiative (NBBI) (as in Mabheleni (KwaZulu) and Herschel (Transkei) ${ }^{27}$ ). Discounts on the purchasing prices of basic goods such as agricultural inputs, building materials, food and fuels, are negotiated

26. Personal communication.

27. Personal communication with Mr Peter Wakelin. by the NBBI with suppliers at a national level, while the mark-ups at the wholesalers and depots are determined by community bodies. This ensures that the savings are passed on to the consumer. At the same time, the interests of poor households who 
run 'spaza' shops are protected by specifying the minimum quantities of fuels which can be sold at these centres. At present these efforts have been focused mainly in KwaZulu/Natal and the northern parts of the Transkej.

In the case of farmworkers, hydrocarbon fuels are usually bought from shops in towns and in some cases from 'farm shops' run by farmers. According to Hofmeyr (1994) the constraints on the use of these fuels by farmworker households include the reported high cost of these fuels at local 'farm shops', lack of transport to reach supply stores, the fact that relatively few farmers take responsibility for providing these fuels to workers, and the cost of appliances, particularly in the case of LPG.

\section{Policy recommendations}

The lack of information on the distribution of hydrocarbon fuels in rural areas clearly limits the scope for policy formulation. Policy needs to aim particularly at improving the availability and reducing the costs of these fuels in the quantities required by rural people - a single candle, for example, or half a litre of paraffin. In general, trade-offs seem to exist between the price paid for fuels and the availability of these fuels at a convenient distance from users. Policy measures aimed at improving the access of households to fuels would therefore need to address both of these simultaneously. Some possible interventions have been identified, but these will have to be investigated further to assess their feasibility in the light of information which becomes available. In particular, interventions would need to avoid undermining the livelihood of poor households involved in the distribution of these fuels.

The cost of paraffin and LPG to rural people could be reduced by shortening the distribution chains: if bulk tanks are installed and deliveries are made by the oil companies to a larger number of points in rural areas (McGregor 1994). These could be located at service stations, ${ }^{28}$ large trading stores, the wholesalers and depots which are being established as part of the NBBI, and agricultural cooperatives, as well as commercial farms in order to supply farmworkers (Hofmeyr 1994). This would also enable the price of paraffin and LPG to be controlled up to this level. It is therefore recommended that the feasibility of this strategy and its possible impact on retail prices should be investigated, as well as the possible location of bulk delivery points which would improve supply in all rural areas.

Hofmeyr (1994) also suggests that farmworker households' access to paraffin and LPG could be improved by encouraging bulk suppliers of paraffin and LPG, such as agricultural cooperatives, to offer incentives to farmers to provide their workers with adequate supplies. However, she points out that this system would still be reliant on the goodwill of farmers.

With regard to the pricing of paraffin, McGregor (1994) recommends that the service differential should be reduced by $5.5 \mathrm{c} / 1$ to $4.2 \mathrm{c} / 1$ (1992 cents), and the equalisation fund levy should be lowered by $3.4 \mathrm{c} / 1$ to $3.6 \mathrm{c} / 1$ (1992 cents), thereby reducing the wholesale price. He indicates that this would result in a retail price of $99 \mathrm{c} / 1$ (1992 cents), including a legislated 33.3\% mark-up on the wholesale price, which is considerably lower than the prices paid at present (see above). McGregor also suggests that the distribution cost differential in the case of LPG should be reduced by $36.2 \mathrm{c} / 1$ (1992 cents), and that the retail price of LPG should also be legislated at $33.3 \%$ above the wholesale price. He indicates that this would result in a retail price of $R 2.33$ per $\mathrm{kg}$ (1992 Rands), including the 33.3\% mark-up on the wholesale price. This can be compared with retail LPG prices of R2.77 to R3.61 per $\mathrm{kg}$ in the Mhala district of Gazankulu (Griffin et al 1992: 12).

However, the suggested reductions in the service differential and distribution cost diffenential for paraffin and LPG respectively are based on the cost structures of these fuels in urban areas, and particularly the discounts given by the oil companies to the distributors. In rural areas, on the other hand, higher service and distribution

28. The supply of paratfin through service stations has also been recommended by Richard Palmer (personal communication). 
differentials would probably be required to facilitate bulk delivery by the oil companies as discussed above. In this regard McGregor (1994) states:

If the drop size diminishes and causes oil industry delivery costs to rise, the service differential could be increased. This is regulated by the State in the case of IP and this regulation could be extended to LPG. If this policy is successful the service differential could be further increased to encourage oil companies to service all retail outlets to a minimum drop size such as 1500 litres in the case of farmer diesel.

This service differential increase could be large enough to increase the margin the oil industry have to play with and increase their incentive to follow this route thereby creating a distribution chain similar to that of petrol service stations, with a single delivery from the depot to the retail outlet, which then onsells directly to the public.

Final recommendations regarding the pricing of paraffin and LPG will therefore only be possible once the cost structures and appropriate delivery mechanisms in rural areas have been established.

The most effective way to police the retail price of paraffin and LPG in rural areas may be to provide avenues by which transgressions of the regulated prices can be reported by consumers, and to actively inform consumers of the legislated prices and of the reporting avenues which exist. At present it does not appear to be widely known that the retail price of paraffin is in fact legislated. Such an approach would serve to empower rural people to act on information which is made available to them. It is therefore recommended that the feasibility of such a strategy should be investigated, as well as the appropriate avenues for reporting which could be utilised. In this regard, it would clearly be necessary to ensure that the reporting avenues do not rely on parties with vested interests in higher mark-ups.

The National Bulk-buying Initiative may provide a vehicle for the supply of fuels at reduced costs to a significant proportion of rural people. However, no attempt has yet been made to document this initiative in the light of its impact on energy supply. It is therefore recommended that this matter should be investigated, and that a strategy should be devised to ensure that the NBBI is maximally utilised for the supply of basic fuels and energy goods in rural areas. The energy sector could possibly play a role in facilitating the expansion of the NBBI to cover most of the rural areas. An attempt should also be made to assess the potential impact of this initiative on energy supply in rural areas on a national scale.

\subsubsection{Diesel}

Gandar and Auerbach (1994) make the following recommendations with regard to the distribution of diesel in rural areas, mainly to improve availability in areas other than commercial farmland:

- There is a need to facilitate access to bulk diesel supplies for tractor operators and for farmers/communities requiring diesel for pumping. The marketing arms of petroleum companies should thenefore become more visible, accessible and responsive. In order to achieve this, formal links are required between the diesel suppliers and the agricultural support and extension services.

- The regulations regarding levies on diesel used in agriculture should be amended to benefit operators in the informal sector, and facilitate the further distribution of diesel from rural bulk tanks.

- The normal 2200 litre bulk tanks would be too large for certain users (such as community gardens with diesel pumps) and smaller options should be readily available. This implies the. :he current distribution policy of not delivering less than 1500 litres at a time should be changed. 


\subsection{Rural electrification}

Rural electrification (RE) in South Africa has been discussed in depth by Horvei and Dahl (1994), while particular aspects of electrification policy - the governance and structure of the electricity supply industry (ESI), and electricity pricing policy - have been dealt with by Steyn (1994) and Pickering (1994) respectively. In this section some guiding principles for an RE programme will be considered first, after which the policy recommendations with regard to rural electrification which have been formulated during the EPRET project, will be summarised.

\subsubsection{Principles to guide rural electrification}

It is suggested that the following principles should guide a rural electrification programme in order to achieve greater equity in access to electricity among poor rural people, without undermining the financial viability of the electricity supply industry:

- The electricity policy formulation and planning processes should be structured to ensure real inputs to decision making by representatives of rural communities.

As discussed in 7.2.4, effective representation of rural communities on bodies involved in electricity policy formulation and planning would be essential to ensure that RE occurs on a significant scale and in a manner acceptable to rural people. Some of the recommendations made by Steyn (1994) regarding the governance and structure of the ESI are particularly relevant in this regard. Within the proposed regulatory framework provision is made for in put by the representatives of consumer groups in the Energy Policy Council (EPC). National energy policy formulation would occur within the EPC, which would include representatives of various government departments, regional governments as well as representatives of key consumer groups.

In addition to the above, provision has to be made for the involvement of rural communities in the planning and implementation of electrification projects. Effective input by communities will be essential to enable the implementation of electrification projects within particular financial constraints (see below). It is also necessary to provide for greater equity at a local level, as opportunities will exist for decisions to be made which favour particular interest groups in communities. Specific attention needs to be given to the facilitation of this process at a local level, as, for example, part of the responsibilities of 'energy development coordinators' operating at the district level (see 7.2.5).

- The electrification of all operational and planned rural community facilities which require energy services, should be one of the primary objectives of an RE programme.

The resources available for RE will be insufficient to provide all rural households with a supply within the next 15-20 years. However, the electrification of all rural community facilities (schools, clinics, domestic water supply, village lighting, community halls) is an achievable objective which will ensure that the greatest possible number of rural households will benefit from the improvements in these services as a result of electrification. It should be noted that the needs fulfilled by community facilities (such as water supply, health and education) are among those considered as of the highest priority to rural communities. Moreover, the ability of poor households to utilise household connections to the full will be more limited than those of more affluent households. The poor will therefore benefit most if community facilities are specifically targeted by an electrification programme. 
communities should be given the opportunity to negotiate ways of reducing actual costs in order to gain access to electricity.

As there will be a limit to the resources available for RE, some limitation would have to be placed on the cost per connection to ensure that overall tariffs are affordable and that the electricity supply industry remains financially viable. Pickering (1994) has formulated some proposals regarding the pricing of electricity services which are relevant here. He suggests that each national domestic tariff should be linked to a national 'cost of connection' parameter which will determine the range of costs supported by the tariff. The costs allowed for rural connections would typically be higher than those in urban areas. For example, a maximum of R7 000 for capital costs per connection could be allowed for sparsely settled rural areas, and R5 000 for more dense rural settlements, as opposed to R3 000 for urban areas.

In cases where the estimated average cost of connection for a community is above the relevant cost of connection parameter, communities would have a number of choices. They could raise funds to cover the difference between the maximum cost of connection parameter supported by the tariff and the estimated cost of connection (different payment arrangements would be available); opt for reduced levels of supply in order to lower the connection costs (RAPS systems would be among the options); and/or contribute to the project in kind to reduce the total costs.

The second requirement relates to a 'cost of service' tariff parameter (Pickering 1994) which would operate in a similar manner. Each national domestic tariff would be linked to a 'cost of service' parameter which will determine the range of service costs supported by the tariff. The costs allowed for rural areas would typically be higher than that in urban areas - for example a maximum of R25 per month for maintenance and service costs per connection in rural areas as opposed to R20 in urban areas. In cases where the estimated average cost of service for a community is above the relevant cost of service parameter, communities would again have a few choices. For example, they could opt for a reduced level of service, or members of the community could be trained and employed in maintenance, billing and other activities.

- The price of electricity services should be structured to reduce the barriers to access by the poor.

In order to provide for greater equity in access at a local level, it is essential that electricity services are made as affordable as possible. The first obstacle to access by poor households in electrified settlements is the price of connection to the consumer. Pickering (1994) suggests that, as part of a new pricing structure, the price of connection should be 'as low as possible yet still retain a signal of value. From Eskom's experience a price of about $\mathrm{R} 30$ seems to be a realistic amount.'

Tariff structures which are currently applied by Eskom in low-income areas are designed to provide for the paying off of capital connection costs through the tariff (such as the S1 tariff). This generally results in a higher unit cost of electricity in these areas as compared to wealthy urban residential areas. Pickering (1994) has suggested that a single national flat-rate domestic tariff should be introduced as part of a new pricing structure. If this is implemented, all urban and rural households would pay an identical unit price, but there would be an effective cross-subsidisation to poor households who use less units than the 'break-even' point by wealthier households using more.

Horvei and Dahl (1994) havesuggested the following additional principles to guide a RE programme, which would serve the objectives of job creation and the transfer of skills to rural people: 
Labour intensive solutions should be used for line construction, using labour from the locality where the electrification actually takes place.

- Operation and maintenance, as well as technical support, should be designed in such a way as to use local labour. Such labour would need to be trained, while the arrangement would leave a part of the local tariff payments behind in the local economy.

The use of local expertise could also involve community based organisations (CBOs) and locally based NGOs.

\subsubsection{Policy recommendations}

Horvei and Dahl (1994) make the following recommendations with regard to an RE programme in South Africa:

- RE should be viewed as an integral part of a comprehensive, broadly based long-term national policy for rural development in South Africa, consistent with current and expected future budgetary constraints.

- An appropriate electricity industry legislation and regulatory framework must be put in place to facilitate national electrification efforts, both in uman and rural areas. The government has a special role to play to foster a more equitable access to electricity in rural areas, and might wish to introduce a form of taxation (electrification levy) in order to facilitate the redistribution of the sector's financial surpluses to assist in financing rural households' access to electricity.

- A national electrification policy and programme must be designed with a balance between electrification of urban and rural areas from the beginning in order to address the need for redistribution and the material needs of the poorest households. Striking a balance between rural and urban electrification will also contribute to diversification of risks (political and commercial) inherent in a major electrification programme. The quality and service level for electricity provision in rural areas should be carefully weighed against the electricity needs of the rural population within the framework of integrated energy planning.

- The government, represented by all ministries involved in rural development, together with the electricity distribution industry, should develop a National Rural Electrification Policy, Programme and Action Plan. The plan should have a defined long-term horizon and contain information about financial and other commitments to rural development programmes of each of the parties involved. The action plan must be based on a clear understanding of how to rank and prioritise RE projects and have monitorable targets as to how many, where and at what cost RE should be carried out.

- Government policy, programmes and plans must be based on the principle of least cost electricity supply solution, including both grid and non-grid developments of electricity provision in rural areas.

- The national RE programme shall not be in conflict with the principle of maintaining a financially viable electricity distribution industry in South Africa. Hence, a capital contribution per connection in rural areas shall be provided by the government to the industry to cover connection costs above a certain national level. It is recommended that the government for each year of the programme period allocates a specific amount as a line item on its annual budgets to the support of rural electrification.

- The tariff charged for electricity in rural areas shall be equal to a national (possibly at a later stage regional) household electricity tariff (set to meet the requirement of a financially viable industry), based on the principle of a straight line tariff, implying a cross-subsidy from domestic consumers with higher 
average consumption levels to consumers in rural areas.

- The RE programme must from the start aim at electrification of a number of rural 'growth centres' (including electrification of both local community facilities and households), with an identified socio-economic potential and possibilities for the establishment of productive activities.

- The national electrification programme must from the start also emphasise electrification of rural dense and rural scattered households, in particular rural dense, in addition to farmworker households on commercial farms.

Detailed guidelines on the electrification of farmworker households have been compiled by Hofmeyr (1994), including aspects such as levels of supply, low-cost technologies, tariffs, payment systems. She has indicated that at least $88 \%$ of farmworker houses, which are located on electrified farms, could be provided with a grid connection at a cost of less than R5 000 per household.

Auerbach and Gandar (1994) have also made the following recommendations with regard to the electrification of small-scale agricultural enterprises:

- Coordination between agricultural development programmes and electrification programmes is essential. All possible opportunities for agricultural and associated development to sustain grid extensions to previously non-electrified communities should be identified, although grid extension in the former homelands is unlikely to be agriculture-driven.

- As far as possible, agriculture-related activities that require electricity will have to be sited near presently electrified centres, or utilise RAPS options.

- Suitable financing arrangements are needed for the installation of PV electric pumping systems in situations where it is the most appropriate technology.

- The issues related to electricity for small-scale agriculture must be addressed in the wider context of rural electrification.

\subsubsection{Financial implications}

The financial implications of the RE programme which is envisaged in the IEP scenario (see 6.2) are discussed by Horvei and Dahl (1994). They indicate that the accumulated financing requirement of the RE programme would reach about R11.7 billion (in constant 1993 Rands) by the year 2010. This comprises both capital expenditure for the connection of rural homes, and operating deficits due to lower tariff revenues than required to cover supply costs, service costs and capital redemption. However, van Horen (1994b) has shown that the peak financing requirement of the proposed household electrification programme (including urban and rural households) would be reached after 11 years, at R9.9 billion, if the following conditions are met:

- A single national flat-rate tariff is instituted which applies to all domestic consumers, including rural and urban, as well as newly-electrified and 'old' consumer groups.

- The distribution function in the electricity supply industry is rationalised such that surpluses generated from some domestic consumer classes are pooled and offset against any deficits from other consumer classes.

\subsection{Health and safety aspects}

Energy use by rural people is associated with a variety of safety risks, and detrimental effects on people's health, some of which were briefly considered in 5.9 . The establishment of a national programme with the aim to identify the areas of 
major health risk which result from energy usage by the urban and rural poor, has been recommended by van Horen (1994a):

This should be a systems-oriented programme to monitor the environmental effects associated with the full range of household fuel usage patterns, and should focus not only on the health effects of air pollution from domestic fuels, but also on other health risks, such as paraffin poisoning, burns and fires.

Based on an understanding of the major health risks, the priority areas for policy intervention can then be identified, and policy options can be formulated. Moreover, the potential exists for significant community involvement in efforts to identify the major health risks facing them, and by extension, communities can become involved in establishing the priorities of, and possible solutions to, their range of needs.

During the EPRET project some attention has been given to particular areas of concern, which will be discussed here shortly.

\subsubsection{Air pollution trom woodfires}

Biomass fuels are generally utilised in open fires, but considerable variation appears to exist with regard to the location and structure of fireplaces, which may be located indoors at the centre of 'the cooking hut' (Eberhard 1986: 59) or outside (May et al 1992:17). Outside fires are commonly shielded or made in special cooking shelters (Eberhard 1986: 62), which may take a variety of forms, with different ventilation characteristics, etc (Terblanche 1993: 23).

Van Horen (1994a) discusses the problem of high levels of air pollution in rural homes as a result of woodfires. International research findings indicate that the exposure of rural people to air pollution from biomass fires often exceed recommended World Health Organization (WHO) levels by factors of ten, twenty or more (WHO 1992: 17). In addition, there is growing evidence which relates high biomass smoke levels to important health effects (ibid: 23). Anecdotal evidence in South Africa suggests that levels of air pollution in many rural homes can reach exceptionally high levels. Only one study has been conducted on the health impact of air pollution resulting from the use of biomass fuels by rural people in South Africa (Terblanche 1993), which included farmworker households only. The findings indicated that pollution and exposures levels far exceed safety guidelines, while these were also much higher than pollution and exposures levels measured in urban studies in South Africa. Van Horen (1994a) concludes that indoor air pollution among rural households seems to be a major environmental health problem which warrants considerably more research attention and resources than it has received in the past.

Clearly this matter needs further investigation to assess the extent and the severity of the problem in the rural areas of South Africa, particularly in former homeland areas, as well as the potential impact of smoke reduction strategies on the health of rural people. This could be done as part of a national energy health programme as suggested by van Horen (1994a).

The development of strategies to reduce the exposure of rural people to air pollution from biomass fuels could draw considerably on experience in other countries. This has indicated that a simplistic approach would not be effective in reducing exposure levels. Rather, a range of factors has to beconsidered, including thelayout and ventilation characteristics of the kitchen or cooking area, cooking practices and preferences, combustion efficiencies, etc (WHO 1992: 32). Where necessary, changes to these aspects need to be investigated, as well as the possible introduction of woodstoves, hoods and chimneys. It is particularly important that the potential social, economic, and political impact of technologies are recognised, and that 
women are involved in planning and design work, to ensure that the potential benefits of interventions are realised, and to prevent women from being disadvantaged by such interventions.

\subsubsection{Air pollution from coal fires}

Van Horen (1994a) recommends that government support should be given to a national low-smoke coal programme which would have as its main goal to facilitate the development and production of low-smoke coals in order to substitute for conventional bituminous coal used by households. Recognising that this issue is already receiving research support from the DMEA, he makes a number of suggestions regarding the areas which require specific attention, as well as possible pricing policies.

As the problem of air pollution due to coal use has primarily received attention in an urban context, it is unclear whether and to what extent rural areas would be targeted for the distribution of low-smoke substitutes. It is therefore recommended that the need and feasibility of introducing low-smoke coal in rural areas, where coal is used by a significant percentage of the population, should be investigated.

\subsubsection{Paraffin poisoning}

Van Horen (1994a) points out that paraffin poisoning is relatively common among paraffin-using households with young children, but that it is an area in which real improvements can be achieved very rapidly. He argues that the prevention of paraffin poisoning should be regarded as a major area for public policy intervention. He identifies four main areas for intervention to reduce the incidence of paraffin poisoning, as well as burns and fires related to paraffin use:

- Education and publicity campaigns should be aimed at adults and older household members with the message to keep paraffin in safe containers and out of the reach of infants.

- The development of affordable child-resistant lids for the most commonly used paraffin containers should continue with more direct state support, and should continue to attempt to optimise the employment potential of this strategy. Van Horen points out that the use of such lids may prove to have the most significant impact on this problem.

- A subsequent phase may involve the design and production of child-resistant containers. This area also requires further research into the acceptability of various container designs and the willingness of people to pay for them.

- In the long-term, legislation may be appropriate to enforce the use of safe containers at all stages of the production and consumption cycle.

\subsubsection{Sofety of LPG botfles}

Although regulations exist regarding the installations and the equipment required, as well as the procedures which should be followed during the filling of LPG bottles, very little control seems to be exercised over this process in rural areas. No information is currently available on the extent to which suppliers of LPG in former homeland areas adhere to safety regulations, and execute safety checks on bottles when these are refilled. The perception that LPG is unsafe seems to be common among rural people, which could be significant. This matter needs to be investigated, and policy measures need to be devised to ensure that safety measures are effectively extended to rural areas. 


\subsection{Energy efficiency}

Energy efficiency at a household level is mainly of concern to energy users because of potential reductions in the costs of energy services. As Thome (1994) points out, access to efficient fuels and appliances, as well as information on fuel and appliance efficiency, are preconditions to the achievement of energy efficiency at a household level. He makes the following recommendations in this regard:

Appliance standards need to be publicised.

- The standards must be tightened by setting goals in collaboration with the appliance manufacturers, so as to avoid the dumping of inefficient appliances from elsewhere.

- Appliance manufacturers must be encouraged to manufacture more efficient appliances.

- Appliances must be labelled to provide economic efficiency data in an accessible manner.

- It should be possible to pay for appliances through the price of the fuel or a tariff.

- End-users of appliances (particularly women) must be consulted and encouraged to participate in the design of more efficient appliances.

- End-users must be encouraged through education and media campaigns, and economic incentives to use more efficient appliances.

Matters of particular concern in rural areas, because of the inadequate infrastructure that exists in these areas, include the availability and affordability of efficient appliances, the availability of maintenance services to ensure that the performance of appliances remain satisfactory, and the effective dissemination of accessible information on fuel and appliance efficiency to energy users. These matters require further investigation to enable the effective implementation of energy efficiency measures in rural areas (see 7.9 for a discussion of service centres).

In addition, Auerbach and Gandar (1994) make the following recommendations which aim to improve energy efficiency in small-scale agriculture:

Systems of cultivation should be promoted which reduce energy requirements, particularly in relation to outputs - for example, systems with low tillage requirements, and systems which reduce the draft power demand by spreading cultivation over a longer season.

- Similarly, partial irrigation combined with methods of agriculture which conserve water should be promoted to reduce the power demand and energy consumption compared to conventional irrigation methods.

- There should be a national policy for agriculture which will promote and favour low-input techniques and discourage processes which consume excessive energy and energy-intensive inputs.

\subsection{Energy goods and suppoit services}

In addition to the fuels discussed in previous sections, a wide range of energy goods is required by people in rural areas, including a variety of appliances ranging from electrical appliances to woodstoves, the components of photovoltaic systems (solar panels, batteries etc), solar water-heaters, and items such as dry-cell batteries, electricity coupons, and matches. The distribution and cost-structure of these goods need to be investigated to assess their availability and affordability to people in rural areas, and to identify the areas where intervention is necessary and possible. 
Particular attention needs to be given to items which feature prominently on the energy budget of rural households. For example, dry-cell batteries are widely used in some areas, where it accounts for a significant percentage of household energy expenditure (Griffin et al 1992: 80). A reduction in the costs of dry-cell batteries in rural areas could therefore result in significant savings on energy by households. However, it is uncertain to what extent such savings would result in the increased availability of household resources for other essential purchases, including fuel purchases, as this would depend on intra-household relations and processes. For example, James (1993: 52) found that the decisions to purchase dry-cell batteries were generally made by young male members of households who did not necessarily contribute to household income (also see 5.8 .5 ).

A range of energy-related support services is also required by rural people, some of which have been referred to in previous discussions:

- appliance maintenance and adjustment;

- battery-charging;

- filling of gas bottles and safety checks on bottles;

- installation and maintenance of RAPS systems;

- installation and first-line maintenance of electricity connections;

- energy information on, for example, efficiency and safety matters, legislated fuel prices, available efficient appliances, financing packages for appliances, and least-cost fuel/appliance options;

- an energy advisory service, to, for example, enable small farmers and small businesses (including home industries) to meet particular needs.

No clear picture exists regarding the energy-related support services which are provided in rural areas at present, but this is known to be extremely limited in nature.

\subsubsection{Rural service centres}

Significant and widespread improvements in the supply of energy goods and the provision of support services in rural areas would not be easy to achieve, particularly because of the inadequate infrastructure that exists in these areas. One possible avenue, to improve support services in particular, is the utilisation of rural service centres for this purpose.

The establishment of rural service centres has received some attention in rural development circles, although no comprehensive framework for such centres has yet been developed. For the purpose of this discussion the exact nature of a rural service centre is not of importance, as it is assumed that the nature and functions of service centres would depend on the needs of particular areas. The Mpako Rural Technology Unit in Zithulele (Transkei), which incorporates a nursery and provides water supply services to rural people, can be seen as a service centre. Another example of a service centre would be the community-controlled depots which have been established in Mabheleni (KwaZulu) to supply building materials and agricultural inputs at reduced cost, and provide credit facilities to rural people.

It is suggested that the feasibility of extending the present services provided by such centres to include various energy-related services, should be explored. The aim would not be to establish a 'blueprint' for rural service centres, but to begin to explore the possibilities that exist at different types of centres and in different areas. The particular energy-related services that would be provided at a centre, would generally depend on the needs in that area, as well as the nature and resources of the existing centre. Some of the energy-related services that could be provided are:

- disseminating energy information, and providing an advisory service;

- training local people to provide services such as the installation and maintenance of RAPS systems and electricity connections, appliance maintenance, etc;

- small-business development - that is, training people with the necessary tech- 
nical skills to provide energy support services, in business skills, and facilitating the formation of small businesses;

- distributing commercial fuelwood, by, for example, establishing a woodyard;

- Selling fuels and energy goods, including appliances, electricity coupons, and so on.

Gandar and Auerbach (1994) also recommend that all such centres should be electrified, and that they should be equipped with the following facilities to serve the small-scale agricultural sector:

- an electrified and equipped venue which could support training and extension programmes to farmers;

- facilities for the maintenance and repair of tractors, pumps and other equipment;

- a grain mill, probably powered by electricity;

- fodder banks for late-winter feeding of draft animals;

- an energy centre which would cater, inter alia, for the different energy requirements and technologies arising from the diversification of small-scale agriculture.

The development of rural service centres to provide energy support services, such as those listed above, would need to be facilitated by appropriately trained people. This matter needs to be investigated in great depth to develop a suitable strategy for implementation. The experience of the Wits Rural Facility, which has recently appointed an energy coordinator, could be particularly valuable in this regard. Aspects that would require particular attention, include the financing of these activities, the skills that would be required by the 'energy development facilitators', their position in relation to other structures (such as a local authority, a Department of Energy, and community-based organisations), and the institutional arrangements that would be required to implement such a strategy on a large scale.

\subsection{Conclusions}

The formulation of energy policy for rural areas has been severely hampered by a lack of the information required to develop a textured understanding of energy use by rural people, as well as a lack of relevant experience with regard to the implementation of energy-related strategies in rural areas.

A framework for rural energy planning would need to comprise the following elements: an integrated approach, a systems-oriented and people-centred approach, flexibility and responsiveness; and accountability and participation.

The supply of fuelwood in rural areas would benefit from initiatives aimed at the management of natural woodland resources, and the promotion of tree planting through a national programme of social forestry, as well as the transport and distribution of local surpluses of fuelwood.

The lack of information on the distribution of hydrocarbon fuels in rural areas limits the scope for policy formulation. The cost of paraffin and LPG to rural people could bereduced by shortening the distribution chains, which would also en able the price of paraffin and LPG to be controlled up to this level. Final recommendations regarding the pricing of paraffin and LPG will only be possible once the cost structures and appropriate delivery mechanisms in rural areas have been established.

A national electrification policy and programme should be designed with a balance between electrification of urban and rural areas from the beginning in order to address the need for redistribution and the material needs of the poorest households. 
ANC Women's League 1993. Status of South African women: $A$ sourcebook in tables and graphs. Marshalltown: ANC Women's League.

Annecke, W J 1992. We are so poor: An investigation into the lives of ten women living in an informal area in the Durban functional region with particular reference to the role of domestic fuels. Unpublished MA thesis, University of Natal, Durban.

Auerbach, R 1990. Towards sustainable development. Indicator SA (Summer 1990), 8 (1): 41-46.

Auerbach, R \& Gandar M 1994. Energy and small-scale agriculture. Energy for Development Research Centre, University of Cape Town.

Bajracharya, D 1985. Rural energy planning in the developing countries of Asia. In D Bajracharya (Ed) 1985, Rural energy planning in China and other developing countries of Asia. FAO Environment and Energy Paper 5. Rome: Food and Agriculture Organization of the United Nations.

Bekker, S, Cross, C \& Bromberger, N 1992. Rural poverty in South Africa: A 1992 study using secondary sources. Draft report, Centre for Social and Development Studies, University of Natal, Durban.

Bembridge, TJ 1986. An overview of agricultural and rural development problems in less developed areas of Southern Africa. Development Southern Africa (February 1986), $3(1)$ : 20-36.

Bembridge, T J 1990. Agricultural development in the developing areas of Southem Africa. Africa insight, 20 (1): 17-24.

Borchers, M L, Archer, FM \& Eberhard, A A 1991. Namaqualand household energy survey. Final report, National Energy Council, Pretoria.

Callear, D, Abedian, I \& May, J 1993. Requirements for a rural safety net to support rural reconstruction and development in South Africa. World Bank Rural Restructuring Programme for South Africa: LAPC Research Paper 4. Johannesburg: Land and Agriculture Policy Centre.

Cecelski, E 1985. The rural energy crisis, women's work and basic needs: Perspectives and approaches to action. Geneva: International Labour Office.

Chambers, R 1983. Rural development: Putting the last first. New York: Longman.

Coetzee, R 1982. Funa-food for Africa: Roots of traditional African food culture. Durban: Butterworth.

Cross, C R 1990. Mythology and mystery tours in land reform: Getting some focus on the South African debate. Development Southern Africa (October 1990), 7: 535-560.

Cross, C 1991. Informal tenures against the state: Landholding systems in African rural areas. In M De Klerk (Ed) 1991. A harvest of discontent - the land question in South Africa. Cape Town: IDASA.

Davis, M, Borchers, M, Dickson, B \& Geerdts, P 1994. Institutions and financing for effective dissemination of PV systems for rural development. Final report, the Energy Branch of the Department of Mineral and Energy Affairs, Pretoria.

Eberhard, A A 1986. Energy consumption patterns in underdeveloped areas in South Africa. Final report to the Foundation for Research Development. Enengy Research Institute, University of Cape Town.

Eberhard, A A \& Dickson, B J 1987. Energy consumption patterns and alternative energy supply strategies for underdeveloped areas of Bophuthatswana. Energy Research Institute, University of Cape Town. 
Eberhard, A 1992. Integrated energy planning: A methodology for policy analysis and research. In A Eberhard \& $P$ Theron (Eds) 1992. International experience in energy policy research and planning. Cape Town: Elàn.

Foley, G 1990. Electricity for nural people. London: Panoss.

Gandar, M 1994. Woodland management and afforestation. Energy for Development Research Centre, University of Cape Town.

Griffin, N J, Banks, D, Mavradonis, J et al 1992. Household energy and wood use in a peripheral rural area of the eastern Transvaal lowveld. Final report, the Energy Branch of the Department of Mineral and Energy Affairs, Pretoria.

Hofmeyr, I 1994. Energy consumption patterns and supply options for farmworker households. Energy for Development Research Centre, University of Cape Town.

Horvei, T \& Dahl, H-E 1994. Rural electrification in South Africa. Energy for Development Research Centre, University of Cape Town.

James, B 1993. Mabibi energy consumption patterns. Final report, the Energy Branch of the Department of Mineral and Energy Affairs, Pretoria.

Jazairy, I, Alamgir, M \& Panuccio T 1992. The state of world poverty: An inquiry into its causes and consequences. London: Intermediate Technology Publications.

Kassier, E \& Groenewald, J 1992. Agriculture: an overview. In R Schrire (Ed). Wealth or poverty? Critical choices for South Africa. Cape Town: Oxford University Press.

Land and Agriculture Policy Centre 1993. Agricultural supporting services for land reform: a summary. Presented at the Land Redistribution Options Conference in Johannesburg (October 1993). Johannesburg: Land and Agriculture Policy Centre.

Leach, G \& Gowen, M 1987. Houschold energy handbook: An interim guide and reference manual. Washington: World Bank.

Lund, S 1993. Input on non-government and community-based organisations. Presented at the Biomass Initiative Workshop on Social Forestry at the University of Natal, Durban (July 1993). Pretoria: Energy Branch of the Department of Mineral and Energy Affairs.

Lund, S, Wakelin, P, Forsyth, $P$ et al 1993. Administrative requirements for rural restructuring: collected investigations and recommendations. World Bank Rural Restructuring Programme for South Africa: LAPC Research Paper 5. Johannesburg: Land and Agriculture Policy Centre.

May, J et al 1992. An in-depth evaluation of fuel use by rural women. The Ingwavuma district - KwaZulu. Final report, the Energy Branch of the Department of Mineral and Energy Affairs, Pretoria.

May, J et al 1993. Rural energy consumption in Natal/KwaZulu. Final report, the Energy Branch of the Department of Mineral and Energy Affairs, Pretoria.

McGregor, G 1994. Household hydrocarbon fuels. Energy for Development Research Centre, University of Cape Town.

Møller, V 1986. Rural Blacks' perceptions of basic need fulfilment. RSA 2000, 8 (1): 9-26. Pretoria: Human Sciences Research Council.

Morse, R, Soesastro, M H \& Schlegel, C 1984. Energy for rural development: principals, issues, and methods. In M N Islam, R Morse \& $M$ H Soesastro (Eds). Rural energy to meet development needs: Asian village approaches. Colorado: Westview.

Pickering, M 1994. Electricity pricing policy. Energy for Development Research Centre, University of Cape Town.

Rathgeber, E 1991. Operationalising gender and development. Paper presented to the Association of Women and Development, Washington. 
Ross, F 1993. Assessment of the impact of fuel-use on residents of an informal settlement. Final report, the Energy Branch of the Department of Mineral and Energy Affairs, Pretoria.

Shiva, V 1989. Staying alive: women, ecology and development. London: Zed.

Steyn, G 1994. Restructuring the South African electricity supply industry. Energy for Development Research Centre, University of Cape Town.

Streeten, P \& Burki, S J 1978. Basic needs: Some issues. World Development, 6 (3): 411-21.

Sunday Nation 1993. The road to reconstruction. 12 December 1993.

Terblanche, P, Danford, I \& Nel, R 1993. Health and safety aspects of household fuels - Phase II. Final report, the Energy Branch of the Department of Mineral and Energy Affairs, Pretoria.

Thome, S 1994. Energy efficiency and conservation. Energy for Development Research Centre, University of Cape Town.

Trollip, H 1994. Energy demand information for integrated energy planning. Energy for Development Research Centre, University of Cape Town.

Tyler, S R 1991. Cooking fuel choice in Thai cities: beyond prices and income. In F Fesharaki \& J P Dorian (Eds). Energy developments in the 1990s: Challenges facing globalPacific markets - Vol 1. Proceedings of the Fourteenth Annual International Conference of the International Association for Energy Economics in Honolulu (July 1991). Honolulu: East-West Centre.

University of the Western Cape 1991. Rehabilitating and settling smallholder black farmers in South Africa: A proposal for establishing a land development unit at the University of the Western Cape. Institute for Social Development, University of the Western Cape, Bellville.

University of the Western Cape 1992. Rural local government. Final report of the Local Government and Planning Policy Research Project, University of the Western Cape, Belville.

Urban Foundation 1991. Policies for a new urban future: Income distribution model. Johannesburg: Urban Foundation.

Van Gass, M 1993. Some observations related to domestic energy requirements based on fieldwork done in informal settlements in the Cape Town metropolitan area. Internal working paper prepared for EPRET. Energy for Development Research Centre, University of Cape Town.

Van Horen, C1994a. Household energy and environment. Energy for Development Research Centre, University of Cape Town.

Van Horen, C 1994b. Financing and economic implications of household energy policies.Energy for Development Research Centre, University of Cape Town.

Water and Sanitation 2000, 1991. Background paper on current situation in rural areas. Presented at Water and Sanitation 2000 Workshop on Strategies for Water Supply and Sanitation Provision at Midrand (August 1991). Halfway House: Development Bank of Southern Africa.

Williams, A 1994. Energy supply options for low-income urban households. Energy for Development Research Centre, University of Cape Town.

World Bank 1993. Options for land reform and rural restructuring in South Africa. Report presented at the Land Redistribution Options Conference in Johannesburg in October 1993.

World Health Organisation 1992. Epidemiological, social and technical aspects of indoor air pollution from biomass fuel. Report of a WHO Consultation, June 1991. Geneva: World Health Organisation. 


\title{
PROJECT DESCRIPTION
}

A major two year research project was launched by the Energy for Development Research Centre in April 1992. It aims to investigate policy options for widening access to basic energy services for the urban and rural poor in South Africa. Research papers are being produced in the following areas:

\section{Background papers}

Research outline

Integrated energy planning: a methodology for policy analysis and research

Development context for energy planning in South Africa

Background on South African energy system

\section{Energy demand analysis}

Energy demand in underdeveloped urban and rural areas

Rural areas

Energy for rural development: an introduction and overview

Energy and small-scale agriculture

Rural household energy supply options

Afforestation and woodland management

Remote area power generation options

\section{Urban areas}

Household energy supply in formal and informal urban settlements

Energy and informal sector production

\section{Ancillary sector}

Energy and mass transportation

Key supply sector

Electricity distribution sector

\section{Cross-sectorial studies}

Energy efficiency and conservation*

Energy and environment*

Southern Africa linkages*

Investment requirements and financing mechanisms*

Pricing policy*

Institutional analysis*

\section{Policy options}

A concludirg document will draw together key policy conclusions

- The scope of these studies is restricted to energy issues conceming the urban and rural poor.

\section{EDRC}

The Energy for Development Research Centre is located at the University of Cape Town. Its objectives are to study energy related problems of developing areas in Southern Africa, and possible ways to address them.

EDRC seeks to achieve its objectives by:

- undertaking research projects;

- running a specialist postgraduate programme to support research projects and to train personnel to contribute to this field;

- transferring relevant information to user groups by offering consulting services and running workshops, and through publishing books, joumal papers, reports, leaflets and design and user manuals.

\author{
Energy for Development Research Centre \\ Energy Research Institute \\ University of Cape Town \\ Private Bag \\ Rondebosch 7700 \\ South Africa
}




\title{
Energy for rural development
}

Cecile Thom

\author{
SOUTH \\ AFRICAN \\ ENERGY \\ POLICY widening \\ RESEARCH basic \\ AND energy \\ AND services \\ TRAINING for the and \\ PROJECT rural
}

